
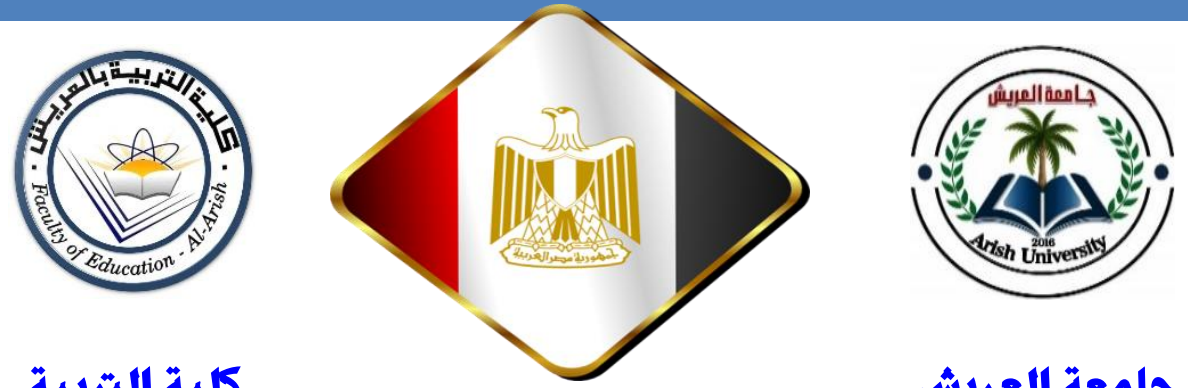

كاية الثربية

\title{
جامعة العريشى
}
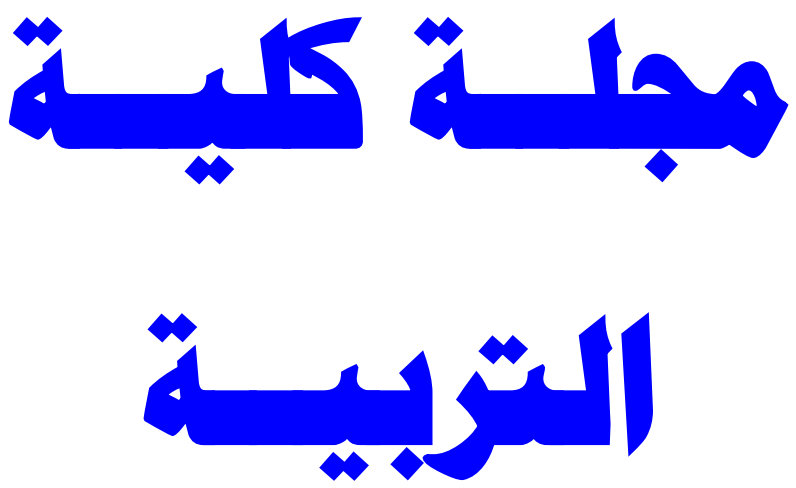

علمية محكمة ربع سنوية

(السنة الثامنة - العدد الحادي والعشرون -يناير •؟+؟م)

j_foea@aru.edu.eg 


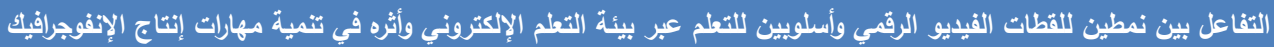

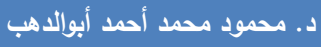
لدي طلاب قسم علم المعومات . 
الإشراف العــــام

\begin{tabular}{|c|c|}
\hline (رئيس مجلـد الكليةة & أ.د. كمال عبد الوهاب أحمد \\
\hline وكيل الكلية للاراسات العليا والبحوث & أ.م.د عصام عطية عبد القتاح \\
\hline
\end{tabular}

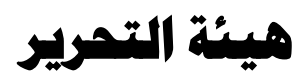

\begin{tabular}{|c|c|}
\hline رئيس التحريز & أ.د. محمد رجب فضل الله \\
\hline عضو & د. كمال طاهر موسى \\
\hline عضو & د. محمد علام محمد طلبة \\
\hline عضو & د. ضياء أبو عاصي فيصل \\
\hline
\end{tabular}

\section{الإشراف المالي والإداري}

\begin{tabular}{|c|c|}
\hline المسؤول المالي & أ. محمد إبراهيم محمد عريبي \\
\hline المسؤول الإداري & أ. أسماء محمد علي الثاعر \\
\hline
\end{tabular}




\section{قواعد النشر بهملة كلية التربية بالعربشي}

ا. تتشر المجلة البحوث والدراسات التي تتوافر فيها الأصالة والمنهجية السليمة على ألا هاء يكون البحث المقدم للنشر قد سبق وأن نشر، أو تم تقديمه للمراجعة والنشر لدى أي جهة أخرى في نفس وقت تقديمه للمجلة. r. تُقبل الأبحاث المقدمة للنشر بإحدى اللغتين: العربية أو الإنجليزية.

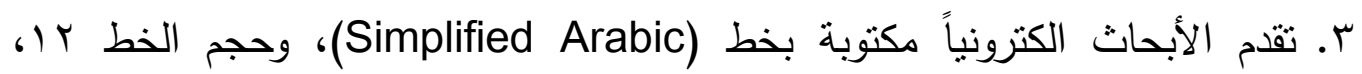
وهوامش حجم الواحد منها ه.بم، مع مراعاة أن تتسق الفقرة بالتساوي ما بين الهامش الأيسر والأيمن (Justify). وترسل إلكترونياً على شكل ملف ( Microsoft) . (Word

ع. يجب ألا يزيد عدد صفحات البحث الئحكم بما في ذلك الأشكال والرسوم والمراجع والجداول والملاحق عن (Y0) صفحة. (الزيادة بحد أقصى • (1 صفحات برسوم إضافية). ولا يزيد البحث المُستل عن ( • r صفحة ) (الزيادة بحد أقصى 0 صفحات برسوم إضافية).

ه. يقدم الباحث ملخصاً لبحثه في صفحة واحدة، تتضمن الفقرة الأولى ملخصاً باللغة

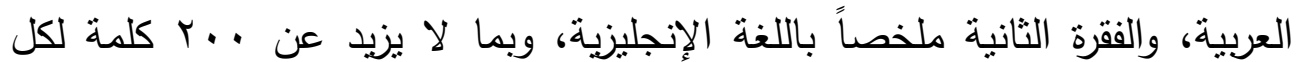

منها.

7. يكتب عنوان البحث واسم المؤلف والمؤسسة التي يعمل بها على صفحة منفصلة ثم يكتب عنوان البحث مرة أخرى على الصفحة الأولى من البحث. V. يجب عدم استخدام اسم الباحث في متن البحث أو قائمة المراجع ويتم استبدال الاسم لإن بكلمة "الباحث"، ويتم أيضاً التخلص من أية إثنارات أخرى تدل على هوية المؤلف.

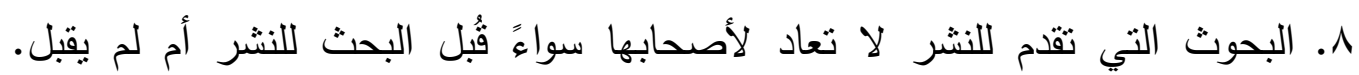
وتحتفظ هيئة التحرير بحقها في تحديد أولويات نشر البحوث. 
9 . لن ينظر في البحوث التي لا تتقق مع شروط النشر في المجلة، أو تلك التي لا تشمل على ملخص البحث في أي من اللغتين، أو يزيد عدد صفحاتها عن هـ

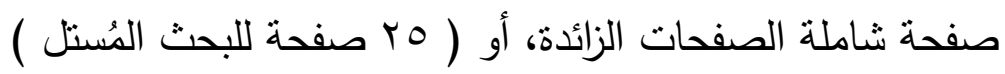
• ا. يقوم كل باحث بنسخ وتوقيع وإرفاق إقرار الموافقة على اتفاقية النشر . 11. يسهم الباحث في تكاليف نشر بحثه، ويتم تحويل التكلفة على الحساب الخاص بالمجلة. يجب إرسال صورة عن قسيمة التحويل أو دفع المبلغ، مع البحث الكترونيا. التكاليف تشمل: مكافأة التحكيم، وتكلفة الطباعة والنشر ، والحصول على نسخة من العدد، وعدد ( 0 ) مستلات من البحث المُحكم، و ( r ) من البحث المُستل. r ا. ـ يتم نشر البحوث أو رفض نشرها في المجلة بناءً على تقارير المحكمين، ولا يسترد المبلغ في حالة رفض نشر البحث من قبل المحكمين. سا. ـيُمنح كل باحث إفادة بقبول بحثه للنشر بعد إتمام كافة التصويبات والتعديلات المطلوبة، وسداد الرسوم المقررة.

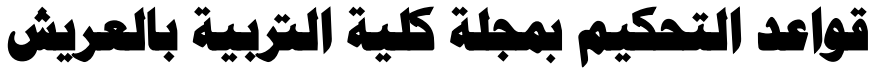

فيما يلي القواعد الأساسية لتحكيم البحوث المقدمة للنشر بمجلة كلية التربية بالعريش

\section{القه|عد عامة:}

1. مدى ارتباط موضوع البحث بمجال التربية. r. مدى مناسبة الدراسات السابقة، وإبرازها لرؤى متعددة. r. درجة وضوح أسئلة وأهداف البحث. ـ. مستوى تحديد عينة ومكان البحث.

ه. درجة إتباع البحث لمعايير التوثيق المحددة في دليل رابطة علم النفس الأمريكية، العدد السادس.

T. احتواء قائمة المراجع على جميع الدراسات المذكورة في منن البحث والعكس أيضاً صحيح. v. حدود الدراسة، وتبريراتها. 
^. سلامة تقرير البحث من الأخطاء اللغوية المتعلقة بالنحو والإملاء وكذا المعنى. 9. تكامل جميع أجزاء تقرير البحث، وترابطها بشكل منطقي.

\section{قواعد المكم على منهمبية البمث:}

ا ـ تحديد الفتزة الزمنية للبحث.

r. تحديد منهجية مناسبة للبحث.

r. تبرير إجراءات للاختيار في حالة دراسة الأفراد أو الجماعات. ع. تضمين البحث إطاراً نظرياً واضحاً.

ه. توضيح الإجراءات المنعلقة بالجوانب المهنية الأخلاقية منل: الحصول على موافقة المشاركين المسبقة.

\section{قواعد تمكيم الإجزاءات:}

1. شرح وسائل جمع المعلومات بوضوح، والعمليات المتبعة فيها. r. تحديد وشرح المتغيرات المختلفة.

r. ترقيم جميع الجداول والأشكال والصور والرسوم البيانية بشكل مناسب وتبويبها والتأكد من سلامتها. ء. شرح عملية التحليل المتبعة ومبرراتها، والتأكد من اكتمالها وسالامتها.

\section{قواعد الهكم على النتانئه:} ا. .عرض النتائج بوضوح. r. توضيح جوانب الاختلاف في حالة تعارض نتائج البحث مع نتائج الدراسات السابقة. r. اتساق الخاتمة والتوصيات مع نتائج البحث. 
محتويات العدد ( IV)

\begin{tabular}{|c|c|c|c|}
\hline \multicolumn{2}{|r|}{ هيئة التحرير } & \multicolumn{2}{|l|}{ السنة السابعة } \\
\hline الصفحات & الباحث & عنوان البحث & الرقم \\
\hline \multicolumn{4}{|c|}{ مقال العدد } \\
\hline$\leqslant r-10$ & 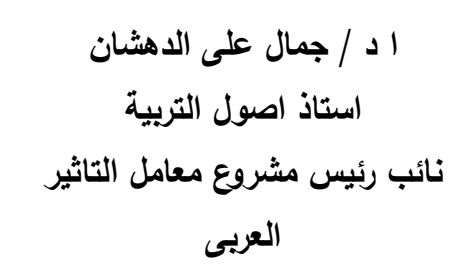 & تقييم وتصنيف الانتاج العلمى المنشور & 1 \\
\hline \multicolumn{4}{|c|}{ بحوث ودراسات محكمة } \\
\hline$I r Y-\varepsilon V$ & 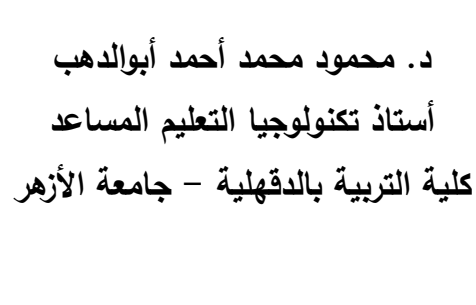 & 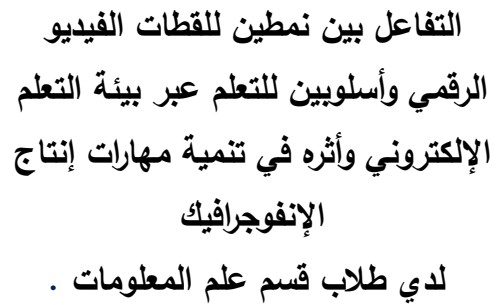 & 1 \\
\hline $19 V-1 m$ & 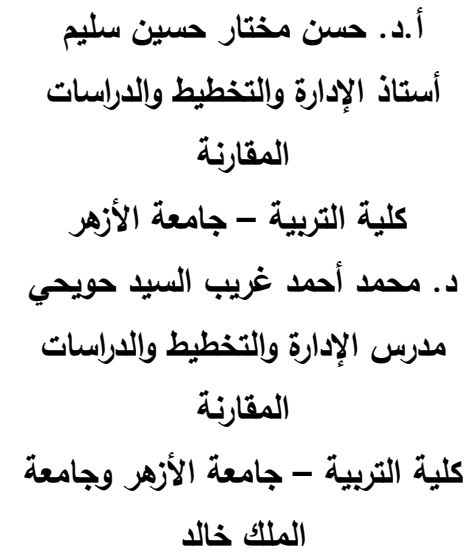 & في ضوير الأداء المؤسسي بجامعة الأزهر & $r$ \\
\hline $7 v 1-199$ & 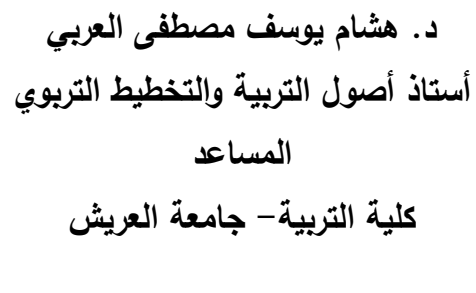 & استراتيجية مقترحة لتفعيل دور جامعة & $r$ \\
\hline
\end{tabular}




\begin{tabular}{|c|c|c|c|}
\hline \multicolumn{4}{|c|}{ بحوث مستلة من رسائل ماجستير ودكتوراه } \\
\hline$r \cdot \theta-r v o$ & 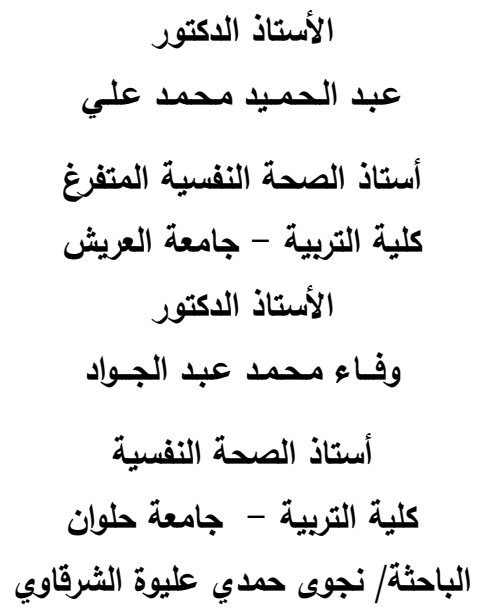 & فعالية برنامج تدريبي في تنمية بعض & 1 \\
\hline$r r \Lambda-r \cdot v$ & 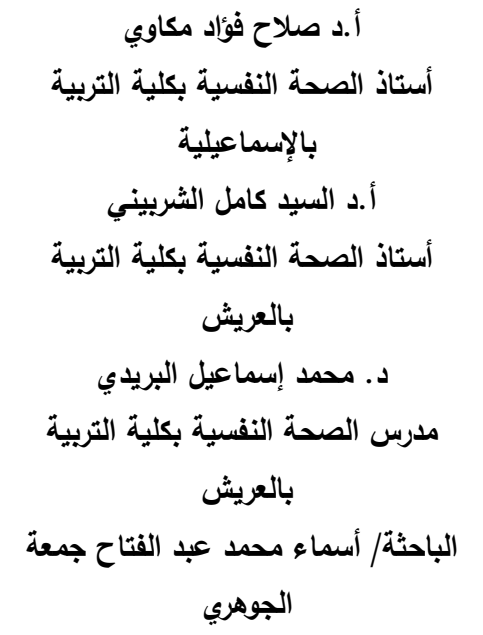 & الأكاء الروحي والتدفق النفسي لاى & r \\
\hline q $r v-r r$ & 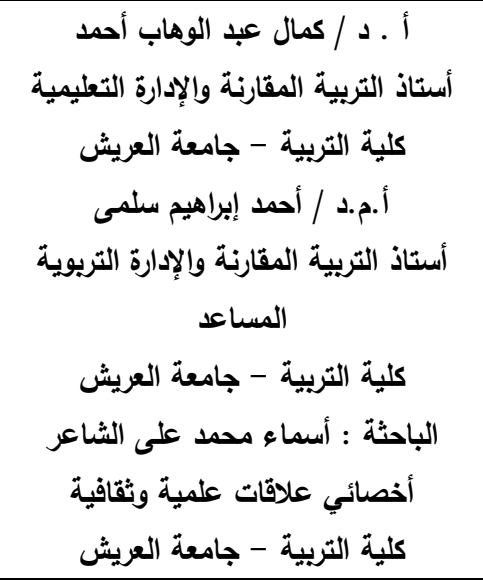 & $\begin{array}{c}\text { تحسين أداء القيادات الإدارية بجامعة } \\
\text { باستخدام الأكرة التنظيمية }\end{array}$ & r \\
\hline
\end{tabular}




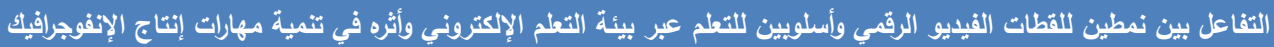

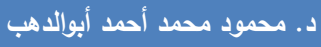
لدي طلاب قسم علم المعومات . 


\section{كلمة هيئة التحريز}

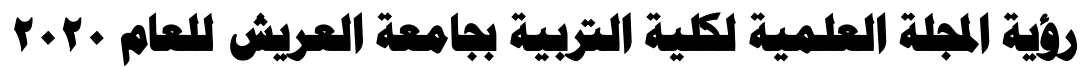

يأتي صدور العدد الحالي الــ ( I Y ) مع بداية عام ميلادي جديد ... العام

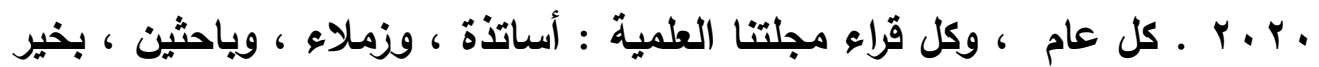

$$
\text { ويصحة وسعادة. }
$$

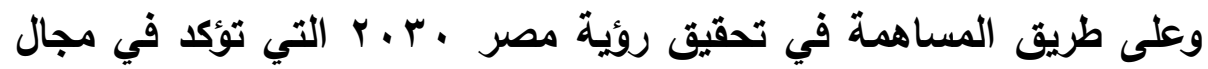

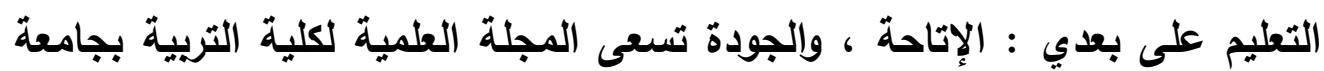

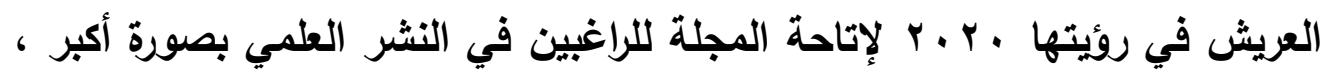
ولوضع ضمانات أكبر لجودة هذا المنشور.

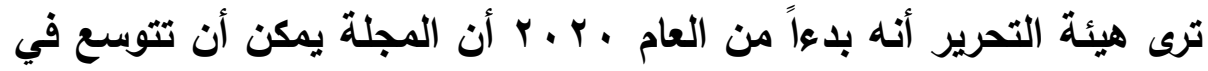
أقسامها فإذا كانت قد بأت بثلاثة أقسام : مقالات علمية - بحوث محكمة - بحوث مستلة من رسائل الماجستير والاكتوراه فإنها ستستقبل هذا العام وما يليه : التقارير العلمية عن المشروعات التعليمية ، والمؤتمرات التريوية، والتدوات ، وغيرها.

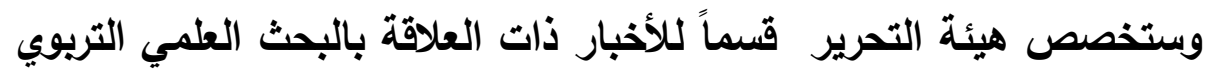
مثل أخبار الأنشطة والفعاليات التعليمية والتربوية. ويمكن - لاحقاً - تخصيص عدد لمناقثة قضية تعليمية / تريوية مطروحة على الساحة المحلية أو الإقليمية أو على المستوى العربي. إن هيئة تحريز المجلة ترى أنه بهذا التوسع في نوعية المنشور ستتيح فرصاً الإنها. أكبر للنشر ، وتستقطب عدداً أكبر من القراء المهتمين بالإنتاج العلمي التريوي : بحوثًاً أو مقالات أو تقارير أو أخبار ، وغيرها. وسيأتي الموقع الاكتروني للمجلة ( الجاري إعداده ، والمتوقع تدشينه خلال

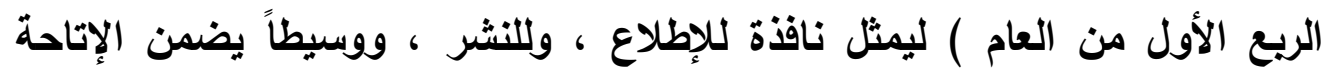
للمجلة عن بعد. 
وفي تطلعها لمزيد من الجودة للمنشور بها تسعى هيئة تحرير المجلة

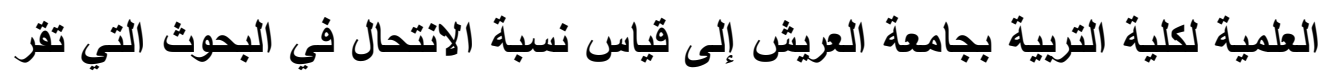
بقبولها ، ويما لا يتجاوز نسبة ال هب\% ، وتهيب أسرة التحريز بالباحثين الإقرار بإخضاع بحوثهم لهذا القياس لاى مركز معتمد بجامعاتهم قبل إرسال البحوث للتحكيم وإلنشر.

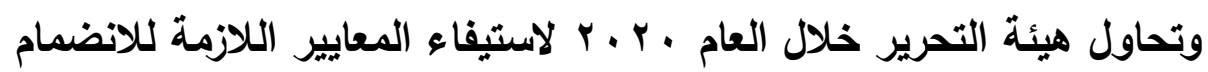
إلى مشروع معامل التأثير العربي التابع لاتحاد الجامعات العربية باعتباره المشروع القومي المناسب لطبيعة الإنتاج العلمي ، وللغة المنشور بها في أغلب الأحوال. إن قياس نسبة الانتحال ، مع السعي لتحقيق معامل تأثير عربي ، وتطوير الإنياج معايير الحكم النوعي والكمي على البحوث ، وغير ذلك يمكن أن تكون إجراءات

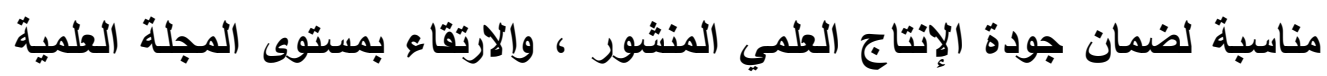
لكلية التربية بجامعة العريش. هون.

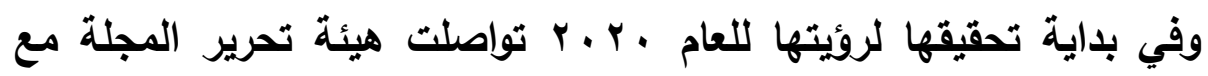
المسؤولين عن مشروع معامل التأثير العربي لاستكتابهم عن المشروع ، وتعرف

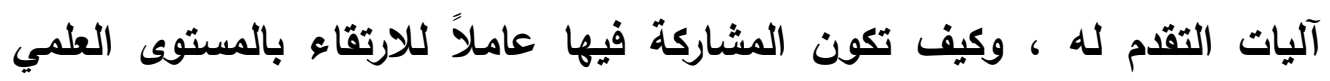
للمجلة. ويتصدر هذا العدد من المجلة مقالاً علمياً لنائب مدير مشروع معامل التأثير

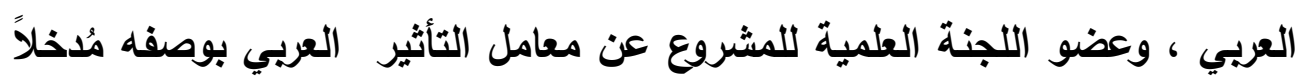
للتميز في تقييم الانتاج العلمي المنشور باللغة العربية وتصنيفه.

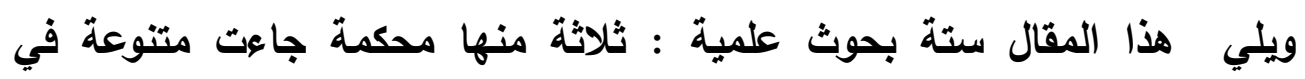
مجالاتها ، وتخصصاتها التي تنتمي لأصول التربية ، والإدارة التعليمية والتربية

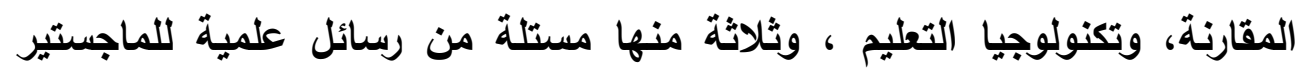

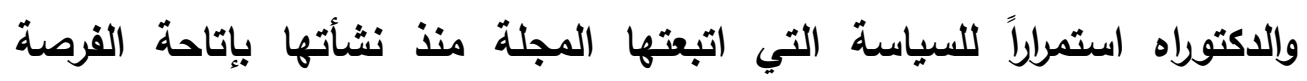
للباحثين التربويين الشبان لنشر ملخصاً عن باكورة إنتاجهم العلمي ، وذلك تحت إثراف أساتذتهم المشرفين على رسائلهم العلمية. 
وتشير قائمة الانتظار للبحوث المقبولة للنشر إلى إمكاتية أن يصدر كل عدد من أعداد المجلة القادمة في جزعين أو نتتقل بالمجلة لتصبح شهرية بالاً من ريع التع سنوية. ويمثل كل ما سبق روئة واضحة ومحددة لهيئة تحرير المجلة العلمية لكلية

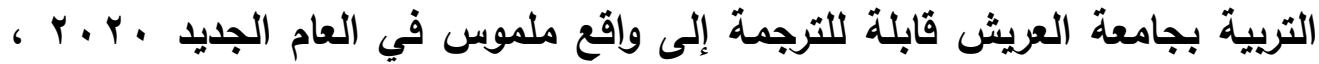

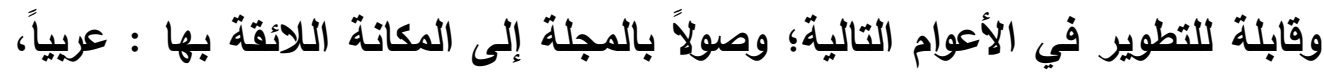
وعالمباً. والله الموفق.... - 2

هيئة التحرير 


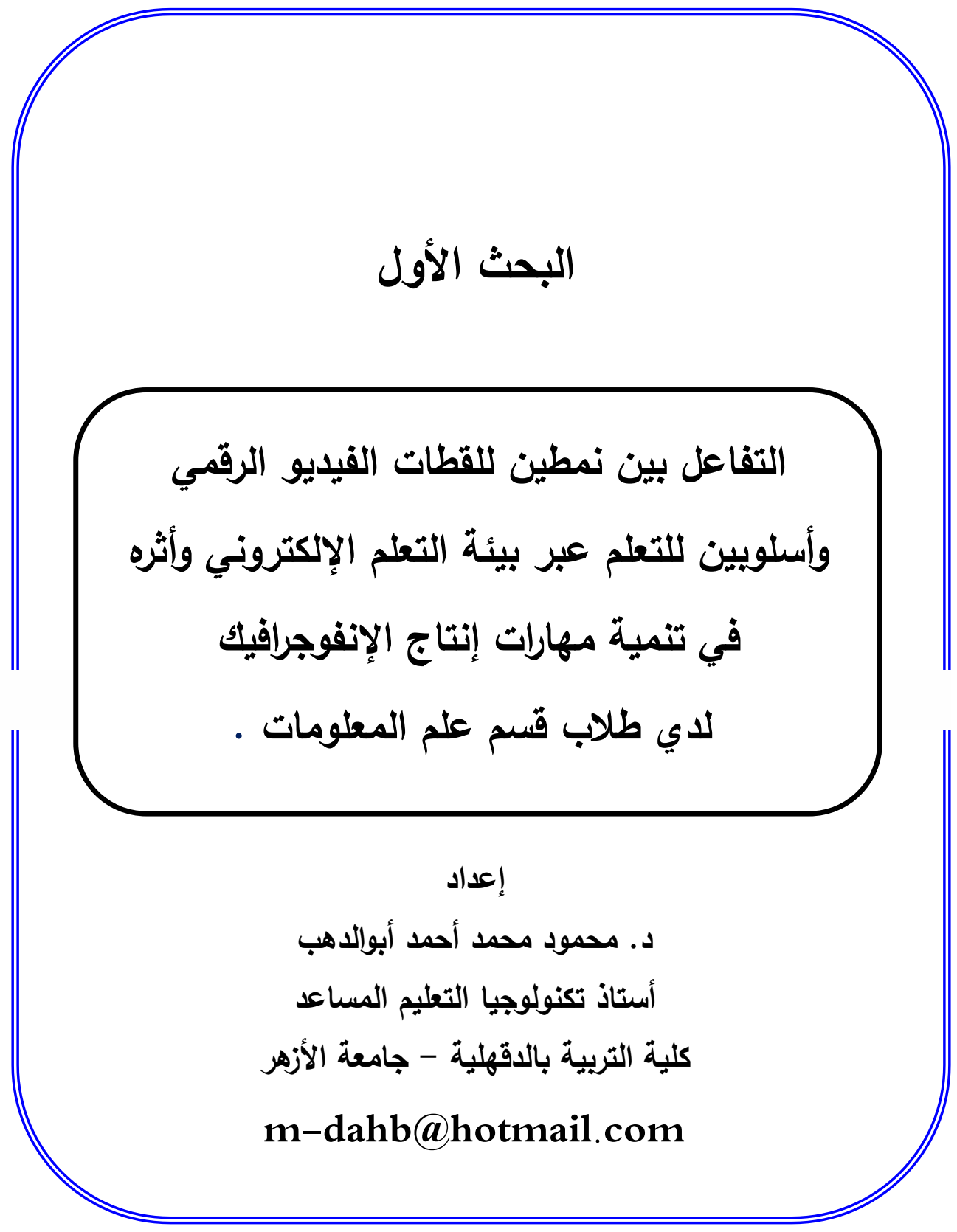




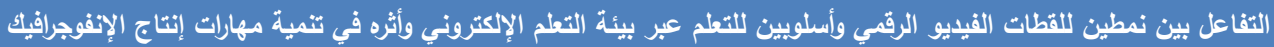

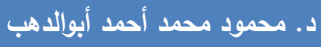
لدي طلاب قسم علم المعومات . 


\section{التفاعل بين نمطين للقطات القيديو الرقمي وأسلويبن للتعلم عبر} بيئة التعلم الإلكتروني وأثره في تنمية مهارات إنتاج الإنفوجرافيك لابي طلاب قسم علم المعلومات . إعداد

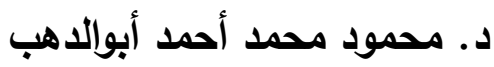

أستاذ تكنولوجيا التعليم المساعد المثال

كلية التربية بالدقهلية - جامعة الأزهر

\section{m-dahb@hotmail.com}

مستخلص البحث

يهرف البحث الحالي قياس أثر التفاعل بين نمطي لقطات الفيديو الرقمي

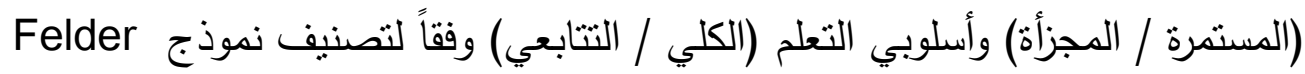
Silverman الإنفوجرافيك الثابت لدي طلاب قسم علم المعلومات، وتكونت عينة البحث من (9 (9)

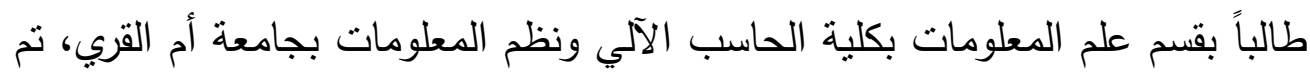

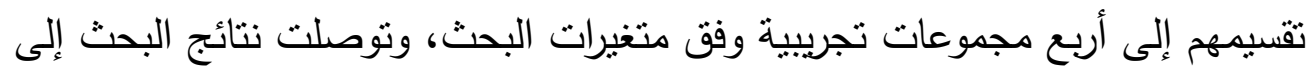
وجود فروق دالة إحصائية بين متوسطات درجات الطلاب في النطبيقين القبلي

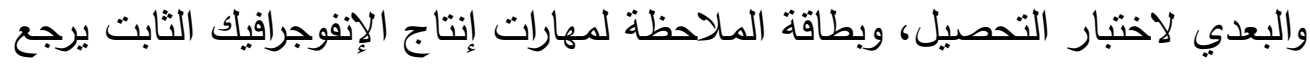

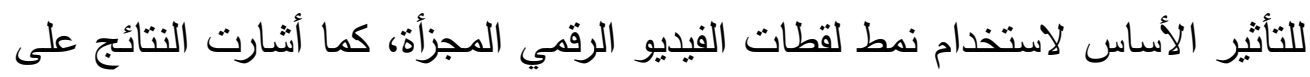
وجود فروق دالة إحصائية عند مستوى بين منوسطي درجات الدجموعتين التجريبيتين

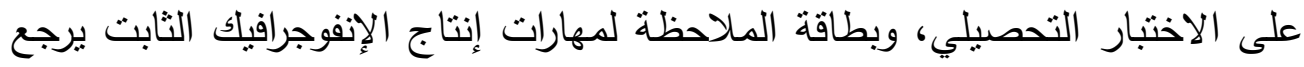

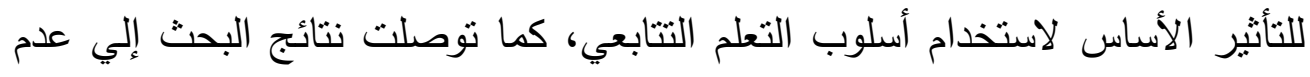
وجود فرق ذو دلالة إحصائية بين منوسطات درجات المجموعات التجريبية للجانبين: التحصيل المعرفي، والجوانب الأدائية لدهارات إنتاج الإنفوجرافيك الثابت يرجع للتنأثير 
الأساس ؛ للتفاعل بين نمطي لقطات الفيديو الرقمي (المستمرة - المجزأة) وأسلوبي التعلم (التتابعي / الكلي)، وأوصى البحث بضرورة توجيه أنظار القائمين على تطوير

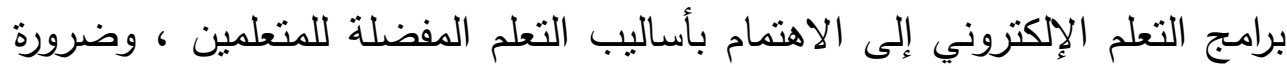

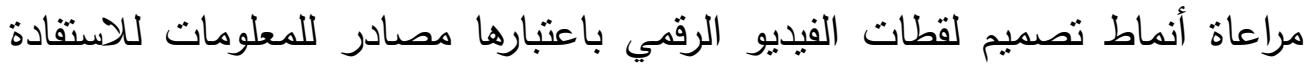
منها في مجال تخصص علم المعلومات. الكلمات المفتاحية: الفيديو الرقمي، لقطات الفيديو الرقمي المستمرة ، لقطات الفيديو الرقمي المجزأة، أسلوب التعلم الكلي، أسلوب التعلم التتابعي، الإنفوجرافيك.

\section{ABSTRACT}

The effects of two types of digital videos and learning styles in an electronic learning environment on developing infographic production skills among informatics department students

The current study aims to study the effects of two types of digital videos (divided/continuous) and two learning styles (sequential/global), based on the classification of Felder Silverman, in an electronic learning environment (Blackboard), on developing infographic production skills among informatics department students in Um Alqura University. Participants of the study comprised of 96 students in the college of Computer and Information Systems. They have been distributed into four experimental groups based on the variables of the study. The results reached indicated that there were statistical significant differences between the mean scores of students in the fixed infographic production skills at $(0.05 \%)$ on the preadministration and post-administration linked to the use of the 
divided digital videos and the sequential style. In addition, there are no statistical significant differences between the mean scores of students in achievement and performance related to the use of digital (divided/continuous) videos and two learning styles (sequential/global). The study ends with some recommendations emphasizing the importance of considering both learning styles and digital videos as sources of information in informatics.

Keywords: Video Digital, Continuous videos, Divided videos, Learning Styles, Sequential-Global, Infographic. 
التفاعل بين نمطين للقطات الفيديو الرقمي وأسلويين للتعلم عبر بيئة التعلم الإلكتروني وأثثره في تنمية مهارات إنتاج الإنفوجرافيك لاي طلاب قسم علم بلمين المعلومات .

\section{د. محمود محمد أحمد أبو الاهب ا}

المقدمة:

يعتبر التعلم الإكتروني أسلوباً حديثاً توظف فيه التقنية بجميع أنواعها ؛ لإيصال

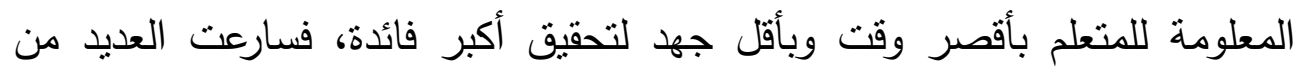
الجامعات لتوفير أنظمة إدارة التعلم (LMS) ؛ لتسهيل إيصال المحتوى التعليمي وتقييمه إلكترونياً مما وفر حلول تعليمية سهله وميسرة يصاحبها إستراتيجيات تعليمية حديثة تسهل التعليم افتراضياً في أي وقت ومن وني أي مكان. وقد شهد التعلم الإكتروني القائم على الويب تطورا كبيرا في الآونة الاخيرة؛ حيث ظهرت بيئات وتكنولوجيات تعليم إلكتروني جديدة قائمة على الويب، بهدف تسهيل عملية التعلم، ومساعدة المتعلمين على ضبط وتتظيم عملية التعلم الخاصة بهم وتقديم الدعم لهم عن طريق: تحديد أهداف التعلم الخاصة بهم، إدارة عملية التعلم، إدارة المحتوى والعملية على حد سواء والتواصل مع الآخرين في عملية التعلم؛ وبالتالي تحقيق أهداف التعلم. (cavus\& kanbul, 2010, 5824-5258) ومن مبررات استخدام التعلم الإكتروني القائم علي الويب ليس فقط لأنه نظام لتوصيل المحتوي والمقررات الإككترونية، أو نظام يستخدم أدوات ومستحدثات تكنولوجية، ولكنه علم نظري تطبيقي، ونظام تكنولوجي تعليمي كامل، وعملية مقصودة، تقوم علي أساس فكري وفلسفي ونظريات تربوية جديدة يمر فيها المتعلم بخبرات مخططة ومدروسة، من خلال تفاعله مع مصادر تعلم إلكترونية متعددة ومتتوعة بطريقة نظامية ومتتابعة وفق إجراءات وأحداث تعليمية منظمة، في بيئات 
تعلم مرنة لدعم عمليات التعليم لتحقيق توصيل المواد التعليمية، الاتصالات، عمل

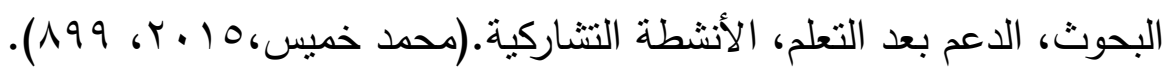
وتبعًا لتالك التطورات شهدت مؤسسات التعليم العالي نقلةً نوعية وإقبالًا منزايدًا من الطلاب، وأصبح تطوير العملية التعليمية مطلبًا ملحَّا في ظل التطورات الحديثة في مؤيسات تكنولوجيا الاتصالات، وبات الطالب الجامعي اليوم أكثر انفتاحًا على ثورة التقنية

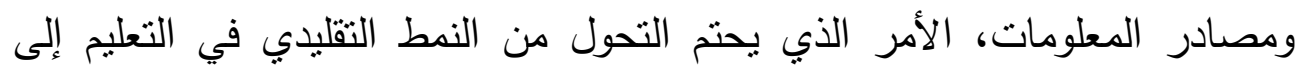
التوجه ؛ لتفعيل نمط تعليمي يتسم بالمرونة ،والكفاءة ، والفعالية وهو التعليم

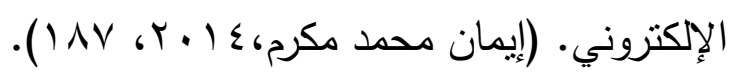

ويواجه التعلم الإلكتروني في العصر الحديث الكثير من التحديات، ولعل أهمها :المعلومات والانفجار المعرفي؛ حيث حرصت الكثير من جامعات العالم حاليا على توفر التقنيات التكنولوجية المتقدمة للكمبيوتر والإنترنت ، وغيرها من الوسائط المتعددة لتطوير التعليم، وأصبح نظام Blackboard من النظم التعليمية التي تأخذ جزءا مهما من البيئة التكنولوجية التعليمية، وله تأثثر كبير في تحسين جودة التعليم والتواصل بين الطلاب إلكترونياً وربطه بأمن الإنترنت، وهو يعمل أيضا لكسر الجمود بين المعلم والطالب.(Em Elsawy \& Ahmed, 2019,49) ويتيح التعلم الإلكتروني بيئة تعلم آمنة؛ حيث يقدم المعلمون مقرراتهم

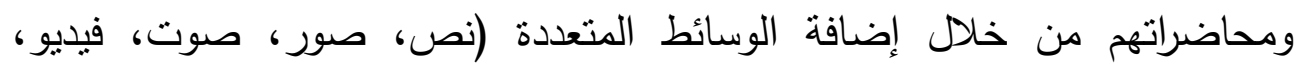
رسوم)، كما يتيح - أيضا - مشاهدة القائمة الكاملة من مقاطع الفيديو واختيار المقاطع، أو يمكنك مشاهدة مقاطع فيديو متعددة في صف واحد عن موضوع محدد باستخدام قوائم النتغيل. ويلعب الفيديو الرقمي دورا مهما في جذب انتباه الطلاب، وجعلهم متحمسين لمشاهدة ومعرفة المعلومات الجديدة بأساليب مرئية متعددة. (رامي زكي إسكندر ، رشاه

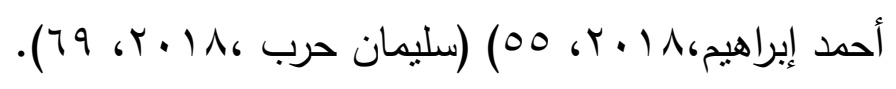




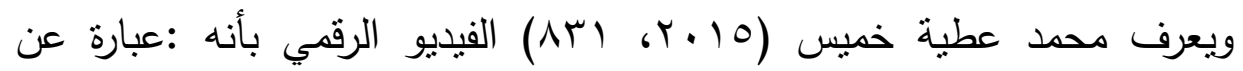

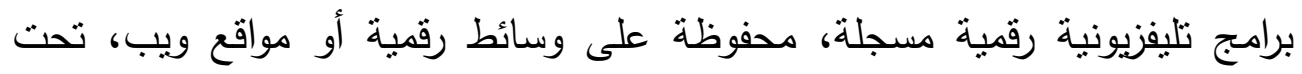
الطلب.

ولقد أكدت العديد من الدراسات على دور الفيديو الرقمي في العملية التعليمية

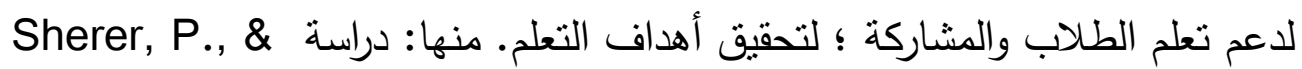
Weeks, B.(2013) ،Shea, T. (2011) كما أوصت دراسة كل من Chtouki,et-al (2012) بجعل الفيديو الرقمي

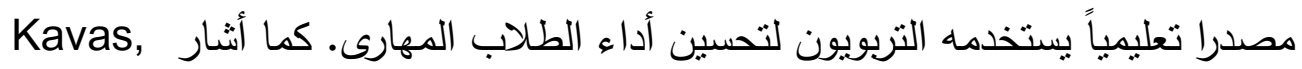
لفعالية الفيديو الرقمي في تطوير مهارات المعلمين في التدريس Ozdener,(2012) في جامعة مرمرة بتركيا.

وأنشارت العديد من الدراسات لفاعلية الفيديو الرقمي في تتمية مهارات الطلاب المعلمين في استخدام المواد اليدوية الملموسة في التدريس على أداء الطلاب والمعلمين. (محمد حسن وآخرون، 17 . Y) ، ودراسة فادي فريد، محمد أبو شقير،

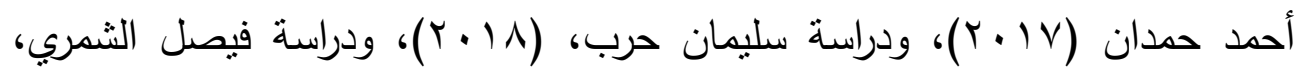
فرحان الثمري (9 ( ب (r). وقد سعى الباحثون إلى إخضاع موضوع تصميم البيئة الرقمية للبحث والتجريب

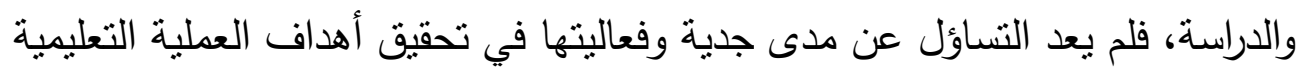
محور اهتمام الباحثين، ولكن أصبح الاهتمام بمتغيرات تصميم تلك البيئة وقياس فاعلية استخدامها. وعند تصميم لقطات الفيديو وما تحتويه من ديناميكية الصورة غالبا ما تتكامل وتدمج الصور والرسوم المتحركة ، والرسوم البيانية كوسائل وتمنيلات للكميات التي تكون عادة غير مرئية، وهذا التمثيل المزدوج يسمح بعرض الظاهرة العلمية بشكل فعال. (Hatsidimitris, G., \& Allen, B. 2010, 1025) 
ويمكن أن يؤثز تصميم لقطات الفيديو على قدرة المتعلمين على الانتباه لكونه عملية حسية تتم من خلال استثارة الحواس باستخدام المؤثرات البصرية ولقطات بونرئ

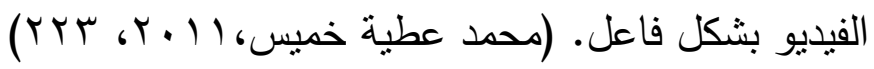

كما أن عرض لقطات الفيديو بشكل كلي أو مجزأ لا يتم عن طريق الثكل فقط من حيث عرض المحتوى كاملا في مقطع واحد أو تجزئة ذات المقطع إلي عدة أجزاء، بل إن عرض هذه اللقطات يرتبط أيضا بما تتضمنه من محتويات يتم تتظيمها إما كليا ، أو يتم تقديمها مجزأة من خلال تقسيم المهارة الرئيسة إلي مهارات فرعية يتم تشكيلها في وحدات تعلم يتم عرضها من خلال اللقطات الجزئية، والتي تختص كل منها بمهارة فرعية محددة تشكل في مجموعها فيما بعد المهارة الرئيسة المطلوبة، وعلى ذلك يمكن القول أن الطريقة الكلية في لقطات الفيديو تثير إلي طريقة تعليم المهارة الرئيسة ككل من حيث أدائها بشكل مجمل، بينما الطريقة الجزئية تعني تعلم المهارة من خلال تقسيمها إلي أجزاء بحيث يتم تعليم كل جزء على حده، ثم تتم عملية ربط هذه الأجزاء بعضها ببعض كلما حدث التقدم في عملية التعلم. (أنثرف

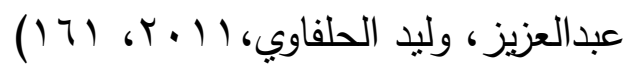

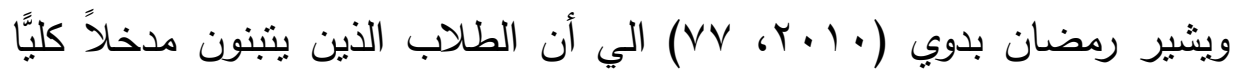
شموليًّا فيميلون في مقابل ذلك إلى العمل بشكل أفضل عن طريق معالجة المهمة

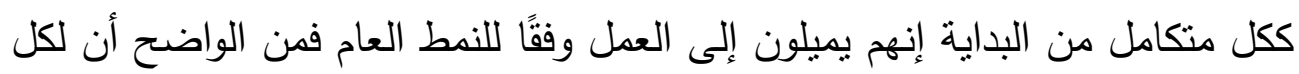
من المدخلين تطبيقاته. إن الاختلاف في أساليب التعلم لا يكون فقط بين الطلبة من ذوي الأعمار ، والقدرات العقلية المختلفة، بل وبين طلبة متكافئين في العمر والقدرات العقلية ؛ وذلك لعدم وجود أساليب مثالية عامة في التعليم تتاسب جميع الطلبة على اختلاف أساليب

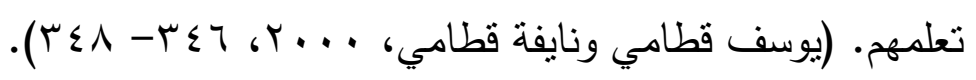

ومما لا شك فيه أن تباين أساليب تعلم بين المتعلمين تجعلهم يختلفون في تفاعلهم مع المثيرات والخبرات، فبيئة التعلم تثير فضول المتعلم؛ للتفاعل مع المعرفة وفق أسلوب تعلمه الخاص، فنجد أن المتعلم ذوي أسلوب التعلم التتابعي يميل إلى ديع 
الحصول على المعلومات وفهمها عن طريق خطوات عملية دقيقة، بينما يميل المتعلم ذوي أسلوب التعلم التكاملي في الحصول على المعلومات إلى التفكير الكلي ، أو

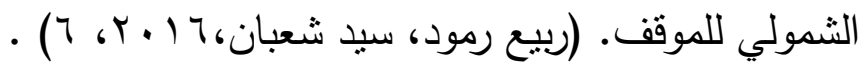

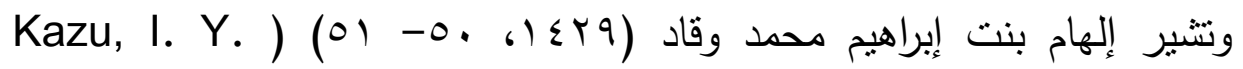
2009,87 إلى تعدد أساليب التعلم حيث لا يوجد أسلوب واحد يحقق أفضل النتائج لجميع التلاميذ؛ لذلك أصبحت معايير جودة التعليم التي تتادي بها الهيئات العالمية والوطنية تتطلب مراعاة أساليب التعلم بين المتعلمين. وتتاولت العديد من البحوث والدراسات أساليب وأنماط التعلم المتتابعة والكلية

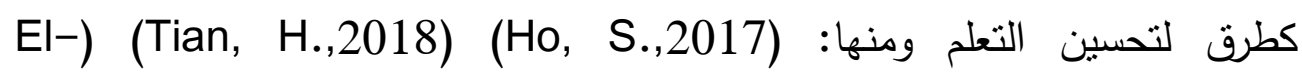
Hou, H. T. التي دعمت نمط التعلم المجزأة، لكن دراسات (Bishouty,2019 (2015) (Kuo, Y. C., Chu,2017) أثنارت الي تفوق أساليب التعلم المستمرة. وتفتح التقنية الحديثة فرصًا جديدة لتخطيط وتتفيذ إستراتيجيات التدريس المختلفة من خلال التطبيقات التقنية، فتم استخدام الإنفوجرافيك أنثاء بناء المحتويات السمعية البصرية المقدمة من نظام الوسائط التشعبية من أجل تحسين قناة الاتصال بين واجهة الإنكاء الويب والمستخدم ، وتؤكد النتائج أن استخدام الإنفوجرافيك بأحدث التقنيات يسهل عملية التعلم من خلال بناء محتويات سمعية بصرية تعتمد على تصميم الجرافيك. (Hassounah, E. O. 2017, 555) ويعد الإنفوجرافيك من الأدوات الثائعة لمشاركة البيانات المؤسسية والبحثية مع الجماهيرعبر الإنترنت، فهناك العديد من مواقع الويب التي تقدم برامج لمساعدة المستخدمين على إنثاء هذه العروض المرئية للمعلومات، منها: موقع Piktochart ، واستخدامه وتوظيفه في إعداد معلومات العلوم الصحية، فضلاً عن الجهود المبذولة لضمان فعالية هذه الاتصالات. (Wright, A. 2016,75) . فيمكن أن يلعب الإنفوجرافيك دورا مهما في العملية التعليمية كأداة لتمثيل مرئي للمعلومات أو البيانات، كما يمكن أن يستخدم كأسلوب نمذجة لتطوير مهارات معرفية 
مختلفة ، منت : التفسير ، والتحليل ، والتقييم ، والاستتناج ، والثرح. Damyanov) I., \& Tsankov, N. 2018,89) وتؤكد دراسة (2019) Martin, L. J., Turnquist, A إلى أن الإنفوجرافيك يمكن أن يلعب دوراً في تلخيص أدبيات البحوث، كما أنه ارتبط بتفضيل أعلى للقراءة وانخفاض الحمل المعرفي أثناء المراجعة الموجزة. ولقد أكدت العديد من الدراسات على ضرورة الاهنمام بتتمية مهارات الإنفوجرافيك al-) الثابت ، DeWitt, D., : (2017) \& Gebre, (2015)

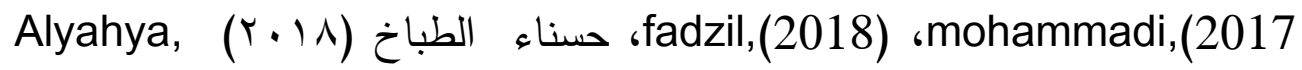
(D. M., 2019) إلا أنه بالاطلاع عليها تبين للباحث عدم تتاولها ، أو استخدامها لموقع -Piktochart علم طلاب المعلومات - في حدود علم الباحث- ضمن عينات البحث التي تم تتاولها. وفي ضوء ما سبق يسعى البحث الحالي إلى التفاعل بين نمطي لقطات الفيديو الرقمي (المستمرة / المجزأة) ، وأسلوب التعلم (الكلي / التتابعي) في بيئة التعلم الإلكتروني ، وأثثر في تتمية مهارات إنتاج الإنفوجرافيك لدي طلاب قسم علم المعلومات. الإحساس بمشكلة البحث: أحد الأدوار المنوطة من طلاب قسم علم المعلومات هو قدرتهم على تصميم

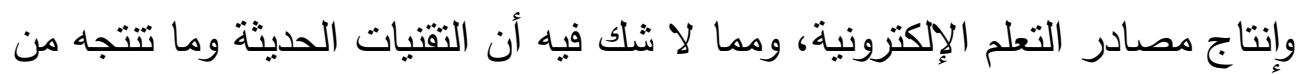
قدرات هائلة في مجال إنتاج المعلومات ومعالجتها ، واختزانها ، واسترجاعها ، وبثها قد أحدثت تغييرات جوهرية في طبيعة المعلومات من ناحية وأشكال الوسائط التي تتطوي عليها من ناحية أخرى. وتتبع مشكلة البحث الحالي من جوانب عدة، هي: 
أولاً: ما أثنارت إليه نتائج الدراسات والبحوث ذات الصلة بأنماط تقديم لقطات الفيديو

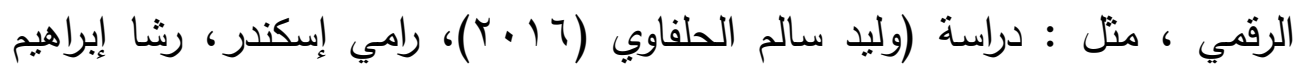

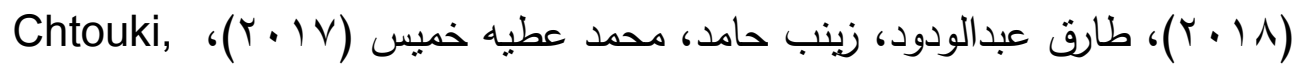

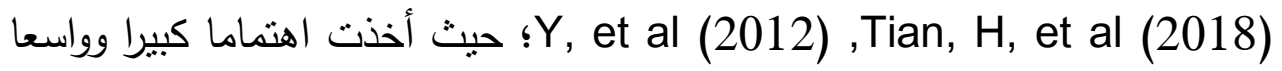
في مجال تكنولوجيا التعليم مما له من أثز متزايد تم دعمه بعدد كبير من الدراسات والبحوث، فلم تعد القضية هي جدوى تقديم لقطات الفيديو إلي أنظمة التعلم الإلكتروني، وتفاعلاتها مع أنماط المتعلمين وأساليب تعلمهم المختلفة. ويمكن التحكم في محتوى لقطات الفيديو نفسها وتجزئتها، والتحكم في السرعة والألوان، وأساليب الانتقال، كذلك إدراج أو حذف مؤثرات حركية أو بصرية أو صوتية أخرى، بما يلفت انتباه المتعلمين للمعلومات الخفية نتيجة سرعة وتيرة حركة الصور والرسوم، وهو ما دعا الباحثون للاهنمام بدراسة نمطي لقطات الفيديو المستمرة

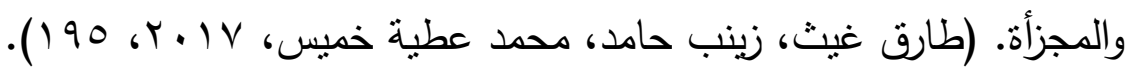
Quinn, M. وقد أكدت دراسات كل من (2018) وVizeshfar, F.

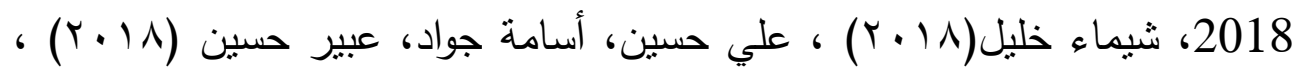

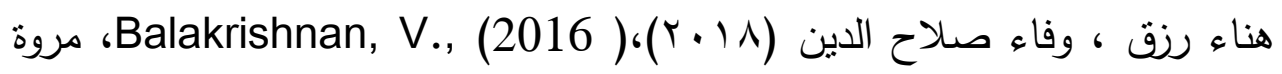

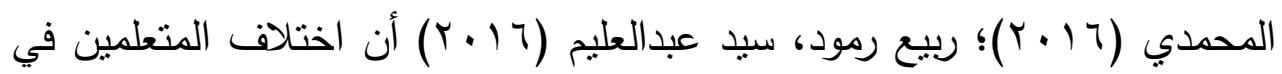
أساليب التعلم يؤثر على نتائجه؛ مما يتطلب الحاجة إلي إيجاد حلول وبدائل تضم أساليب تعلم مختلفة، وتقديم معالجة تربوية تكنولوجية تساعد المعلمين على مراعاة أساليب تعلم المتعلمين. ثانياً: يقع البحث الحالي في نطاق الاهتمام بأبحاث التفاعل بين المعالجة نمطي لقطات الفيديو الرقمي (المستمرة الكلي / المجزأة التتابعي) ، وأسلوب تعلمهم (الكلي / التتابعي) ، والتي تضع تصورات خاصة بأساليب التعلم المناسبة للخصائص الفردية لكل متعلم؛ وبالتالي تقديم معالجات تتفق مع الاستعدادات والسمات الثخصية التي

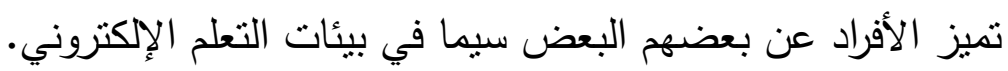


ثالثاً: ملاحظة الباحث من خلال تدريس مقرر إنتاج الوسائط المتعددة لطلاب قسم علم المعلومات بكلية الحاسب الآلي بجامعة أم القرى، والتي تتمثل في تدني مهارات إنتاج الإنفوجرافيك الثابت، باعتبارة أحد الوسائط التعليمية الرقمية. في ضوء ما سبق، تتحدد مشكلة البحث الحالي في وجود حاجة إلى تحديد أثز الإنر التفاعل بين نمطي لقطات الفيديو الرقمي (المستمرة / المجزأة) ، وأسلوب التعلم (الكلي/التتابعي) في بيئة التعلم الإلكتروني ، وأثزه في تتمية مهارات إنتاج الإنفوجرافيك الثابت لدي طلاب قسم علم المعلومات بجامعة أم القري.

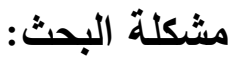

استتادا لما سبق سعى البحث الحالي إلى الكثف عن أثز التفاعل بين نمطي لقطات الفيديو الرقمي (المستمرة / المجزأة) ، وأسلوب التعلم (الكلي/التتابعي) في بيئة

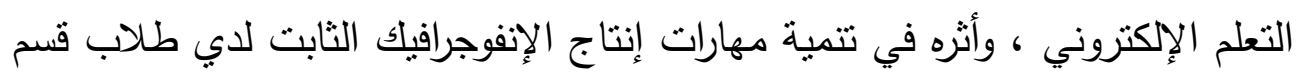
علم المعلومات بجامعة أم القري. تساؤلات البحث: تم بلورة مشكلة البحث الحالي في التساؤل الرئيس التالي: ما أثز التفاعل بين نمطي لقطات الفيديو الرقمي (المستمرة / المجزأة) ، وأسلوب التعلم (الكلي/التتابعي)

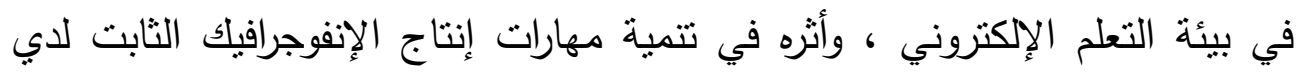
طلاب قسم علم المعلومات بجامعة أم القري؟ لئه ويتقرع منه التساؤلات التالية: ا - ما مهارات إنتاج الإنفوجرافيك الثابت اللازمة لطلاب قسم علم المعلومات بجامعة أم القرى؟ ץ- ما أثز استخدام نمطي لقطات الفيديو الرقمي (المستمرة / المجزأة) على كل من:

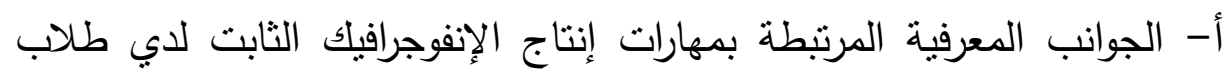
قسم علم المعلومات بجامعة أم القرى؟ لانبه ب-الأداء العملي لمهارات إنتاج الإنفوجرافيك الثابت لدي طلاب قسم علم المعلومات بجامعة أم القرى؟ - مبعاء 


$$
\text { r- ما أثز استخدام أسلوبي التعلم (الكلي / التتابعي) على كل من: }
$$

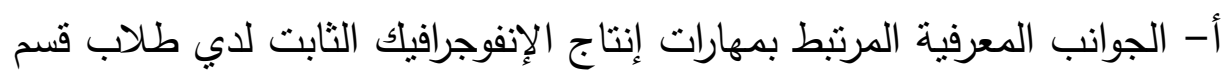

$$
\text { علم المعلومات بجامعة أم القرى؟ }
$$

ب- الأداء العملي لمهارات إنتاج الإنفوجرافيك الثابت لدي طلاب قسم علم

$$
\text { المعلومات بجامعة أم القرى؟ }
$$

ع- ما أثز التفاعل بين نمطي لقطات الفيديو الرقمي (المستمرة / المجزأة) وأسلوب المبات

$$
\text { التعلم (الكلي / التتابعي) على كل من: }
$$

أ- الجوانب المعرفية المرتبط بمهارات إنتاج الإنفوجرافيك الثابت لدي طلاب قسم

$$
\text { علم المعلومات بجامعة أم القرى؟ }
$$

ب- الأداء العملي لمهارات إنتاج الإنفوجرافيك الثابت لدي طلاب قسم علم

$$
\text { المعلومات بجامعة أم القرى؟ - ماءك }
$$

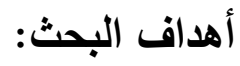

سعى البحث الحالي إلى تحقيق الأهداف التالية: - - تحديد مهارات إنتاج الإنفوجرافيك الثابت لدي طلاب قسم علم المعلومات. - الكثف عن أثز استخدام نمطي لقطات الفيديو الرقمي (المستمرة / المجزأة) ، وأسلوب التعلم (الكلي / التتابعي) في بيئة التعلم الإلكتروني في تتمية الجوانب

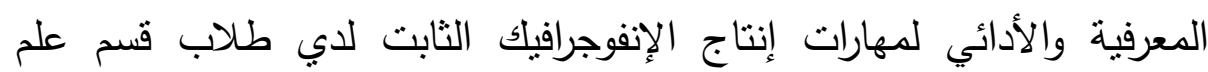
المعلومات.

- تحديد النمط الأنسب لتقديم نمطي لقطات الفيديو الرقمي (المستمرة / المجزأة) بييئة التعلم الإلكتروني، والذي من الممكن أن يسهم في تتمية الجوانب المعرفية والأدائي لمهارات إنتاج الإنفوجرافيك الثابت لاي طلاب قسم علم المعلومات. - التعرف على أثز التفاعل بين نمطي لقطات الفيديو الرقمي (المستمرة / المجزأة) ، وأسلوب التعلم (الكلي / التتابعي) ببيئة نظام ادارة التعلم الإلكتروني.

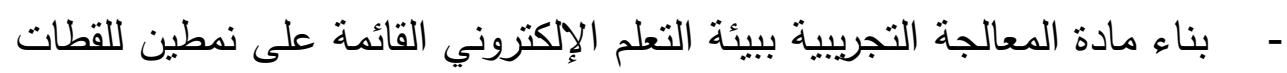

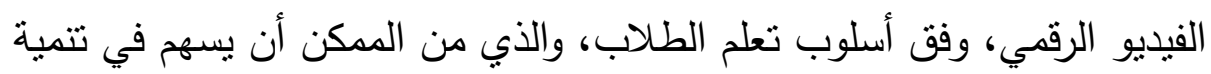


الجوانب المعرفية والأدائي لمهارات إنتاج الإنفوجرافيك الثابت لدي طلاب قسم

$$
\begin{aligned}
& \text { علم المعلومات. } \\
& \text { أهمية البحث: } \\
& \text { يسهم البحث الحالي في: }
\end{aligned}
$$

- تحسين نواتج التعلم من خلال الاستفادة من نمطي لقطات الفيديو الرقمي (المستمرة / المجزأة) بييئة التعلم الإلكتروني.

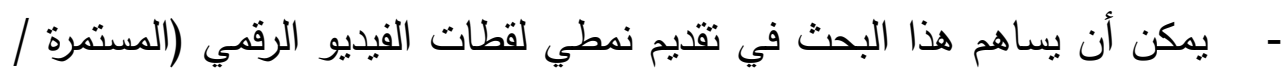
المجزأة) ؛ حتى بمكن استخدام هما في تصميم واجهة تفاعل المتعلم ببرامج

$$
\text { التعلم القائم على الويب. }
$$

- يتوقع أن يقدم هذا البحث نتائج تساعد القائمين على تطوير برامج التعلم الإلكتروني القائم على الويب في تصميم وتطبيق إستراتيجيات تعليمية تتناسب

$$
\text { وأسلوب التعلم للمتعلمين (الكلي / التتابعي). }
$$

- وضع أسلوب التعلم (الكلي / التتابعي) بيئة التعلم الإلكتروني عند تصميم عملية التعلم.

- تزويد الزملاء من أعضاء هيئة التذريس بمجموعة من المبادئ والأسس العلمية

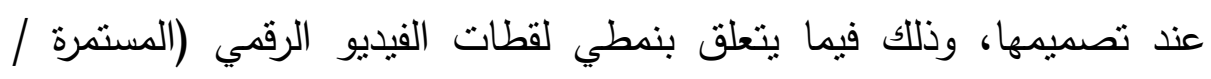
المجزأة).

- تزويد أعضاء هيئة التدريس بإرشادات حول أساليب التعلم الملائمة للطلاب للحصول على تأثير فعال في تحسين أداء الطلاب في نواتج التعلم المختلفة.

$$
\text { متغيرات البحث: }
$$

$$
\text { تمنلات متغيرات البحث في الآتي: }
$$

المتغيرات المستقّة: اشتثل البحث الحالي على متغيرين مستقلين ، هما: المتغير المستقل: لقطات الفيديو الرقمي ببيئة التعلم الإلكتروني وله نمطان:

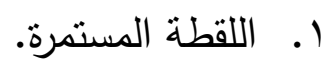

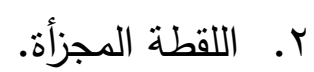




$$
\begin{aligned}
& \text { المتغير التصنيفي: أسلوب التعلم: } \\
& \text { ا. الكلي. } \\
& \text { r. r. التتابعي. }
\end{aligned}
$$

المتغيرات التابعة: اشتمل البحث الحالي على متغيرين تابعين هما: ا ـ الجوانب المعرفية لمهارات إنتاج الإنفوجرافيك الثابت.

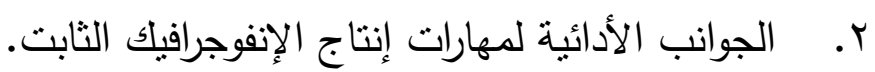

اقتصرت عينة البحث على (79) من طلاب قسم علم المعلومات في المستوي السادس بكلية الحاسب الآلي ونظم المعلومات بجامعة أم القري، وتم تقسيمهم الى لى

$$
\text { أربع مجموعات تجريبية في ضوء متغيرات البحث. }
$$

Factorial تم اختيار التصميم التجريبي المعروف باسم (التصميم العاملي (Design 2×2 2) ؛تحديد دلالة الفروق بين المجموعتين، وقياس حجم الأثر الناتج عن تطبيق التجربة؛ لقياس الجوانب المعرفية والأدائية لمهارات إنتاج الإنفوجرافيك الثابت لدي طلاب قسم علم المعلومات. أدوات البحث: البت لتحقيق أهداف البحث، ثم تصميم الأدوات البحثية ، وهي كالتالي: - الاختبار التحصيلي لقياس الجوانب المعرفية المرنبطة بمهارات إنتاج الإنفوجرافيك الثابت لدي طلاب قسم علم المعلومات. - بطاقة ملاحظة لقياس الأداء العملي لمهارات إنتاج الإنفوجرافيك الثابت لدي طلاب قسم علم المعلومات.

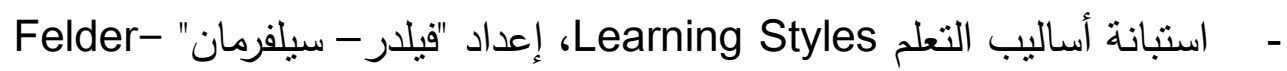

.Silverman حدود البحث: اقتصر البحث على الحدود التالية: - التئ 
الحدود البشرية: اقتصر البحث على طلاب قسم علم المعلومات بكلية الحاسب الآلي

$$
\text { ونظم المعلومات بجامعة أم القري. }
$$

الحدود الزمانية: نم تطبيق تجربة البحث خلال الفصل الدراسي الثاني للعام الجامعي

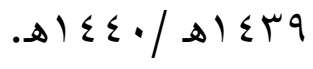

الدود المكانية: قسم علم المعلومات بكلية الحاسب الآلي ونظم المعلومات بجامعة أم

$$
\text { منهج البحث: }
$$

اتبع الباحث منهج البحث التطويري والذي يتضمن الوصف التحليلي في تحليل المحتوي وخصائص المتعلمين، وتقديم حلول للتحديات والمشكلات التعليمية، وقد تبني الباحث نموذج عبداللطيف الجزار (Elgazzar,2014) للتصميم التعليمي وتوظيفه في تصميم بيئة التعلم الإككتروني، وتم استخدام المنهج شبه التجريبي للكثف عن أثز التفاعل بين نمطي لقطات الفيديو الرقمي (المستمرة / المجزأة) وأسلوب التعلم (الكلي / التتابعي) في تتمية الجانب المعرفي والأدائي لمهارات إنتاج الإنفوجرافيك الثابت لدي طلاب قسم علم المعلومات بكلية الحاسب الآلي بجامعة ام القري.

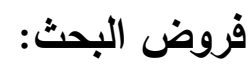

سعى البحث الحالي للتحقق من صحة الفروض التالية: ا. لا يوجد فرق ذو دلالة إحصائية عند مستوى (0...) بين متوسطي درجات المجموعتين التجريبيتين في اختبار التحصيل المعرفي المرتبط بمهارات إنتاج الإنفوجرافيك الثابت يرجع للتأثيرالأساسي لاختلاف نمطي لقطات الفيديو الرقمي

$$
\text { (المستمرة / المجزأة). }
$$

r. لا يوجد فرق ذو دلالة إحصائية عند مسنوى (0...) بين متوسطي درجات المجموعتين التجريبيتين على بطاقة ملاحظة الأداء العملي لمهارات إنتاج الإنفوجرافيك الثابت يرجع للتأثنير الأساس لاختلاف نمطي لقطات الفيديو الرقمي (المستمرة / المجزاة). (الإنج) 
r. لا يوجد فرق ذو دلالة إحصائية عند مستوى (0...) بين منوسطي درجات المجموعتين التجريبيتين في اختبار التحصيل المعرفي المرتبط بمهارات إنتاج الإنفوجرافيك الثابت يرجع للنأثير الأساسي لاختلاف أسلوب التعلم (الكلي التنابعي). ع. لا يوجد فرق ذو دلالة إحصائية عند مستوى (0...) بين متوسطي درجات المجموعتين التجربيينين على بطاقة ملاحظة الأداء العملي لمهارات إنتاج الإنفوجرافيك الثابت يرجع للنأثير الأساسي لاختلاف أسلوب التعلم (الكلي التهني (التنابعي). 0. لا يوجد فرق ذو دلالة إحصائية عند مستوى (0...) بين منوسطي درجات المجموعات التجريبية في اختبار التحصيل المعرفي المرتبط بمهارات إنتاج الإنفوجرافيك الثابت يرجع للتأثير الأساسي للتفاعل بين بين نمطي لقطات الفيديو الرقمي (المستمرة / المجزأة) ، وأسلوب التعلم (الكلي / التتابعي). 7. لا يوجد فرق ذو دلالة إحصائية عند مستوى (0. . ) بين متوسطي درجات المجموعات التجريبية على بطاقة ملاحظة الأداء العملي لمهارات إنتاج الإنفوجرافيك الثابت يرجع للتأثير الأساسي للتفاعل بين بين نمطي لقطات الفيديو

$$
\text { مصطلحات البحث: (المستمرة / المجزأة) ، وأسلوب التعلم (الكلي / التتابعي). }
$$

\section{Video Digital الفيديو الرقمي:}

عبارة عن : برامج تليفزيونية رقمية مسجلة، محفوظة على وسائط رقمية أو مواقع

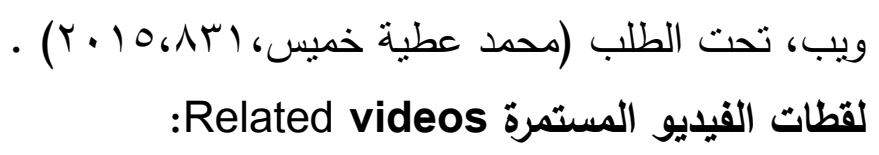

يقصد بها سلسلة متتالية من الأطر Frames الفردية المعروضة في تتابع مستمر، تظهر حركة المحتوى البصري، وتظل هذه الأطر متحركة في استمرارية تامة

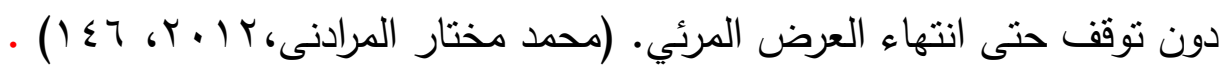


وتعرف إجرائياً بأنها عبارة عن :عملية لعرض مقطع فيديو لعرض المحتوي بشكل مستمر ومنواصل بلا توقف، وحتى انتهاء المقطع بشكل كامل. لقطات الفيديو المجزأة Divided videos: يقصد بها سلسلة متتالية من الأطر Frames الفردية المعروضة في تتابع مجزأ بوقفات ساكنة عبارة عن صورة ثابتة (مجمدة) لآخر إطار تم عرضه قبل الوقفة؛ للفت الانتباه والتأكيد على معلومات جوهرية أو أحداث مفصلية تربط الجزء السابق بالجزء اللاحق لهذه الوقفة من خلال التلميحات. (طارق عبدالودود، زينب حسن حامد، محمد

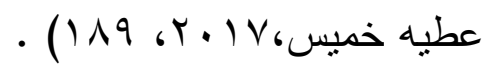
وتعرف إجرائياً بأنها عبارة عن : عملية لعرض مقطع فيديو يعرض المحتوي من خلال عملية تقسيم مقطع الفيديو إلى مجموعة من الأجزاء، حيث يكون بين الجزء باءئ والجزء الذي يليه فترة توقف زمنية تسمح للمتعلم بالتدقيق في المهارة الجزئية. أسلوب التعلم Learning Style: يقصد بها مجموعة خصائص سلوكية ومعرفية تمنل مؤشرات ثابتة نسبياً في تكييف إدراك المتعلّم للبيئة التعليمية وتفاعله معها ؛ لذا فهي تصف عمليات التكيف التي تجعل منه مستجيبا للمثيرات المتتوعة بما يلاعم خصائصه. Manochehri) and young, 2006, p.315) أسلوب التعلم (التتابعي، الكلي): Sequential-Global: يقصد بها ميل المتعلم إلى الاستيعاب والفهم إما باستخدام خطوات متسلسلة ومتدرجة ، أو بالمرور بقفزات كبيرة ومفاجئة، ويقاس بالدرجة التي يحصل عليها الفيا الفرد

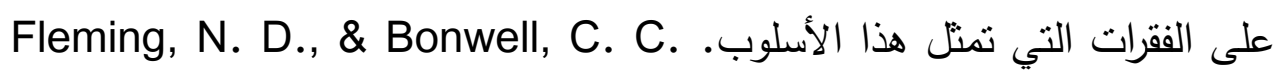
. $(2002,13)$

وتعرف إجرائياً في البحث الحالي : ميل المتعلم التتابعي إلى الاستيعاب والفهم باستخدام خطوات دقيقة منسلسلة، والتقدم في عملية التعلم بشكل متتابع، بينما بميل المتعلم الكلي إلى التفكير، والتقدم في عملية التعلم بشكل شمولي من خلا قفزات 
الانفوجرافيك: Infographic فن تحويل البيانات والمعلومات والمفاهيم المعقدة إلى صور ورسوم يمكن فهمها واستيعابها بوضوح وتتويق ، وهذا الأسلوب يتميز بعرض المعلومات المعقدة والصعبة بطريقة سلسة وسهلة وواضحة ،وهذه من أكثر التعريفات شيوعا بين المتخصصين وصفحات الإنترنت. :Static Infographic الإنفوجرافيك الثابت يقصد بها تصميمات تشرح المعلومات والأفكار المتضمنة عن طريق صور ورسومات تمكن الفرد من فهمها واستيعابها بسهولة، حيث يتم انتاجها على شكل

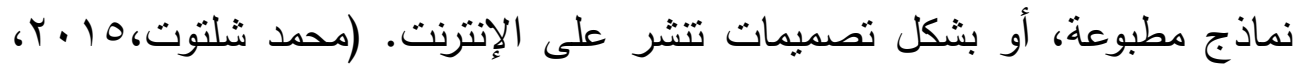

الإطار المفاهيمي للبحث المحور الأول: التعلم الإلكتروني

تتتوع بيئات التعلم الإككتروني ؛ لنتاسب مع تتوع المتعلمين وتتوع المقررات

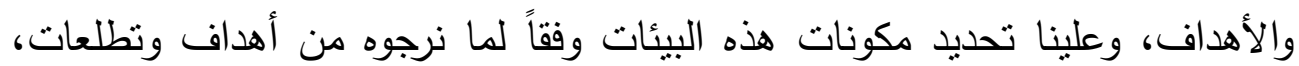
وأن نضيف لها إستراتيجيات وبرامج تتتاسب مع المحتوى العلمي وطبيعة المتعلمين،

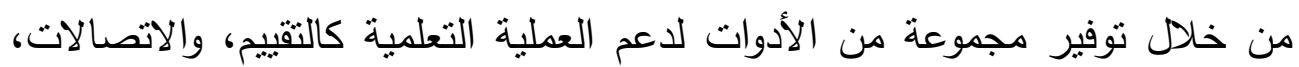
وتحميل المحتوى، وتسليم أعمال الطلاب، وتقييم الأقران، وإدارة المجموعات الطلابية،

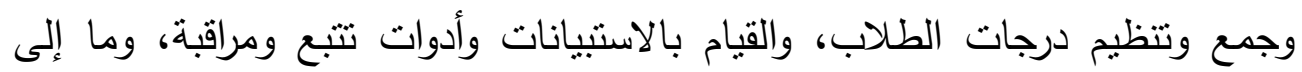
ذلك، ومن أمثلتها نظام بلاك بورد ( Blackboard)، ونظام مودل ( Moodel)

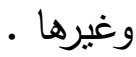

وقد أضحى التعلم الإكتروني عبر الويب مجالا من أهم المجالات التي تهتم بها نظم تعليمية عديدة على مستوى العالم، وهو شكل فردى يقدم للمتعلمين عبر شبكات كمبيوتز عامة أو خاصة، وهو لا يعنى مجرد تحميل لبرامج التعليم المبنية على

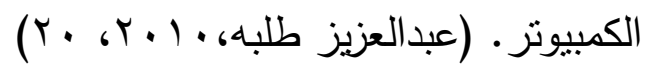
ومن مبررات استخدام التعلم الإلكتروني القائم علي الويب ليس فقط لأنه نظام لتوصيل المحتوي والمقررات الإكترونية، أو نظام يستخدم أدوات ومستحدثات 
تكنولوجية، ولكنه علم نظري تطبيقي، ونظام تكنولوجي تعليمي كامل، وعملية مقصودة، تقوم علي أساس فكري وفلسفي ونظريات تربوية جديدة يمر فيها المتعلم بخبرات مخططة ومدروسة، من خلال تفاعله مع مصادر تعلم إلكترونية متعددة ومتتوعة بطريقة نظامية ومتتابعة وفق إجراءات وأحداث تعليمية منظمة، في بيئات تعلم مرنة ؛ لاعم عمليات التعليم لتحقيق توصيل المواد التعليمية، الاتصالات،عمل

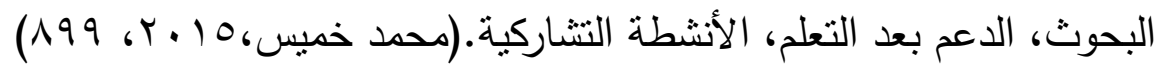
وقد اهتمت العديد من الدراسات بيئات التعلم الإلكتروني ؛ لتحقيق نواتج نعلم أفضدل بمقررات دراسية مختلفة، حيث تتاول كل من سمر فهر الدسيماني، عبدالرحمن

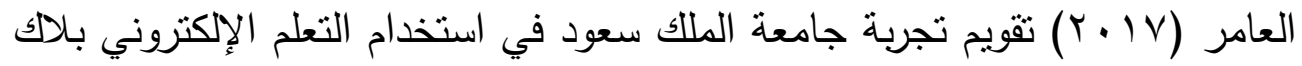
بورد (blackboard) من وجهة نظر أعضاء هيئة التدريس، كما تتاول عبدالرحمن

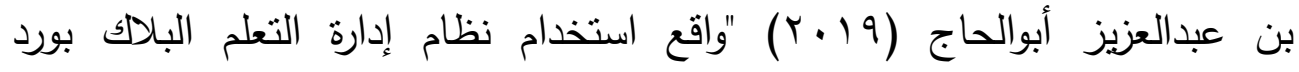
Blackboard من وجهة نظر طلاب جامعة القصيم. كما كثفت ريم المبارك (Yl1) عن أثر نمطين من أنماط التعلم (المدمج) و (الداعم) على التحصيل المعرفي لمحتوي مقرر تقنيات التعليم واتجاه الطالبات نحو لموني استخدام نظام إدارة التعلم (البلاك بورد).

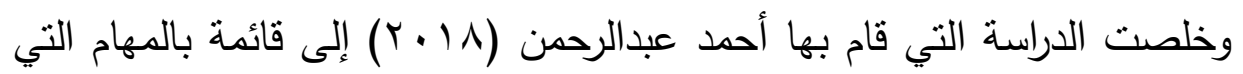
يتيحها نظام البلآك بورد منها: الاطلاع على إعلانات، وتتبيهات، ومحتوى، ودرجات المقرر، إضافة إلى تسليم الواجبات.

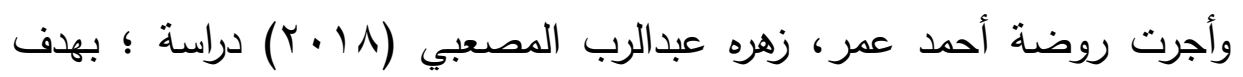
التعرف على أثز استخدام تطبيق Black board Mobile learn على تتمية اتجاهات طالبات جامعة نجران نحو التعليم الإلكتروني النقال. وسعت دراسة عبدالعزيز حسين (1/ • ب) إلى التعرف على المعوقات التي تواجه طلاب كليه التربية في جامعة الملك سعود في استخدام التعلم الإلكتروني. ويقوم التعلم الإلكتروني بإدارة العملية التعليمية بطريقة تزامنية وغير منزامنة، ويتيح بيئة تعلم آمنة يقدم المعلمون مقرراتهم ومحاضراتهم من خلال إضافة الوسائط 
المتعددة (نص، صور ، صوت، فيديو، رسوم)، كما يتيح أنظمة إدارة التعلم الإكتروني

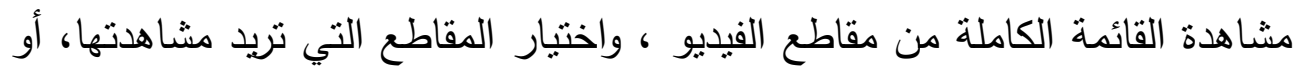
مشاهدة مقاطع فيديو متعددة في صف واحد عن موضوع محدد باستخدام قوائم التشغيل. المحور الثاني: الفيديو الرقمي يعد الفيديو الرقمي أحد المصادر التعليمية التي تسهم في توفير المواءمة ، والتتاول المباشر ،والمعالجة والمعيارية في عرض المعلومات والكفاءة والفاعلية في التقديم ؛ مما يسهم في زيادة الدافعية والقدرة على الاستيعاب والابتكار . والفيديو الرقمي من أهم الوسائل للتفاعل المباشر وغير المباشر، ويزداد استخدام الفيديو كأداة تعليمية ؛ بهدف تحسين تعلم الطلاب من خلال تعليمات حول سلوكيات المشاهدة الأخرى، وما إذا كانت نأثثرات التعلم هذه تعتمد على معرفتهم السابقة. (De Boer, J., 2016, 1137)

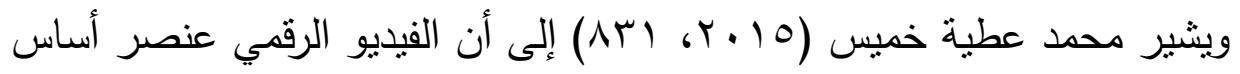
لا غنى عنه في التعليم والتعلم الإكتروني؛ لقدرته علي مساعدة الطلاب لفهم الحقائق والمفاهيم والتعليمات، التي يصعب فهمها بطرق أخرى مثل النصوص والرسوم فقط. ويمكن القول إن للقطات الفيديو المرئية قواعد تحكمها كما هو الحال في قواعد اللغة الواجب مراعاتها لإنتاج جمل مفهومة، ومن ثم فإن القواعد البنائية للقطات المرئية المتمثلة في مفردات هذه اللغة يجب مراعاتها لإنتاج تسلسل مرئي مفهوم، فاللقطة تعد بمثابة فكرة، والتتابع المرئي للقطات بمثابة تتابع أفكار يتم تركيبها لإعطاء تدفق وتجانس منطقي يعبر عن الأفكار ، والحقائق ، والمفاهيم ، والمهارات المختلفة

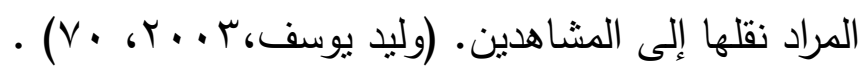
وبالنظر إلي تكنولوجيات تسجيل محاضرات الفيديو الرقمي، فإن اللقطات تتتوع من حيث حجم اللقطة أو حركة الكاميرا أو زاوية التصوير، فمحتوى اللقطة، وسرعة تدفقها، يتم من خلال نمطين للقطات الفيديو، أولهما لقطات الفيديو المستمرة وهى "سلسلة متتالية من الأطر Frames الفردية المعروضة في تتابع مستمر، تظهر 
حركة المحتوى البصرى، وتظل هذه الأطر متحركة في استمرارية تامة دون توقف حتى انتهاء العرض المرئي"، وثانيهما : لقطات الفيديو المزأة ، وهى "سلسلة متنالية

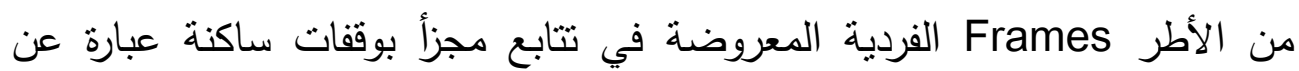
صورة ثابتة لآخر إطار تم عرضه قبل الوقفة؛ للفت الانتباه والتأكيد على معلومات جوهرية أو أحداث مفصلية تربط الجزء السابق بالجزء اللاحق لهذه الوقفة. (طارق

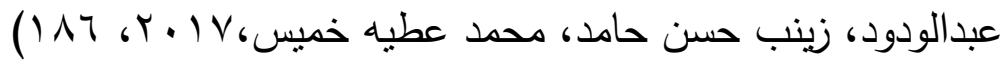

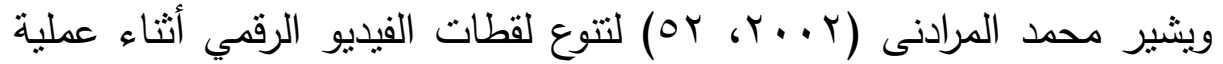
التسجيل بكاميرا الفيديو من حيث حجم اللقطة إلي اللقطة المقربة، واللقطة المتوسطة ، واللقطة البعيدة.

وتزتبط لقطات الفيديو بالعديد من الخصائص التي تحدد فاعليتها وجودتها التعليمية ، وهي درجة وضوح الصورة ودرجة اللون، ويعرف عدد الإطارات المعروضة في الثانية الواحدة بمعدل عرض الإطارات، وتعطى صورة الفيديو الإحساس بالحركة عن طريق عرض سلسلة من الصور تعرف بالإطارات" Frames" ، وذللك في تتابع سريع. (Betancourt, 2005,293) كما تتقم لقطات الفيديو الرقمية إلي نمطين أساسيين للعرض ،وهما : نمط العرض الكلي، ونمط العرض المجزأ، وترتبط هذه اللقطات في تصنيفها بالمحتوى الذي تقدمه حيث توجد علاقة ارتباطية بين الفيديو وقدرته على إكساب المتعلمين المهارات المتتوعة، وبعني ذلك أن لقطات الفيديو الكلية تقوم بعرض لقطات الأداء الخاص بمهارة معينة دفعة واحدة ودون أي فواصل أو فصل خطوة من خطوات الأداء ، وبحيث يمكن للمتعلم التعرف على كافة خطوات الأداء، والعلاقات بين كل خطوة وأخرى من خلال هذا العرض الكلي، وينطلق العرض المزأ من فكرة تجزئة المهارات إلى وحدات مستقلة تشكل في مجموعها المهارة الرئيسية المطلوب من المتعلم اكتسابها ، وبحيث يمكن للمتعلم اختيار أي مقطع فيديو من هذه المقاطع المجزأة ليقوم Fajardo, I., ) بمشاهدته ، والتفاعل معه ؛ ليكتسب جزء من المهارة الكلية المطلوبة (Parra, E., \& Canas, J. J.2010,245 


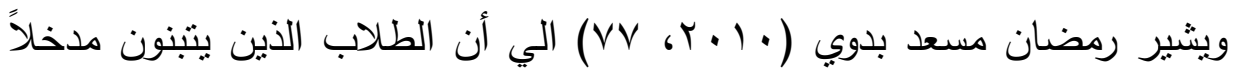
كليَّا شموليَّا يميلون في مقابل ذلك إلى العمل بشكل أفضل عن طريق معالجة المهمة ككل متكامل من البداية ، ويميلون للعمل وفقًا للنمط العام التالي: لئي - يعملون بشكل مندفع وفقًا للمزاج والاهتمام. - - مينظرون أولاً إلى الصورة العامة. - - يركزوا بشكل واسع على المهمة في سياق البرنامج العام. - - يستفيدون من مورد ثري من التتاظرات والحكايات. - - يفرضون تفسيرا شخصيًّا على كل الأدلة. - - بفضلون التدريب والتدريس الحر.

فمن الواضح أن لكل من المدخلين تطبيقاته ،ولابد من نتجيع الطلاب على تهذيب كلا الأسلوبين ، واختيار المدخل الذي يلائم الموقف المعطى أكثر فعند فحص هل

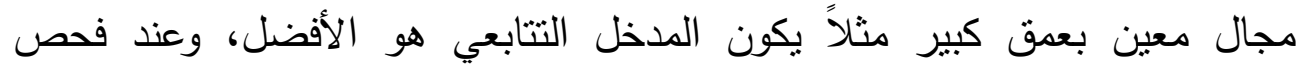
الموضوع في سياقه العام يكون المدخل الكلي أكثر فاعلية. وتعرف لقطات الفيديو المجزأة: بأنها سلسلة متتالية من الأطر Frames الفردية المعروضة في تتابع مجزأ بوقفات ساكنة عبارة عن صورة ثابتة (مجمدة) لآخر إطار تم عرضه قبل الوقفة؛ للفت الانتباه ، والتأكيد على معلومات جوهرية ، أو أحداث مفصلية تربط الجزء السابق بالجزء اللاحق لهذه الوقفة من خلال التلميحات. (طارق

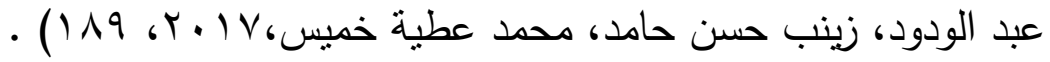
كما تم تعريف لقطات الفيديو المستمرة: بأنها عبارة عن سلسلة متتالية من الأطر Frames هذه الأطر متحركة في استمرارية تامة دون توقف حتى انتهاء العرض المرئي. (محمد

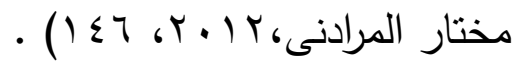
والمدقق لغالبية الدراسات السابقة يلاحظ ندرة في البحوث التي تتاولت متغيرات تصميم الفيديو الرقمي؛ حيث تحتاج لمزيد من الدراسات كمتغير التجزئة حيث يعد 
واحدا من أهم متغيرات الفيديو المرتبطة بالسبطرة على سرعة التعلم ، والتقليل من

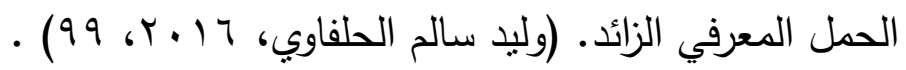
كما أن تجزئة اللقطات إلى أجزاء قصيرة يساهم بشكل كبير في إكساب المتعلمين

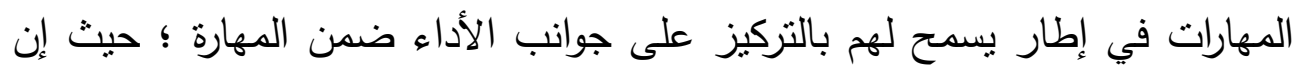
المتغيرات المرتبطة بلقطات الفيديو الرقمي لها دور كبير في إكساب المتعلمين المهارات المتتوعة ، وبخاصة المهارات المعقدة التي يتم تقديمها للمتعلمين. - (D'Alene, P., \& Taylor, B. ,2003,7) وتتميز لقطات الفيديو الرقمية التي يتم التعامل معها من خلا الكمبيوتز عن لقطات الفيديو التتاظرية التقليدية بما يسمى السعة المضافة الناشئة عن التكامل بين مصدرين ، أو أكثر من مصادر التعلم ، ويحدث هذا التكامل نتيجة للاندماج أو التقارب التكنولوجي فيما بينها. , Betancourt, M., \& Benetos, K. 2018)

كما تحقق لقطات الفيديو المجزأة "مبدأ التطابق" من خلال توفير تمثيل خارجي لإجراءات أقرب إلى التمثيل العقلي الداخلي المتوقع من المتعلمين، والذي يصور الأحداث على أنها خطوات منفصلة بدلا من تصورها واحدة واحدة مستمرة، كما تحقق ملى إلى لقطات الفيديو المجزأة "مبدأ القبض" ، وهو : إدراك الصورة وإجراء المعالجة المعرفية عليها بشكل لم يكن ممكنا مع سرعة تدفق الصور المتحركة. (طارق عبدالودود، زينب

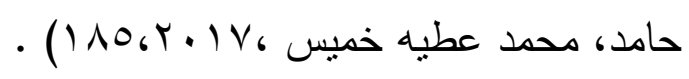
ويشير معايير تصميم مقاطع الفيديو الرقمية المجزأة - عرض لقطات الأداء الخاص بمهارة معينة دفعة واحدة. - يتم عرض المهارات دون أي فواصل أو فصل خطوة من خطوات الأداء. - - يمكن للمتعلم التعرف على كافة خطوات الأداء والعلاقات بين كل خطوة Fajardo, I., Parra, E., \& ) وأخرى من خلال هذا العرض الكلي. (Canas, J. 2010,245 
كما أضاف الباحثون طارق عبدالودود، زينب حسن حامد، محمد عطيه خميس

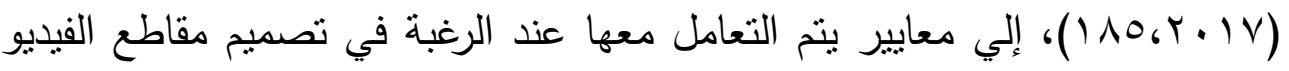
المجزأة ، وهي كالتالي:

- أن تحتوي لقطات الفيديو المجزأة على خصائص الصور الثابتة والمتحركة. - ربط الأجزاء بعضها ببعض من حيث المعلومات المقدمة، بحيث تكون المعلومة في الجزء مرتبطة بالجزء الذي يليه. - أن يكون المدى الزمني لمقطع الفيديو المجزأ من 10 - 1 - 1 دقيقة.

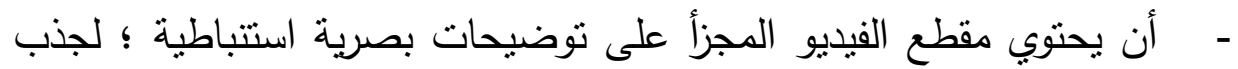

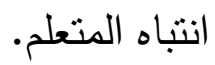

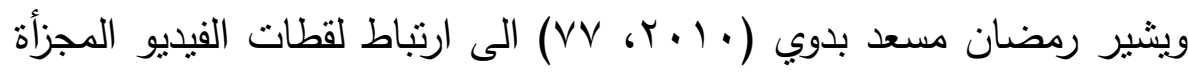
بالأسس الفلسفية للبناء العقلي للمتعلم ؛ حيث إن الطلاب الذين يتبنون المدخل التتابعي وميولهم إلى العمل بطريقة منظمة وخطية في الأساس ويميلون إلى الدخول

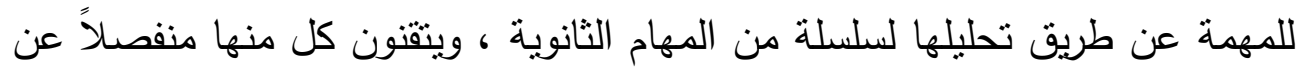
غيرها ، وبعد ذلك يجمعونها لكي يتقنوا المهمة ككل، فهم يميلون لأن يعملوا وفقًا للنمط العام التالي: - n - - يعملون بشكل منظم خطوة واحدة في المرة الواحدة. - يركزون بشكل ضيق على المادة المحددة التي يدرسونها. - - مينظرون أولاً إلى التفاصيل والأدلة. - - يعتبرون الأمنتة والإيضاحات الكثيرة مشتتة للانتباه. - - يكونون حذرين في قبول التقسير المقدم. - يتمتعون بالتدريب والتدريس المنظم بإحكام.

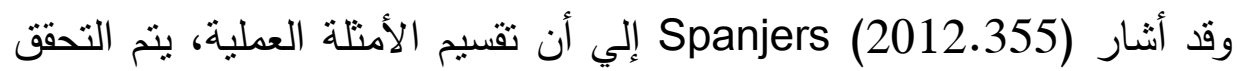
منه بطريقتين لتحسينها: تقديمها في شكل مجزأ وإرشاد الطلاب إلي تقسيمها بشكل نشط (بمعنى أنه يجب على الطلاب تقسيم الأمنلة إلي أجزاء)، فمن المتوقع أن تدعم 
الأمثلة المجزأة التعلم أكثر من الظروف الأخرى ، منثل : تقديم الأمتلة العملية بشكل مستمر وكلي. وقد اهتم (2012) chiu,(20حث لقطات الفيديو الرقمية ؛ حيث استخدم العناوين الفرعية الجزئية القابلة للتحكم ، والميزات التفاعلية في مقاطع الفيديو التعليمية، وتوصلت الدراسة إلي أن الطلبة الذين يشاهدون مقاطع الفيديو المجزأة أفضل من ونديه الذين بشاهدون بترجمات كاملة، كما تُظهر سجلات النظام أن المتعلمين في مجموعة إنهان

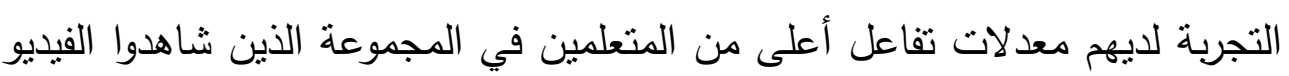
كاملا بدون تجزئة.

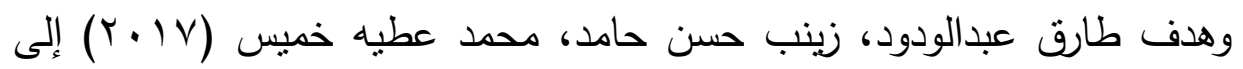
معرفة أثز نمطي لقطات الفيديو (المستمرة - المجزأة) المقدمة في نموذج الفصل المقلوب على تتمية الانتباه لدى طلاب المدارس الصناعية، وكثفت النتائج عن وجود فرق دالا إحصائيا بين المجموعتين في التطبيق البعدي لمقياس الانتباه، لصالح

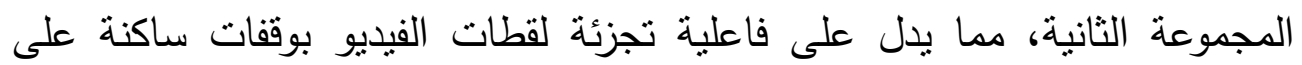
تتمية الانتباه وقد تتاول عبدالله محمد عبداله (19) أبنز استخدام نمطي الفيديو الرقمي "مجزأ- متصل" في تتمية مهارات البرمجة لدى طلاب الصف الثالث المتوسط في مدينة الطائف، وتوصلت النتائج لصالح المجموعة التي تستخدم (مقاطع الفيديو الرقمية المجزأة). المحور الثالث: أساليب التعلم إن معرفة الطريقة المفضلة التي يستخدمها الفرد في تتظيم المعلومات ، أو أساليب تعلم الطلاب يساعد المعلم على تقديم الفرص التعليمية لهم وفقًا لأنماط تعلمهم؛ وبذلك يستطيع أن يكيف أساليبه والبيئة من حوله ؛لتتاسب أنماط تعلم طلابه لغابه لاستخدامها في حل المشكلات التي تواجهه أثناء المواقف التعليمية. ويعد أسلوب التعلم من المفاهيم التربوية والنفسية التي ما زالت على مدار البحث

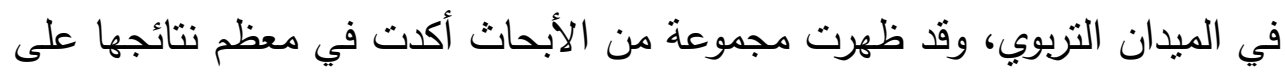


وجود فروق فردية في أساليب التعلم المفضلة لدى الطلبة وأخذها بعين الاعتبار في العملية التعلمية، مع أن تطور هذه الأبحاث في مجال الفروق الفردية بدأت الاهتمامات تتجه نحو الفروق الفردية في ضوء أساليب التعلم المفضلة لدى الطلبة.

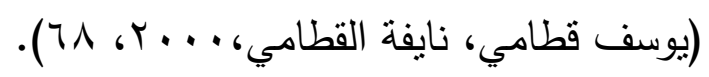
وبعد البحث في أساليب التعلم اتجاها مهما في ميدان علم النفس المعرفي، وخاصة عندما بدأ بحث التعلم الإنساني من وجهة نظر المتعلم نفسه، على عكس مما كان سائدا من قبل حيث كان يعتمد على وجهة نظر الآخرين في تقويم أداء المتعلم، وفي ضوء ذللك الاتجاه المهم يتم إجراء العديد من البحوث لمعرفة كيف يتعلم الطالب؟

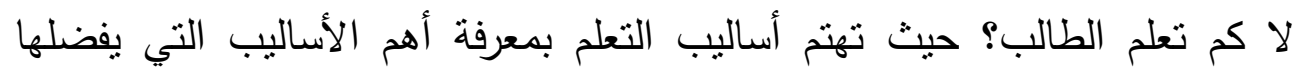
الطلاب في تعلمه ودراستهم، وفقا لما يبذله من عمليات ذهنية معرفية مطورة بذلك

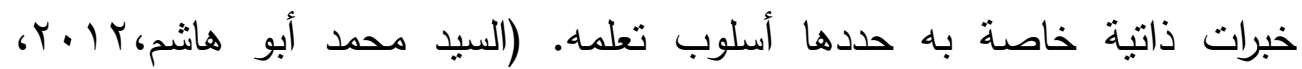
. (1) 19. ويزخر الأدب التربوي بالعديد من تعريفات أساليب التعلم فقد تم تعريفها بأنها :

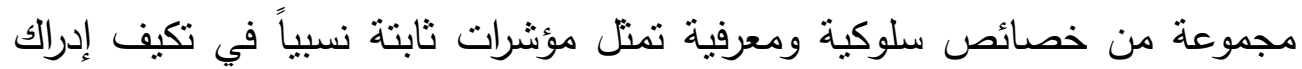
المتعلم للبيئة التعليمية وتفاعله معها، لذلك فهي تصف عمليات التكيف التي تجعل Manochehri, N. \& ) منه مستجيباً للمثيرات المتتوعة بما يلائم خصائصه. (Sharif, K. 2010,37 كما عرفها (2018,1538) الطبيعية والعادات المفضلة لامتصاصه ،ومعالجته واسترجاعه للمعلومات الجديدة ، والمهارات التي تستمر بصرف النظر عن طرق التعليم أو المحتوى.

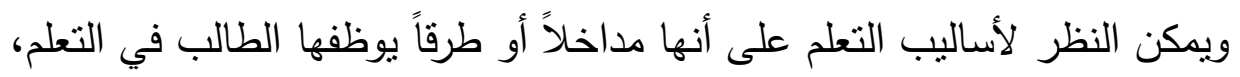
أي أنها تعبر عن الصفات والسلوكيات التي تختلف من فرد إلى آخر، والتي تختص لهص بمعالجة المعلومات واسترجاعها وبالتالي تؤثز على إستراتيجيات التعلم، وهذا ما لها أنشارت إليه نظرية الحمل المعرفي. 
وتوجد عدة نماذج وتصنيفات لأساليب التعلم، يحمل كل نموذج منها اسم العالم الذي قام بنطوبره، وتم وضع تصنيفات أساليب التعلم ضمن خمس فئات أساسية هي: فئة الوسائط الحسية الإدراكية، فئة التفضيلات المعرفية، فئة التفاعل الاجنماعي، فئة معالجة المعلومات، وفئة النماذج الثخصية، ومن أهم نماذج تصنيف أساليب التعلم

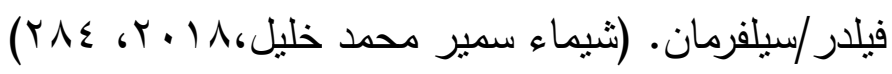
ووفقا لفيلدر وسيلفرمان(Felder and Silverman model) فالمتعلمين يتعلمون بعدة طرق بواسطة الرؤية، السمع ،التفكير ،العمل ،رسم أثكال معينة ؛

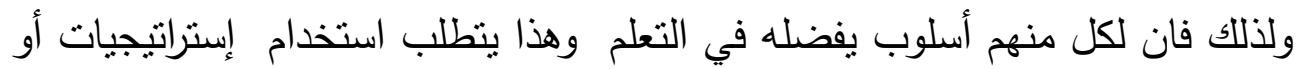
طرق تعليمية تلائم ما يفضله المتعلمين، فالبعض يفضل التعلم عن طريق إلقاء المحاضرات والبعض الآخر عن طريق العروض العملية والبعض عن طريق المناقتة

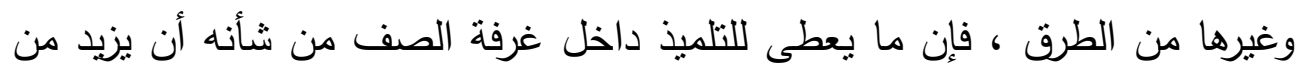

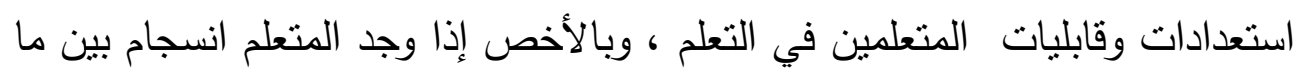

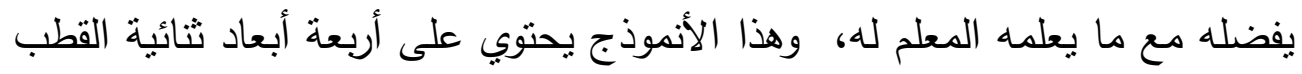
وذللك كما يلي:

ا. أسلوب التعلم (الحسي، الحدسي):Sensing-Intuitive حبث يفضل المتعلم الحدسي إلي اكتشاف العلاقات والاحتمالات، ويميل إلي العمل السريع والتجديد والإبداع، والطرق التي يفضلها المتعلم الحسي تكون من خلال تطبيقات واقعية عملية، معلومات مادية، بينما المتعلم الحدسي فيكون تدريسه عن طريق عمل ارتباطات او مخططات مفاهيمية، واجبات فكرية مفتوحة والتوجه نحو النظريات

$$
\text { ما وراء المعنى. }
$$

r. أسلوب التعلم (النشط ، التأملي) :Active-Reflective يميل المتعلم النشط إلي الحصول على المعلومات، وفهمها عن طريق إجراءات عملية تطبيقية، كمناقتتها أو تطبيقها أو شرحها للآخرين، ويميل إلى العمل الجماعي، أما المتعلم التأملي

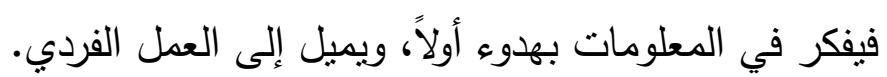


r. أسلوب التعلم (اللفظي، البصري): Visual-Verbal يميل المتعلم البصري إلى الى

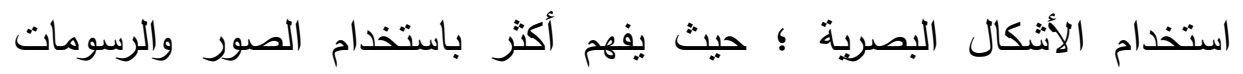
والعروض التوضيحية، أما المتعلم اللفظي يميل إلى المعلومات اللفظية من شرح، لفظ الكلمات، كتابة الكلمات والرموز . ع. أسلوب التعلم (التتابعي، الكلي) :Sequential-Global أسلوب التعلم التتابعي إلالاستيعاب والفهم باستخدام خطوات دقيقة منسلسلة،

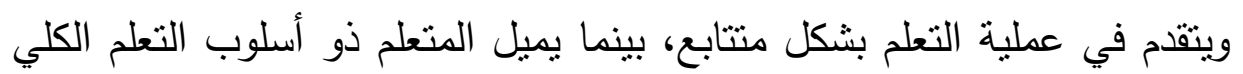

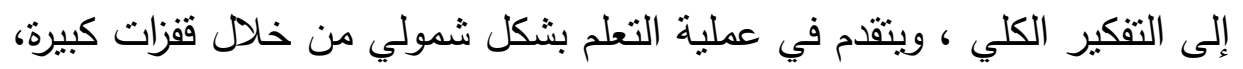

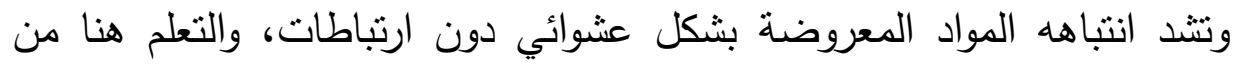
خلال خطوات دقيقة تتابعية ، ويتم تدريس المتعلم الثمولي من خلال النقديم

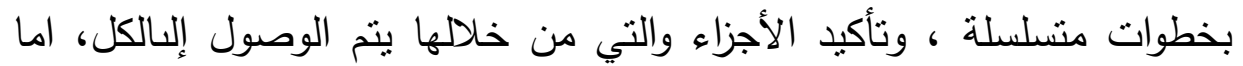

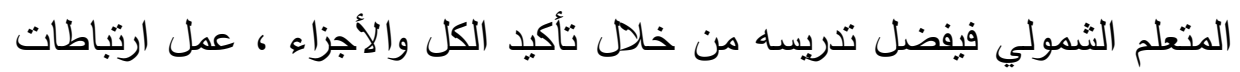

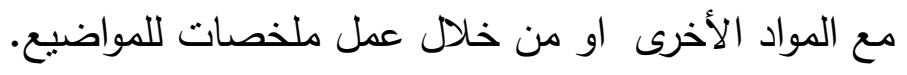
Ahmed, M. U., Hussain, S., \& Bagram, M. M. M.( ) ويشير الونات 2017,128 إلى أهمية تحديد أسلوب التعلم للمتعلمين عند نطوير بيئات التعلم

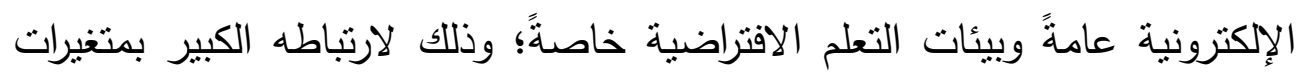
تصميم تلك البيئات. وتستكثف دراسة Demirkan, H. 2016) التفضيلات المتعلقة بأسلوب التعلم وبناء المعرفة لدى طلاب الهنسة المعمارية الداخلية باستخدام أنماط التعلم من Felder - Soloman

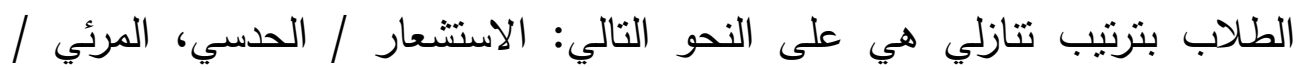
اللفظي، / التتابعي / الكلي في التحليل ذي الاتجاهين. Quinn, M., Smith, T., Kalmar, , \& Burgoon, J. (2018) للبحث عن أساليب التعلم المفضلة للطلاب الجامعيين في علم التتريح وفقا لأساليب 
التعلم، وأظهرت التحليلات أنماط التعلم المفضلة لدى الطلاب ، ومنها : الأسلوب التتابعي.

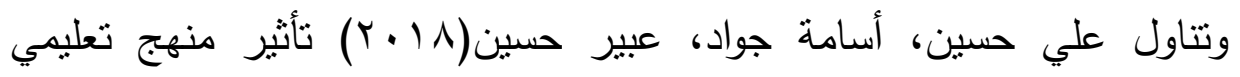
بالأسلوب (التتابعي - الكلي) في تعلم بعض المهارات الاساسية بالجمناستك الفني لطلاب جامعة كربلاء، وأظهرت النتائج أن هنالك تفضيل لأسلوب (التتابعي - بلابه (الكلي).

ونتير نتائج دراسة (2018) Heidrich, L إلى تأثثر أكثر قدرة في أبعاد نمط

التعلم Felder-Silverman على تتخيص المتعلم في البُعد التتابعي / الكلي. وركز (2017), Ho, S. على أساليبب وأنماط التعلم المتتابعة والكلية كطرق لتحسين نعلم البرمجة، ويخلص إلي أن حلول التوثيق المتسلسلة يمكن أن نقود الطلاب الجامعيين منخفضي التحصيل مع أساليب التعلم المنتالية إلي نمو أسرع في اكتساب المعرفة البرمجية.

وبحث (2018) Tian, H., التعلم العميق التسلسلي لتصنيف الفيديو؛ حيث تعمل مقاطع الفيديو على نقل المعلومات الدلالية المعقدة وتسهيل فهم المعرفة الجديدة.

واستخدم (El-Bishouty, نموذج نمط التعلم Silverman و (2019) لتصميم الدورة التدريبية "برنامج الماجستير في تكنولوجيا التعليم" في كلية التربية، وتشير النتائج إلى أن دعم نمط التعلم المنسلسل، بنسبة ^ج ٪ ٪ ولم تدعم أسلوب التعلم الكلي.

\section{المحور الرابع: الإنفوجرافيك :}

يعتبر الإنفوجرافيك Infographics من أسهل وأسرع الوسائل التي تستخدم لعرض الأفكار ؛ حيث يستخدم بشكل واسع وفي مجالات مختلفة سواء في العمل ،

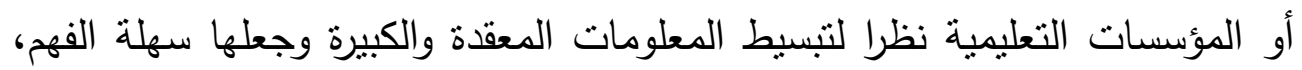
والاعتماد على المؤثرات البصرية في توصيل المعلومة، وتحويل المعلومات والبيانات من ارقام وحروف مملة إلى صور ورسوم جذابة. 
والإنفوجرافيك عبارة عن تمثيلات بصرية للمعلومات والبيانات وما يرافقها من نصوص، ومصدم لتقديم المعلومات المعقدة بشكل أكثر وضوحا من النص بمفرده؛ وتستخدم فيه الكلمات والأرقام والرموز والألوان والصور؛ بهدف توصندئ توصيل الرسالة للمستقيدين. (Niebaum, Cunningham, \& Bellows, 2015,2) كما تم تعريفه بأنه : مجموعة من العروض المرئية والرسومية للمعلومات ،أو

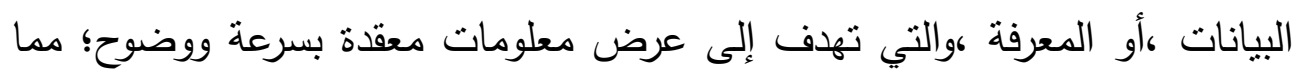
al-) يعمل علي تحسين الفهم والادراك لاي الطلاب المتعلمين من خلالها. (mohammadi,2017,27 وتطلق العديد من التسميات على الإنفوجرافيك أبرزها: التمثيل البصري للبيانات، تصميم المعلومات، هندسة المعلومات، والبيانات التصورية التقاعلية. (عاصم

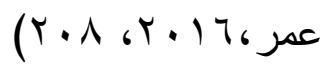

وسعت العديد من البحوث والدراسات لإثبات فاعلية استخدام الإنفوجرافيك في

Alshehri, (Hassan, H. G. ,2016) تدريس مقررات منتوعة، ومنها دراسات Dahmash, A. B., Al-Hamid, A., \& (M. A., \& Ebaid, M. 2016) (Afify, M. K. (2018) (Alrwele, N. S. 2017) (Alrajhi, M. 2017)

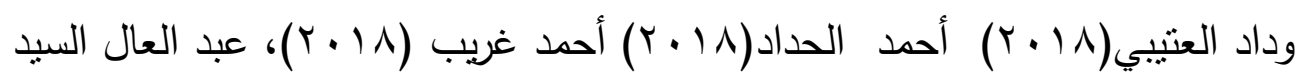
(Y.11)

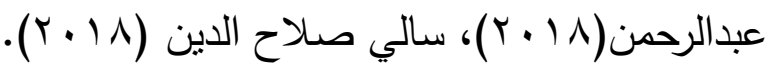

$$
\begin{aligned}
& \text { ثانياً: أنواع الانفوجرافيك: }
\end{aligned}
$$

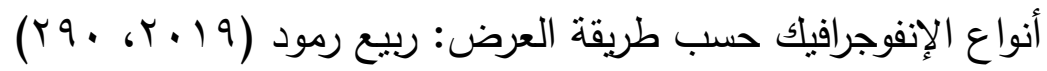

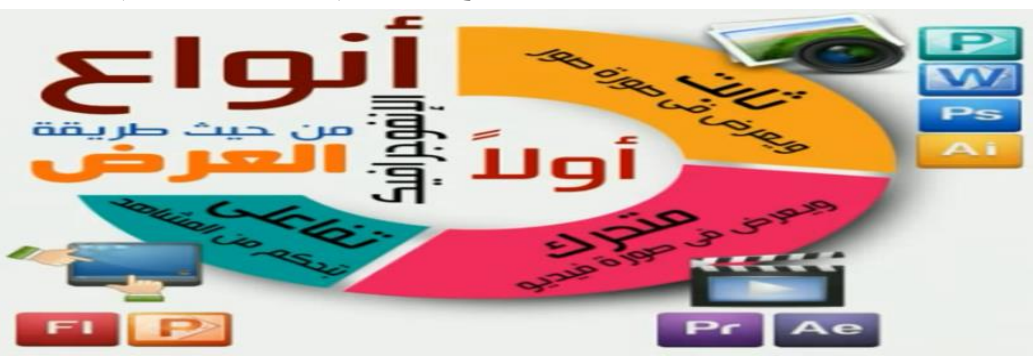


شكل ( ) أنواع الإنفوجرافيك من حيث طريقة العرض Kibar, P. N., \& Akkoyunlu, B. أنواع الإنفوجرافيك حسب طريقة التخطيط: $(2014,457)$.

\section{أنواع الإنفوجرافيك}

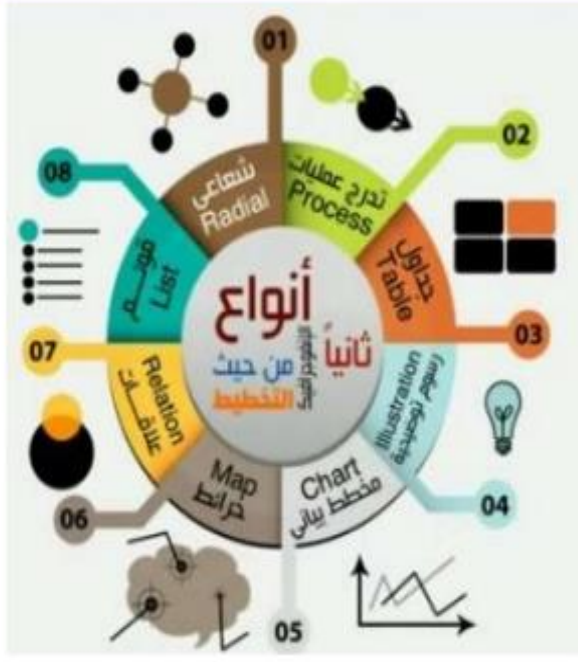

أنواع الإنفوجرافيك: (من التخطيط:

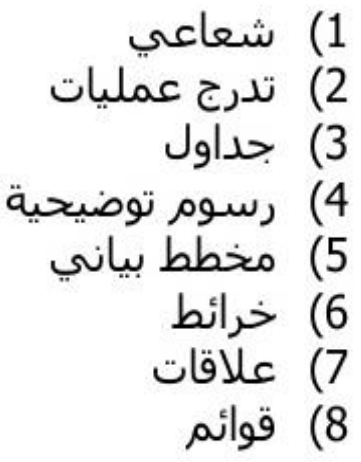

شكل (Y) أنواع الإنفوجرافيك من حيث طريقة التخطيط

ولقد أكدت العديد من الدراسات على أهمية الاهتمام بإنتاج الإنفوجرافيك، فقد أجرى (2015) Polman, \& Gebre, دراسة ؛ لتحديد مكونات الإنفوجرافيك العلمية

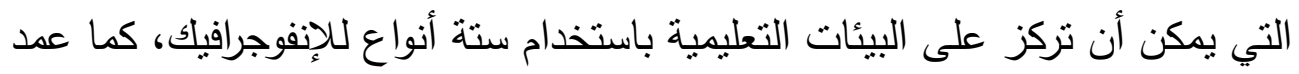
(2018) fadzil (لتمية مهارات إنتاج الإنفوجرافيلك لدي (10 1 ) طالبا بجامعة كوالا لامبور، من خلال بيئة التعلم الإلكتروني.

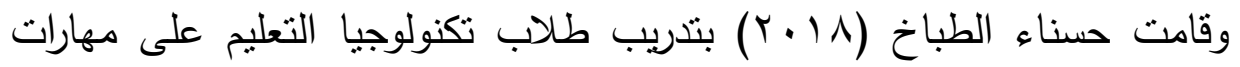
إنتاج الإنفوجرافيك من خلال نظم التعلم الذكية ، وأظهرت نتائج دراسة منى الغامدي

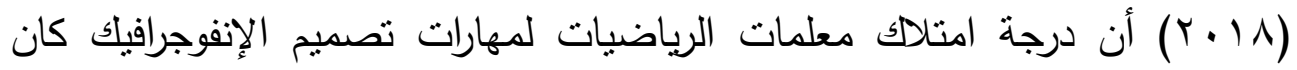


وأعدت (2018) Yuruk, E., Yilmaz., \& Bilici, S. دراسة لقياس التحصيل

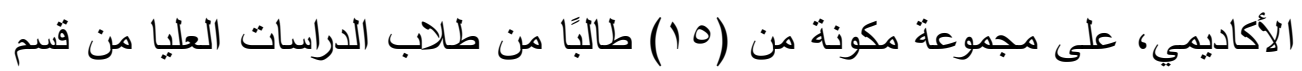

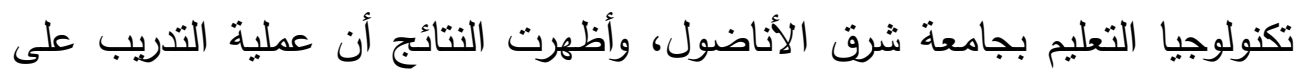
أساس إنتاج الإنفوجرافيك لها تأثير كبير على التحصيل الأكاديمي، وتسهيل إدارة عملية التعلم. وأجري (2018) تطوير لنظام تدريب إلكتروني حول موضوع "تصميم الانفوجرافيك، وتتألف عينة البحث من ع ع طالبًا من جامعة Silpakorn لدراسة أربع موضوعات، وكثفت نتائج البحث أن تصميم الإنفوجرافيك خلا التدريب الإكتروني بنظام إدارة التعلم كان لها تأثنير إيجابي. كما قدم ربيع رمود (19 ( + برنامج لتتمية مهارات إنتاج الإنفوجرافيك التعليمي لاى طلاب تقنيات التعليم من خلال بيئة الحياة الثانية ثلاثية الأبعاد، وقدم (2019) \& Nasser (راسة لنطوير تصميم الإنفوجرافيك لتحسين ذاكرة الطلاب ودعم استدعاء معرفتهم. وفي ضوء مراجعة الدراسات والبحوث السابقة، اتضح عدم وجود بحوث تتاولت تتمية مهارات إنتاج الإنفوجرافيك لدي طلاب قسم علم المعلومات في الوطن العربي في حدود علم الباحث- لكن توجد بعض الدراسات التي تتاولت تتمية مهارات

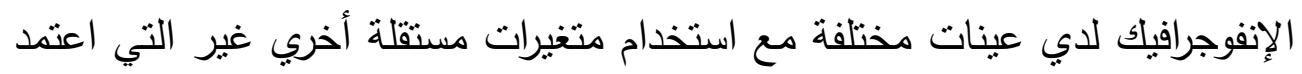

$$
\text { علبها البحث الحالي. }
$$

نظرًا لأن البحث الحالي يهدف إلى الكثف عن أثز التفاعل بين نمطي لقطات الفيديو الرقمي (المستمرة / المجزأة) ببيئة التعلم الإلكتروني (Black Board) وأسلوب الفي التعلم (الكلي / التتابعي) ، وأثنره في تتمية مهارات إنتاج الإنفوجرافيك الثابت لدي الدي طلاب قسم علم المعلومات؛ حيث سارت الإجراءات على النحو التالي: اولا: إعداد قائمة مهارات إنتاج الإنفوجرافيك الثابت: 
فيما يلي استعراض الإجراءات التي استخدمت لإعداد قائمة المهارات اللازمة لإنتاج الإنفوجرافيك الثابت ، وهي كما يلي:

أ- تحديد الهرف من القائمة:

تهذف القائمة إلى حصر المهارات الرئيسة والفرعية اللازمة لإنتاج الإنفوجرافيك الثابت لدى طلاب قسم علم المعلومات. ب- تحديا محتوى القائمة: لتحديد المهارات الرئيسية والفرعية اللازمة لإنتاج الإنفوجرافيك الثابت التي تم تضمينها في القائمة، قام الباحث بما يلي: - الاطلاع على الأدبيات والبحوث والمراجع العربية والأجنبية في مجال مهارات إنتاج الإنفوجرافيك الثابت بصفة خاصة. - - تحليل نماذج مهارات إنتاج الإنفوجرافيك الثابت. - قيام الباحث بتدريس دورات تدريبية لأعضاء هيئة التذريس والطلاب على الابلى مهارات إنتاج الإنفوجرافيك الثابت. - الاستعانة بآراء منتجي الإنفوجرافيك من الخبراء والمتخصصين. وبعد الحصول على المهارات تم تقسيمها إلى مهارات أساسية، ويتبع كل مهارة الإنهاء أساسية مجموعة من المهارات الفرعية المتعلقة بها، وبلغ عدد المهارات الرئيسية (IT)

$$
\text { مهارة، وبلغ عدد المهارات الفرعية (10 (1) ). }
$$

تم عرض القائمة في صورتها الأولية على مجموعة من الخبراء والمتخصصين في مجالي المناهج وطرق التدريس، وتكنولوجيا التعليم، الخبراء في مجال التعليم الإلكتروني ملحق (1)، وبعد الحذف والإضافة والتعديل بناء على آراء السادة المحكمين تم التوصل إلى الصورة النهائية لقائمة المهارات، وبلغ عدد المهارات الرئيسة (Y ( ))، والمهارات الفرعية (1) (1) كما يتضح بالجدول التالي. 
جدول (1) المهارات الرئيسة والفرعية لقائمة مهارات إنتاج الإنفوجرافيك الثابت

\begin{tabular}{|c|c|c|}
\hline | لعدد المهارات & |لمهـارة الرئيسة & r \\
\hline$\varepsilon$ & piktochart الدخول علي & 1 \\
\hline$\varepsilon$ & انشاء حساب علي piktochart & r \\
\hline$r$ & piktochart التعرف على واجهة موقع & r \\
\hline$\circ$ & | إنشاء قالب جديد علي موقع piktochart & $\varepsilon$ \\
\hline $1 \leqslant$ & مهارات التعامل مع قالب جاهز لإنتاج الإنفوجرافيك & 0 \\
\hline$\wedge$ & مهارات التعامل مع قالب جديد فارغ لإنتاج الإنفوجرافيك & 7 \\
\hline$r \varepsilon$ & مهارات إنشاء نص بالقالب الجديد الفارغ علي piktochart & V \\
\hline 7 & مهارات إدراج صورة من جهاز الكمبيوتز علي piktochart & $\wedge$ \\
\hline 14 & | مهارات إدراج رسوم بيانية & 9 \\
\hline v & Back Ground مهارات التعامل مع قائمة & $1 \cdot$ \\
\hline $1 Y$ & مهارات مراجعة وحفظ العمل & 11 \\
\hline 11 & نشر ومشاركة العمل & $\pi$ \\
\hline
\end{tabular}

وتم عرض القائمة على مجموعة من المتخصصين ملحق ( (1) ؛ بغرض الوصول للثكل النهائي للقائمة، ثم تم استخدام حساب نسبة اتفاق المحكمين لتحليل المهمات

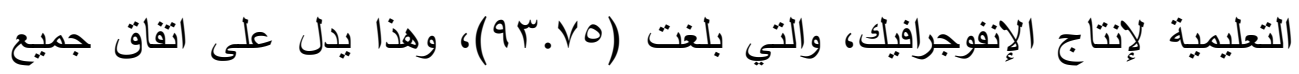
المحكمين على أهمية جميع المهارات.

وبذلك تمت الإجابة عن التساؤل الأول من نساؤلات البحث وهو: ما مهارئ مهارات

الإنفوجرافيك الثابت اللازم توافرها لدي طلاب قسم علم المعلومات. ملحق (ب) ثانيا: تصميم بيئة التعليمية الإكترونية يتبع البحث الحالي الإجراءات القائمة علي التصميم التعليمي لتطوير بيئات التعلم الإكتروني، وفق نموذج عبداللطيف الجزار ؟1 ؟ب) ؛ لتطوير بيئات التعلم 
الإلكترونية ، والذي تبناه الباحث؛ حيث إنه يتتاسب وطبيعة البحث الحالي، مع إجراء بعض التعديلات ليتوافق مع طبيعة البحث الحالي ، وقد مرت إجراءات تصميم البرنامج القائم على نمطي لقطات الفيديو الرقمي (المستمرة / المجزأة) ببيئة التعلم الإلكتروني ، حسب المراحل التالية: (شكل r) 
التفاعل بين نمطين للاتطات الفيديو الرقمي وأسلوبين للتعلم عبر بيئة التعلم الإكتروني وأثثره في تنمية مهارت إنتاج الإنفوجراقيك

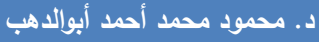

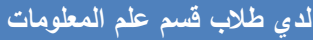

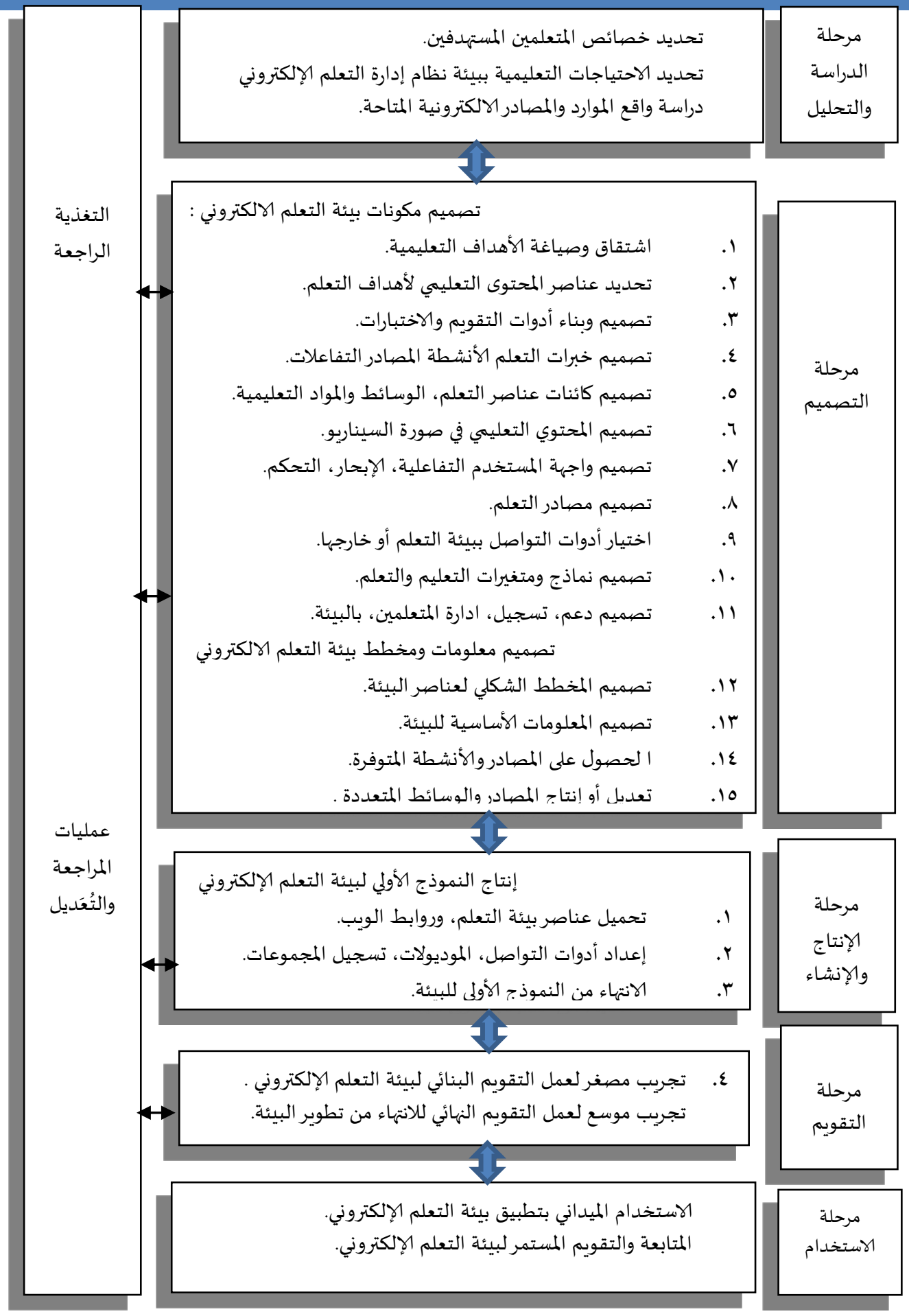

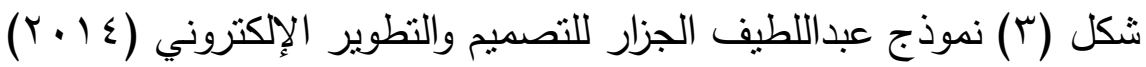


أولا: مرحلة التحليل: وشملت هذه المرحلة الخطوات الآتية : ا ـ ت تحديد خصائص المتعلمين المستهرفين: تم تحديد العينة ، وكانت لطلاب قسم علم المعلومات بكلية الحاسب الآلي ونظم المعلومات بجامعة أم القري منمنلة في (79) طالبا بالمستوي السادس، ممن أبدوا رغبتهم بالمشاركة، ويمتلكون مهارات التعامل الأساسية للتعامل مع الإنترنت. r. تحديد الاحتياجات التعليمية بيئة التعلم الإكتروني: تم الاعتماد على تحديد الاحتياجات التعليمية بيئة التعلم الإلكتروني من خلد الص دراسة متطلباتها r. دراسة واقع الموارد والمصادر الإكترونية المتاحة: تم تحليل واقع الموارد والمصادر الإلكترونية المتاحة ، مثل : المواقع الإكترونية، ولقطات الفيديو، والعروض، كما تم تحديد نمطين للقطات الفيديو الرقمي (المستمرةالمجزأة)، ووضع حلول بديلة للتحديات والمعوقات أثثاء عملية التطبيق. ثانيا: مرحلة التصميم: شملت هذه المرحلة العديد من الخطوات الأساسية ، وهي كما يلي: 1. تصميم مكونات بيئة نظام إدارة التعلم الإكتروني: اشتملت هذه المرحلة على العديد من الخطوات الفرعية: - اشتقاق وصياغة الأهداف التعليمية: في ضوء مهارات إنتاج الإنفوجرافيك الثابت من خلال موقع piktochart لطلاب قسم علم المعلومات، بحيث يقدم وصف دقيق للمهارات والمعارف المرتبطة

- تحديا عناصر المحتوى التعليمي لأهداف التعلم: تم تحديد عناصر المحتوى التعليمي لأهداف التعلم من خلال خطوتين ، وهما : تحديد المحاور الأساسية لنمطي لقطات الفيديو الرقمي (المستمرة-المجزأة) بييئة التعلم piktochart الإكتروني من خلال تحليل مهارات الإنفوجرافيك الثابت من خلال موقي الثعب 
، والمعارف المرنبطة بها، ثم تم جمع وتتظيم المحتوي للمهارات ؛ بهدف الوصول لإنجاز الأهداف التعليمية المطلوبة.

\section{- - تصميم ويناء ادوات التقويم والاختبارات:}

تم تصميم اختبار تحصيلي، بطاقة ملاحظة، استبانة تحديد أساليب التعلم Learning Styles - تصميم خبرات التعلم الأنشطة المصادر التفاعلات: يوفر التعلم الإلكتروني العديد من الأنشطة والتفاعلات، بحيث يتم اختيار الأنشطة التي تتناسب مع طبيعة مهارات الإنفوجرافيك الثابت ، وتتضمن الأنشطة الإكترونية حل الواجبات الإلكترونية، والمشاركة في لوحات النقاش الإلكترونية، واستخدام البريد الإككتروني للنظام ؛ للاستفسارات ومتابعة الأداء، ومتابعة الإعلانات عبر الإدلهات النظام. - تصميم كائنات عناصر التعلم، الوسائط والمواد التعليمية: يقوم التعلم الإكتروني بإدارة العملية التعليمية بطريقة تزامنية وغير منزامنة، وينيح بيئة تعلم يقدم المعلمون مقرراتهم ومحاضراتهم من خلال إضافة الوسائط المتعددة

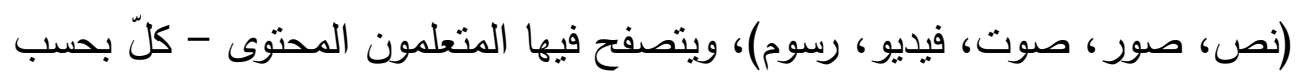
حاجته - ويتواصلون فيما بينهم عبر أدوات الاتصال المتعددة (البريد الإكتروني

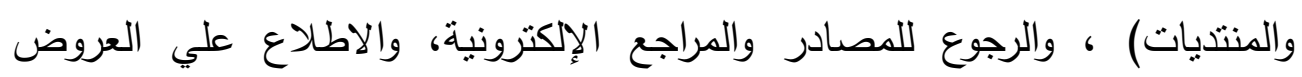
التقديمية الإككترونية، ومتابعة المحتوى المدعم بالكائنات التعليمية، ومشاهدة مقاطع الفيديو التعليمية.

- تصميم المحتوي التعليمي في صورة السيناريو: تم إعداده في ضوء نمطي لقطات الفيديو (المستمرة-المجزاة) ببيئة التعلم الإلكتروني وفق أسلوب تعلم الطلبة (الكلي - التتابعي). - تصميم واجهة المستخدم التفاعلية، الابحار، التحكم: 
تم تصميم حسب نمطي لقطات الفيديو (المستمرة-المجزأة) بييئة التعلم الإلكتروني وفق أسلوب نعلم الطلبة (الكلي- التتابعي) بطريقة تسمح للمستخدم التتقل فيما بينها بسهولة ويسر ؛ مما يساعده للوصول إلى مواد التعلم المختلفة. - تصميم مصادر التعلم. تصميم عناصر التعلم يختلف وفقاً لطبيعة المادة التعليمية فأي مصدر رقمي يمكن إعادة استخدامه لدعم عملية التعلم مع تتويعها وتقديم المساندة للطلبة عينة البحث أثناء التطبيق على مهارات إنتاج الإنفوجرافيك الثابت من خلال موقع - piktochart ـ اختيار أدوات التواصل ببيئة التعلم أو خارجها: تم اختبار ادوات المحادثة، الفصول الافتراضية، منتديات المناقتنة، مشاركة الملفات.

\section{- تصميم نماذج ومتغيرات التعليم والتعلم:} تم تصميم التعلم وفقا لمتغيري البحث نمط تقديم لقطات الفيديو وأسلوب التعلم. - تصميم دعم، تسجيل، ادارة المتعلمين، بالبيئة: تم تصميم تسجيل الدخول التعلم الإلكتروني للمتعلمين من خلال تفعيل البريد الإلكتروني الجامعي الخاص بالطالب عن طريق الذهاب إلى رابط بوابة التعلم

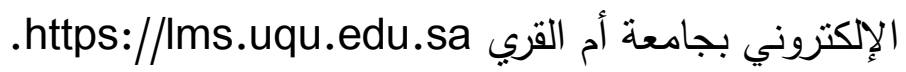
r- تصميم معلومات ومخطط بيئة التعلم الإلكتروني . اشتملت مرحلة تصميم معلومات ومخطط بيئة التعلم الإلكتروني على تصميم الأدلة الإرشادية ؛ ليتم اتباعها من قبل عينة البحث مع الوضع في الاعتبار أسلوب تعلم كل منهم (كلي -تتابعي)، كما تم تصميم الاطارات للإنفوجرافيك الثابت من خلال موقع piktochart والجوانب المعرفية المرتبطة بها. ثالثا: مرحلة الإنتاج والإنشاء 
تم إنتاج مكونات بيئة التعلم الإلكتروني من خلال الحصول على الوسائط والمصادر، والأنشطة، وكائنات التعلم، وغيرها من المكونات، وإنتاج معلومات بيئة

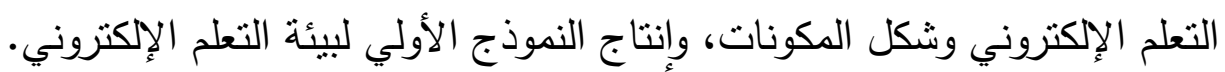
رابعا: مرحلة التقويم:

وشملت هذه المرحلة إجراء التجريب المصغر على عينة استطلاعية مكونة من (0) طالباً - تم استبعادهم من النطبيق النهائي- لإجراء التقويم البنائي للمحتوي؛ وذلك بهدف التأكد من وضوح المادة التعليمية، ومناسبة المحتوي التعليمي لمستوي المتعلمين، ومناسبة الثكل النهائي للشاشات المحتوي ، ومناسبة طريقة سير المتعلم داخله، ومناسبة الأنشطة التعليمية، والفاعلية الداخلية للمحتوي ، وفي ضوء ذلك تم إجراء التعديلات المطلوبة، ثم تجريب موسع لعمل التقويم النهائي للانتهاء من تطوير البيئة؛ ليصبح النموذج المقترح للمحتوي صالحاً للنطبيق. خامسا: مرحلة الاستخدام: ترتبط مرحلة الاستخدام للبيئة القائمة على نمطي لقطات الفيديو الرقمي (المستمرة

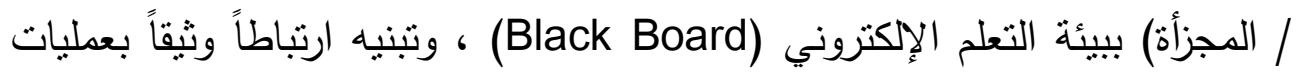
الاستخدام والتوظيف، وتشمل هذه المرحلة خطوتين، هما : - الاستخدام الميداني بتطبيق بيئة التعلم الإكتروني. نشر المحتوي على بيئة التعلم الإلكتروني (Black Board): تم نشر المحتوى المي التعليمي على موقع جامعة أم القري على بوابة التعلم الإكتروني عنوانه الإنه https://Ims.uqu.edu.sa/webapps/portal/execute/tabs/tabActio n?tab_tab_group_id=_2_1

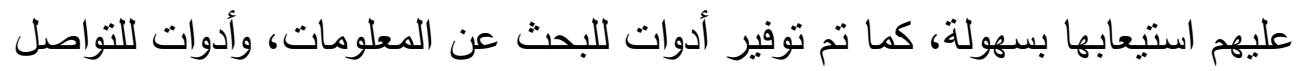
بين الطلاب والمعلم على الموقع التعليمي. - المتابعة والتقويم المستمر لبيئة التعلم الإكتروني. تم ضبط المحتوي ومراقبته بهدف المتابعة ، والتقويم المستمر لبيئة التعلم الإلكتروني ، ووضع أدوات لمراقبة أداء المتعلمين وتقدمه في تعلم المحتوي، من 
خلال اختبار موضوعي (اختيار من متعدد) تكويني داخل المحتوي التعليمي، وسجل للأنشطة التي يقوم بها المتعلم حتى يمكن متابعته من قبل مدير الموقع (الباحث).

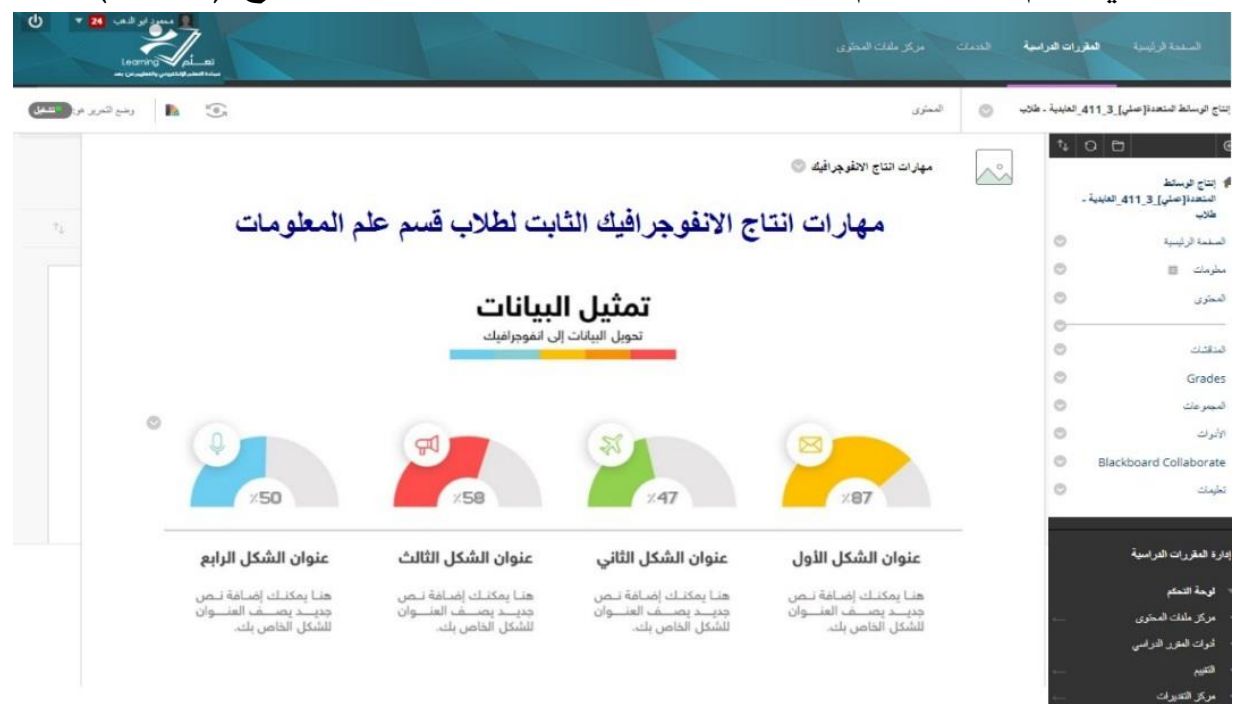

شكل (ء ) واجهة تفاعل المستخدم ببيئة التعلم الإكتروني عبر بلاك بورد

$$
\text { إعداد أدوات البحث }
$$

في ضوء طبيعة البحث تم بناء ثلاث أدوات ، وهي: اختبار تحصيلي، وبطاقة ملاحظة تقدير الأداء، واستخدم الباحث، نموذج أساليب التعلم لفيلدر - سيلفرمان Felder-Silverman Learning Style Model عينة البحث، وذللك كما يلي: 1. إعداد الاختبار التحصيلي ؛ لقياس الجانب المعرفي لمهارات إنتاج الإنفوجرافيك الثابت تم إتباع الإجراءات التالية في إعداد الاختبار التحصيلي: يهذف هذا الاختبار إلى قياس تحصيل عينة من طلاب قسم علم المعلومات، في الجانب المعرفي لمهارات إنتاج الإنفوجرافيك الثنابت. - - صياغة مفردات الاختبار: 
تكون الاختبار ذو الأسئلة الموضوعية في صورته الأولية من جزأين: الأول منها الصواب والخطأ وعددها (V) مفردة ، والجزء الثاني من الاختبار الاختيار من متعدد وعددها (7 (1) مفردة، وتم مراعاة الثروط اللازمة لكل نوع منها حتى يكون الاختبار بصورة جيدة، وفى ضوء المحتوى تمت صياغة مفردات الاختبار، وقد روعي في بناء الاختبار التوزيع العشوائي للإجابات أي غير مرتبة بنظام معين بياعد على اكتشافها، ولكل سؤال أربعة بدائل ؛ مما يقلل من أثز التخمين. -

تم تحديد جدول لمواصفات الاختبار التحصيلي، وذلك من خلا توزيع الأهداف بمستوياتها (التذكر ، والفهم، والتطبيق)، وحساب الأوزان النسبية لمفردات الاختبار .

\section{- مريقة تصحيح الاختبار:}

يحصل الطالب على درجة واحدة على كل مفردة يجيب عنها إجابة صحيحة، وصفر على كل مفردة يتركها ، أو يجيب عنها إجابة خطأ، وبذلك تكون الدرجة الكلية لעختبار (T) (7).

\section{- - 2 - مدق الاختبار:}

يقصد بصدق الاختبار قدرة الاختبار على قياس ما وضع لقياسه ، وقد تم تقدير

صدق الاختبار في البحث الحالي بطريقتين هما:

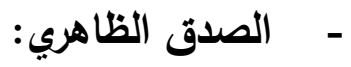

تم تحديد صدق الاختبار عن طريق الصدق الظاهري، ونم التحقق من مدى

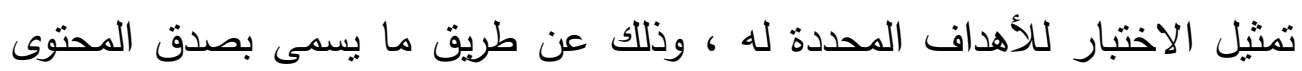

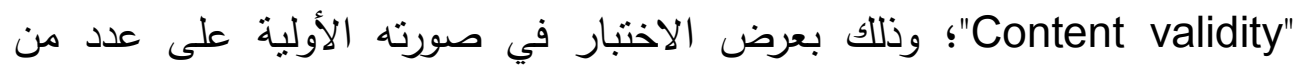
المحكمين المتخصصين في مجال المناهج وطرق التريس وعلم النفس وتكنولوجيا التعليم ؛ بهدف الاسترشاد برأيهم فيما يلي : - مدى وضوح تعليمات الاختبار ومناسبتها -

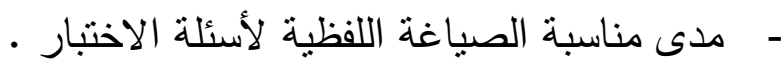
- مدى سلامة صياغة كل سؤال، ومدى اتساق البدائل. 
- صلاحية كل مفردة ؛ لقياس تحصبل الطلاب على المستوى المعرفي المحدد

\section{لها.}

وقد أوصى السادة المحكمين ببعض التعديلات على صياغات الاختبار ، وقد تم إجراء التعديلات التي أوصى بها المحكمون.

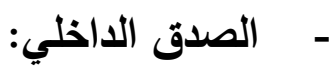

ويعنى تمثيل الاختبار للجوانب التي وضع لقياسها، والذي يتم التأكد منه عن طريق تحديد مدى ارتباط البنود الاختبارية بمستويات الأهداف المراد قياسها، ونم التأكد من الصدق الداخلي للاختبارعن طريق وضع جدول مواصفات وفق الوحدات التعليمية وتوزيع الأهداف بمستوياتها. جدول (r) مواصفات الاختبار التحصيلي

\begin{tabular}{|c|c|c|c|c|c|c|c|c|}
\hline & & & لأسئلة & ف & الأسة & & & \\
\hline لأوزان & الكلي & |وخطأ & ختعدد & تطبيـق & $\overbrace{}^{\circ}$ & تذكر & إسمور & \\
\hline$\% 19.0$ & ir & 9 & r & & $\mu$ & 9 & |لمقدمة & 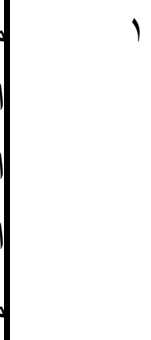 \\
\hline$\% \backslash \vee . \leq 7$ & 11 & 9 & r & $\varepsilon$ & $\mu$ & & |لالإنفوجرافيكا & r \\
\hline \%тr. & $\varepsilon \cdot$ & rq & 11 & $r \leqslant$ & $M$ & $\varepsilon$ & |لموقاستخدام & \\
\hline$\% 1 \ldots$ & $7 \pi$ & $\leqslant v$ & 17 & rN & 11 & IV & & المجموع الكا \\
\hline
\end{tabular}




\section{- -}

يقصد بثنات الاختبار أن الاختبار يعطى نفس النتائج إذا استخدم أكثر من مرة تحت نفس الظروف، أو ظروف منمانلة، وهناك طرق مختلفة لحساب ثبات الاختبار ، وفي هذا البحث تم استخدام إعادة تطبيق الاختبار على أفراد العينة (10)

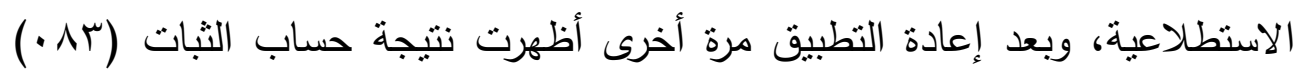
وهذا يدل على أن الاختبار بتمتع بدرجة عالية الثبات؛ مما يؤكد صلاحية استخدامه

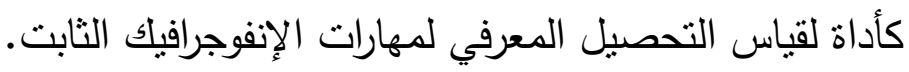
- ساب معاملات الصعوية والسهولة لمفردات الاختبار:

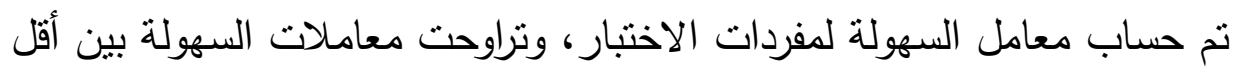
من (ץ. •) أو أكبر من (^. •) ، وهذا يؤكد على أن معاملات السهولة والصعوبة ونرابة مقبولة؛ وبالتي ظلت مفردات الاختبار كما هي.

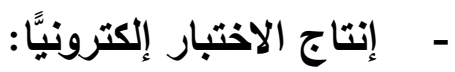
بعد صياغة عبارات الاختبار وفقاً لجدول المواصفات، تم إنتاج الاختبار الإلكتروني باستخدام "نماذج Google".، ومن مميزاتها: سهولة وسرعة تحميل الاختبار على الإنترنت بطريقة خفيفة، والتعامل معها بشكل تفاعلي، وإمكانية تسجيل

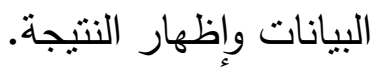
- - الصورة النهائية للاختبار: تم التأكد من صدق الاختبار التحصيلي وثباته، وأصبح الاختبار في شكله النهائي يتكون من (T/7) مفردة موزعة على جزأين منها (گV) مفردة للجزء الأول: وهو الصواب والخطأ، و (7 (1) مفردة للجزء الثاني: وهو الاختيار من متعدد؛ وبهذا يمكن هودين استخدامه لقياس تحصيل طلاب قسم علم المعلومات في المعلومات المعرفية المرتبطة بمهارات إنتاج الإنفوجرافيك الثابت، وأعطيت لكل مفردة درجة واحدة، وأصبحت في في في النهاية العظمى للاختبار هي (بآ) درجة. 


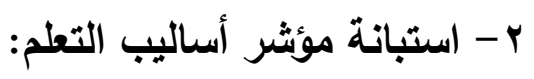

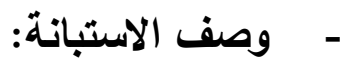

تهذف الاستبانة إلى تصنيف الطلاب الي ذوي أسلوب التعلم (التتابعي مقابل الكلي) ،وقد وضع كلا من فلدر وسيلفرمان Felder-Silverman مؤشر نموذج

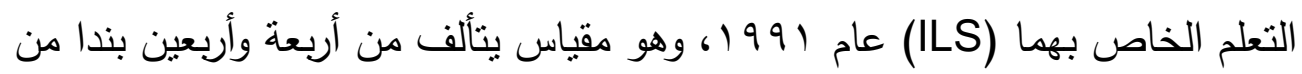
الاختيارات المركزة؛ لتقييم تقضيلات الفرد في أربع فئات قياسية ثنائية القطبية، وهي الأسلوب العملي - التأملي، الأسلوب الحسي - الحدسي، الأسلوب اللفظي البصري، الأسلوب التتابعي - الكلي؛ بحيث يشمل كل بعد على أحد عشر فقرة الابلى

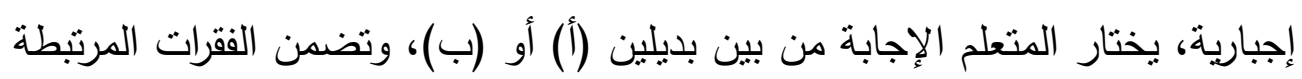

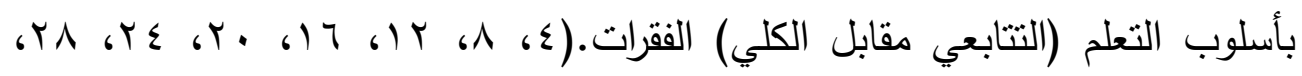

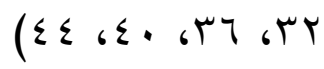
ويصنف الطالب وفقا لهذا النموذج على النحو التالي: - إذا حصل الطالب على درجة محصورة بين (-ب+@+r) فهذا يعني أنه لا يفضل أي أسلوب على البعدين. - إذا حصل الطالب على درجة محصورة بين (-0-@- أو (V+@) فهذا يعني أنه لا يفضل أي أسلوب على البعدين بدرجة متوسطة.

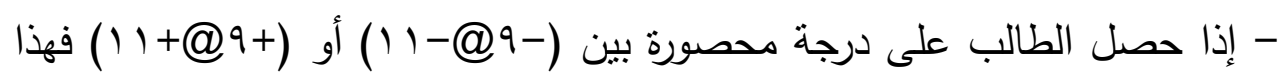
يعني أنه لا يفضل أي أسلوب على البعدين بدرجة مرتفعة.

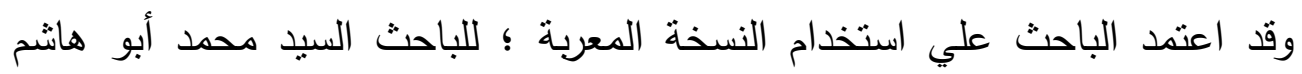

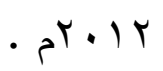

\section{- - مدق الاستبانة وثباتها}

وتم التأكد من صدق الاستبانة وثباتها؛ وذلك عن طريق تطبيقه على عينة

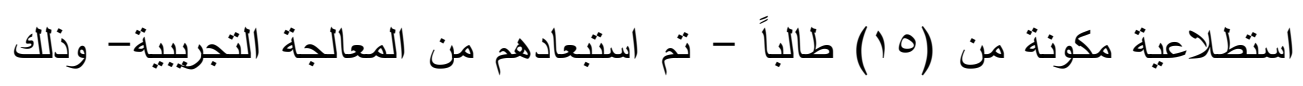

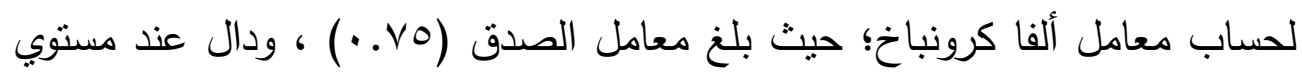

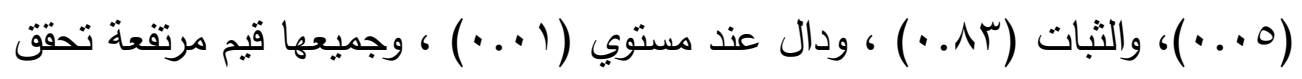


تمتع المقياس بدرجة مرتفعة من الثبات تؤكد صلاحية الاسنبانة للتطبيق على أفراد العينة الأساسية للبحث الحالي.

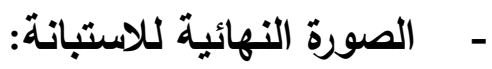

تم التأكد من صدق الاستبانة وثباتها، وأصبحت في شكلها النهائي فتم إنتاجها بشكل إلكتروني باستخدام "نماذج Google".، ومن مميزاتها : سهولة وسرعة تحميل الاختبار على الإنترنت بطريقة خفيفة، والتعامل معها بشكل تفاعلي، وإمكانية تسجيل البيانات وإظهار النتيجة. r- بطاقة الملاحظة الأداء العملي لمهارات إنتاج الإنفوجرافيك: بعد الاطلاع على البحوث والدراسات السابقة ذات الصلة بموضوع البحث الحالي قام الباحث بإعداد بطاقة ملاحظة ؛ لقياس مدى إلمام طلاب قسم علم المعلومات لمهارات إنتاج الإنفوجرافيك الثابت، وصياغة المهارات الرئيسة ، وقد تم بناء وضبط بطاقة الملاحظة بإتباع الخطوات التالية: أ- تحديد الهذف من بناء بطاقة الملاحظة: تهذف بطاقة الملاحظة إلى قياس مدى المام طلاب قسم علم المعلومات لمهارات إنتاج الإنفوجرافيك الثابت. ب- تحديد الأداعات التي تتضمنها بطاقة الملاحظة: تم تحديد الأداءات من خلال الاعتماد على الصورة النهائية لقائمة مهارات إنتاج الإنفوجرافيك الثابت التي تم ذكرها، واشتملت البطاقة على مجموعة من المهارات الرئيسة والفرعية المرتبطة بها. ج- تعليمات بطاقة الملاحظة: وضعت تعليمات البطاقة ؛ بحيث تكون واضحة ومحددة وشاملة وسهلة الاستخدام لأي ملاحظ يقوم بعملية الملاحظة، وتضمنت أن يقوم بقراءة البطاقة جيداً قبل القيام بعملية الملاحظة، وتوجيه الأخصائي للمهارة ؛ ليقوم بتتفيذها. د - الصورة الأولية لبطاقة الملاحظة: 
بعد الانتهاء من تحديد الهدف من بناء بطاقة الملاحظة ، وتحليل المحاور الرئيسية إلى المهارات الفرعية المكونة لها، وتمت صياغة بطاقات الملاحظة في صورتها الأولية ، وتتكونت من (111) مهارة فرعية. هـ- التقدير الكمي لأداء المهارات:

تم استخدام التقدير الكمي بالدرجات ؛ لقياس أداء المهارة في ضوء مستوين للأداء، وهما (أدى - لم يؤد) ، وذلك يرجع إلى أن المهارات نم تحليلها إلى مهارات

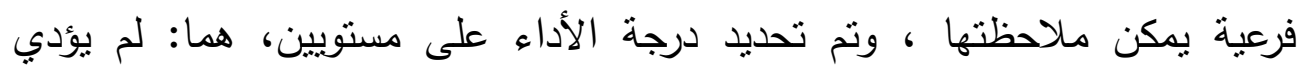

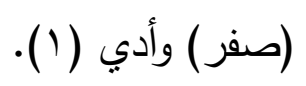

و - ضبط بطاقة الملاحظة:

تم ضبط بطاقة الملاحظة عن طريق التأكد من صدقها وثباتها ، ويتضح ذلك من

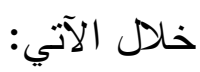

1 ا ـ صدق بطاقة الملاحظة:

تم عرض البطاقة على مجموعة من السادة المحكمين ؛ بهدف التأكد من دقة التعليمات، وسلامة الصياغة الإجرائية لمفردات البطاقة ووضوحها، وجاءت نسبة تكرار استجاباتهم مرتفعة (9 \% \%) ؛ لتؤكد صدق البطاقة وصلاحيتها لقياس المهارات المطلوبة، وإمكانية ملاحظة المهارات التي تتضمنها. r r ب بات بطاقة الملاحظة: تم حساب ثبات بطاقة الملاحظة بأسلوب تعدد الملاحظين على أداء الطالب

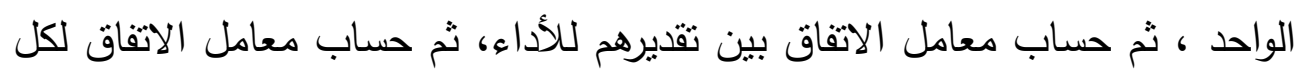
طالب باستخدام معادلة كوبر(Cooper) ، واتضح أن جدول معامل الاتفاق بين الملاحظين على أداء الطلاب منوسط يساوى (77. .9\%\%) ، وهذا بعنى أن بطاقة الملاحظة على درجة عالية من الثبات ، وأنها صالحة كأداة للقياس. ز - الصورة النهائية لبطاقة الملاحظة: 
بعد التأكد من صدق بطاقة الملاحظة وثباتها، أصبحت البطاقة في صورتها النهائية صالحة ؛ لقياس أداء طلاب قسم علم المعلومات لمهارات إنتاج الإنفوجرافيك ولك الثابت، وأصبحت البطاقة في صورتها النهائية تتكون من (11) مهارة. رابعاً: التجربة الأساسية للبحث:

تم إجراء التجربة الأساسية في قسم علم المعلومات بكلية الحاسب الآلي ونظم

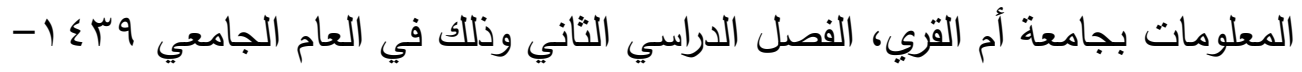
• ع أهـ ، وقد مرت التجربة بالمراحل التالية:

\section{1 - اختيار عينة البحث:}

تم اختيار عينة البحث من طلاب قسم علم المعلومات بالمستوي السادس، وقد بلغ عدد العينة (97) طالبا تم تقسيمهم إلى أربع مجموعات تجريبية. r - تطبيق أدوات البحث قبليًا:

تم التأكد من تكافؤ المجموعات التجريبية قبل نتفيذ التجربة، وذللك بالتطبيق القبلي لأدوات البحث (الاختبار التحصيلي، وبطاقة ملاحظة الأداء لمهارات إنتاج الإنفوجرافيك الثابت ؛ وذلك لحساب تجانس العينة حيث قام الباحث بتحليل نتائج الاختبار التحصيلي وبطاقة الملاحظة ؛ بهدف التعرف على مدى تجانس عينة التجربة قبل إجراء التجربة الأساسية للبحث. ب- تنفيذ التجرية الأساسية للبحث: وتم ذلك من خلال الاجراءات التالية:

\section{الإعداد للتجربة: ميث}

r. تم الحصول على موافقة سعادة عميد كلية الحاسب الآلي ونظم المعلومات، ورئيس قسم علم المعلومات موضع العينة لإجراء البحث.

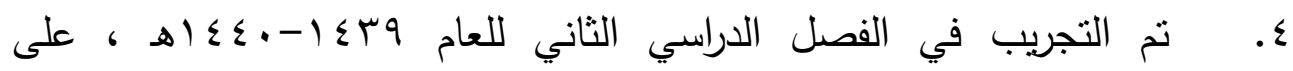
مجموعة من طلاب قسم علم المعلومات، على عينة قدرها (79) طالبا من طلاب قسم علم المعلومات، تم تقسيمهم الى أربع مجموعات تجريبية. التأكد من تكافؤ المجموعات التجريبية قبل تنفيذ التجربة: 
تم التطبيق القبلي لاختبار التحصيل المعرفي وبطاقة ملاحظة الأداء العملي لمهارات إنتاج الإنفوجرافيك الثابت، وذلك على مجموعات المعالجة التجريبية؛ بهدف التحقق من نكافؤها في متغيري التحصيل والمهارات. إجراء التجرية الأساسية للبحث :

مرت تجربة البحث بعدة خطوات إجرائية للكثف عن أثز المتغيرات المستقلة على المتغيرات التابعة تمنلت في: ا ـ اختبار عينة البحث: ثم اختيار عينة عشوائية مكونة من (79) طالباً من طلاب قسم علم المعلومات بكلية الحاسب الآلي ونظم المعلومات، جامعة أم القري، مني، ويدرسون مقرر إنتاج الوسائط المتعددة بالمستوى السادس. r. تسجيل الدخول لعينة البحث علي التعلم الإلكتروني الخاص بجامعة أم القري من خاص الرابط التالي: خل r. يقوم الطالب بوضع اسم المستخدم، وكلمة السر للبريد الإلكتروني الجامعي. ع. تصنيف الطلاب من خلال تطبيق مقياس "فليدر، وسيلفرمان" على عينة البحث، بعد تسجيل دخول الطالب؛ ليتم تقسيمهر وتحديد أسلوب تعلمهم، فالطلاب الذين حصلوا على (YY) درجة فأكثر، يكون أسلوب تعلمهم تتابعي، وجاء عددهم

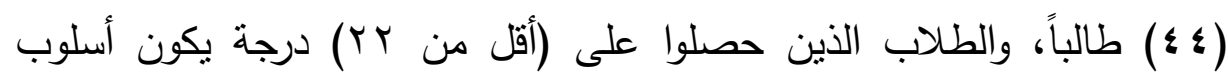
تعلمهر تكاملي، وعددهم (O Y ) طالباً. 0. إجراء التجربة الاستطلاعية: تم التطبيق على عينة استطلاعية عددهم (10) طالباً - نم استبعادهم من التطبيق النهائي- ؛ وذللك بهدف التأكد من وضوح المادة التعليمية، ومناسبة المحتوى التعليمي لمستوي الطلاب، ومناسبة الثكل النهائي للثاشات البرمجية، ومناسبة طريقة سير المتعلم داخل محتوي كل منها مع استراتيجية نمط الإبحار، ومناسبة الأنشطة التعليمية، والفاعلية الداخلية للبرمجية، وفي ضوء النتائج تم إجراء التعديلات المطلوبة؛ لتصبح البرمجية صالحة للتطبيق. 
7 7. عقد ورشة عمل: نم عقد ورشة تدريبية لأفراد عينة البحث مدتها ساعتان للتأكد من الخطوات الإجرائية لاستخدام نظام بورد. V.تطبيق أدوات القياس قبلياً: وذلك للتأكد من تجانس أفراد عينة البحث قبل بلهن إجراء التجربة الأساسية، من خلال استخدام اختبار "ليفين" Levine's Test لحساب ولهن قيمة (ف)، تم التطبيق القبلي لاختبار التحصيل المعرفي وبطاقة ملاحظة الأداء العملي لمهارات إنتاج الإنفوجرافيك، وذلك على مجموعات المعالجة التجريبية ؛ وذللك للتحقق من تكافؤها في متغيري التحصيل والمهارات. ورصدت النتائج في

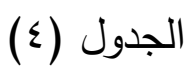

\section{تطبيق الاختبار التحصيلي ويطاقة الملاحظة قبليا:}

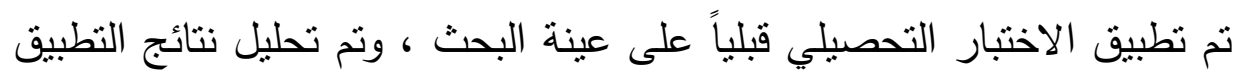

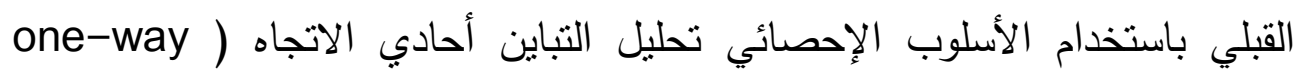
analysis of variance)؛ للتحقق من وجود فروق دالة إحصائياً بين منوسطات الإهي درجات الطلاب في التطبيق القبلي للاختبار التحصيلي وبطاقة الملاحظة ، وذلك ملك لزوم الضبط التجريبي؛ ليتم معرفة مدى تجانس طلاب العينة، وتم التوصل إلى النتائج التالية: جدول (ع) تجانس مجتمع عينة البحث

\begin{tabular}{|c|c|c|c|c|c|c|c|}
\hline |لدمتوى لالة & تقيمة ت & لرجات الحرية & |الانحراف & |الحستوسط & |العدد & |أنتعلم & المتغيرات \\
\hline \multirow[t]{2}{*}{ غير دالة } & \multirow[t]{2}{*}{$\cdot .1 \cdot v$} & \multirow[t]{2}{*}{$9 \leqslant$} & r.01 & 0.9 & $O Y$ & |الكلي & التحصيل \\
\hline & & & T.rT & 0.91 & $\varepsilon \varepsilon$ & |التتابعي & المعرفي \\
\hline \multirow[t]{2}{*}{ غير دالة } & \multirow[t]{2}{*}{$. r V \leqslant$} & \multirow[t]{2}{*}{$9 \leqslant$} & 0.1 & rI.rY & or & |الكلي & \multirow[t]{2}{*}{ الملاحظة } \\
\hline & & & 0.9 & $r . . \wedge q$ & $\varepsilon \varepsilon$ & |لنتابعي & \\
\hline
\end{tabular}

يتضح من الجدول السابق عدم وجود فروق في التحصيل الدراسي بين مجموعتي الدراسة وهم الطلاب ذوي أسلوب التعلم الكلي والتتابعي لاى طلاب قسم علم المعلومات في التحصيل المعرفي لمهارات إنتاج الإنفوجرافيك الثابت؛ ديث كانت 
قيمة ت تساوي V• • . ••عند درجات حرية ؟9 ، وكذلك عدم وجود فروق في الأداء العملي بين مجموعتي الدراسة وهم الطلاب ذوي أسلوب التعلم الكلي والتتابعي في الأداء العملي لمهارات إنتاج الإنفوجرافيك الثابت؛ حيث كانت قيمة تهاب ت تساوي ع ع . . ، ، وبذلك يتم قبول فرض العدم، والذي يؤكد على وجود تجانس بين أفراد عينة البحث وتكافؤ بين المجموعات. إجراء التجربة الأساسية للبحث: تم تطبيق أدوات التقييم الخاصة بالبحث (الاختبار التحصيلي- بطاقة ملاحظة إنتاج الإنفوجرافيك الثابت) قبلياً على مجموعات المعالجة التجريبية للبحث. 1. التطبيق على مجموعات المعالجة التجريبية للبحث: تم التطبيق على مجموعات المعالجة التجريبية للبحث، وتوضيح الهدف منه، والمهارات التي يتضمنها، وتقديم بعض الإششادات والتوجيهات لخطوات السير في دراسة المحتوي المتاح بييئة التعلم الإكتروني بلآك بورد، وبعد دراسته للمحتوى وتطبيق الأنشطة التعليمية يتم تطبيق الاختبار البعدي على المتعلمين. r r تطبيق أدوات القياس بعدياً: بعد الانتهاء من تطبيق البرنامج ثم التطبيق البعدي لأدوات البحث بالطريقة نفسها

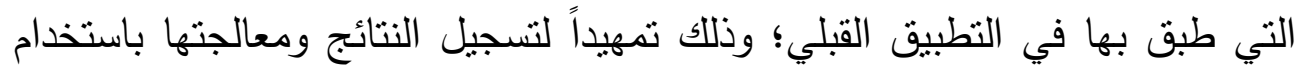
الأساليب الإحصائية المناسبة. نتائج البحث وتفسيرها:

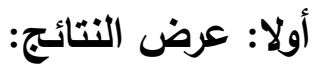
فيما يلي عرض للنتائج التي أسفر عنها التحليل الإحصائي:

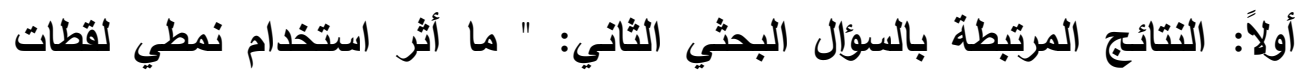
الفيديو الرقمي (المستمرة / المجزأة) في تنمية الجواتب المعرفية المرتبطة بمهارات إنتاج الإنفوجرافيك الثابث لدي طلاب قسم علم المعلومات؟؟." ولإجابة عنه نم التحقق من صحة الفرض التالي: : وينص على " لا يوجد فرق ذو دلالة إحصائية (عند مستوى > ه...) بين متوسطات درجات الطلاب في 
التطبيقين القبلي والبعدي لاختبار التحصيل المعرفي المرتبط بمهارات إنتاج الإنفوجرافيك الثابت يرجع للتأثير الأساس ؛ لاختلاف نمطي لقطات الفيديو الرقمي

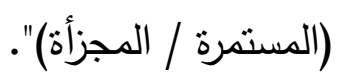
ولاختبار صحة هذا الفرض تم استخدام اختبار t-test للمجموعات المرتبطة ؛ لمقارنة منوسطات درجات الطلاب في التطبيقين القبلي والبعدي للاختبار التحصيلي المعرفي لمهارات إنتاج الإنفوجرافيك الثابت، كما في جدول (0) جدول (•) نتائج اختبار t-test للفروق بين طريقة التقديم (المستمرة- المجزأة)

\begin{tabular}{|c|c|c|c|c|c|c|}
\hline مستوى الدلالة & قيمة ت & |لرجات & |الانحراف & |الحستوسطي & |لعدد | & أسلوب التعلم \\
\hline \multirow[t]{2}{*}{$\ldots 1$} & \multirow[t]{2}{*}{$0.57-$} & \multirow[t]{2}{*}{$9 \leqslant$} & $0.1 \mathrm{~V}$ & $\varepsilon V . r \Psi$ & $\varepsilon \wedge$ & المستمرة \\
\hline & & & $7 . .1$ & Or.Tr & $\leqslant \Lambda$ & المجزأة \\
\hline
\end{tabular}

يتضح من الجدول السابق وجود فروق في التحصيل الدراسي بين طريقتي التقديم والمعالجة التجريبية لدى طلاب قسم المعلومات بكلية الحاسب الآلي في التحصيل المعرفي لمهارات إنتاج الإنفوجرافيك الثابت؛ حيث كانت قيمة ت تساوي -7 عند درجات حرية §9 مما يجعلنا نعزو الفروق لصالح طربقة التقديم المجزأة وهي الأعلى متوسطًا، ومما يجعلنا نرفض الفرض الصفري ونقبل بالفرض البديل وهو : " يوجد فرق ذو دلالة إحصائية (عند مستوى > ه . . ) بين متوسطات درجات الطلاب في التطبيقين القبلي والبعدي لاختبار التحصيل المعرفي المرتبط بمهارات إنتاج الإنفوجرافيك الثابت يرجع للتأثير الأساس لاستخدام نمطي لقطات الفيديو الرقمي

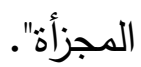

ولحساب حجم الأثر لاستخدام نمطي لقطات الفيديو الرقمي (المستمرة / المجزأة) في تتمية الجوانب المعرفية المرتبطة بمهارات إنتاج الإنفوجرافيك الثابت لدي طلاب قسم علم المعلومات، تم تطبيق معادلة حجم التأثير الموجه المكمل للالالة الإحصائية، في ضوء قيمة (ت) ودرجة الحرية، والتي تتضح نتائجها بالجدول التالي. 
جدول (†) مربع إيتا (2') لقياس حجم التأثير لاستخدام نمطي لقطات القيايو الرقمي (المستمرة / المجزأة) في تنمية الجوانب المعرفية المرتبطة بمهارات إنتاج الإنفوجرافيك الثابت لدى عينة الدراسة

\begin{tabular}{|c|c|c|c|}
\hline مستوى & مريع إيتا ( $\left.{ }^{2}\right)$ & قيمة " ت " & ב.د \\
\hline كبير & $. r \leq 1$ & $0 . \leqslant 7$ & $9 \leq$ \\
\hline
\end{tabular}

يتضح من الجدول السابق أن قيمة حجم التأثير المرتبطة بقيمة مربع إينا ذات تأثثير كبير ، مما يؤكد لاستخدام نمطي لقطات الفيديو الرقمي (المستمرة / المجزأة) في تتمية الجوانب المعرفية المرتبطة بمهارات إنتاج الإنفوجرافيك الثابت لدي طلاب قسم علم المعلومات. ثانيا: النتائج المرتبطة بالسؤال البحثي الثالث " ما أثر استخدام نمطي لقطات الفيديو الرقمي (المستمرة / المجزأة) في تنمية الأداء العملي المرتبط بمهارات إنتاج الإنفوجرافيك الثابت لاي طلاب قسم علم المعلومات؟". وللإجابة عنه تم التحقق من صحة الفرض التالي: وينص على " لا يوجد فرق ذو دلالة إحصائية عند مستوى (0...) بين متوسطي درجات المجموعتين التجريبيتين على بطاقة ملاحظة الأداء العملي لمهارات إنتاج الإنفوجرافيك الثابت يرجع للتأثنر الأساس لاختلاف نمطي لقطات الفيديو الرقمي (المستمرة / المجزأة). ولاختبار صحة هذا الفرض تم استخدام اختبار t-test للمجموعات المرتبطة لمقارنة متوسطات درجات الطلاب في التطبيقين القبلي والبعدي لبطاقة ملاحظة الأداء العملي لمهارات إنتاج الإنفوجرافيك الثابت، كما في جدول (v) جدول (V) نتائج اختبار ت للفروق بين طريقة التقديم والمعالجة التجريبية (المستمرة- المجزأة) في الأداء العملي

\begin{tabular}{|c|c|c|c|c|c|c|}
\hline مستوى الدلالة & |قيمة ت & |لرجات & |الانحراف & |الحسابي & |العدد & أسلوب التعلم \\
\hline$\ldots 1$ & 9.Y- & $9 \leqslant$ & $0 . r_{1}$ & $19.9 \mathrm{Y}$ & $\leq \wedge$ & المستمرة \\
\hline
\end{tabular}


\begin{tabular}{l|l|l|l|l|l|l}
\hline & & & $\varepsilon . v \varepsilon$ & $99 . \mathrm{r}$ & $\varepsilon \wedge$ & المجزأة \\
\hline
\end{tabular}

يتضح من الجدول السابق وجود فروق في التحصيل الدراسي بين طريقتي التقديم

والمعالجة التجريبية لاى طلاب قسم علم المعلومات في التحصيل المعرفي لمهارات

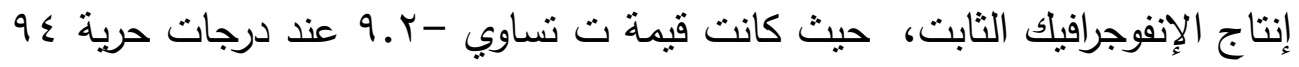

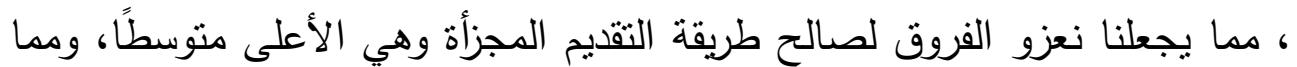
يجعلنا نرفض الفرض الصفري ونقبل بالفرض البديل وهو : " يوجد فرق ذو دلالة إحصائية عند مستوى (0... بين متوسطي درجات المجموعتين التجريبينين على

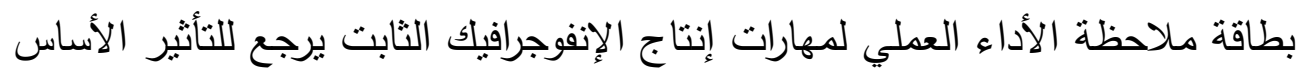
لاستخدام نمط لقطات الفيديو الرقمي المجزأة. ولحساب حجم الأثر لاستخدام نمطي لقطات الفيديو الرقمي (المستمرة / المجزأة) في تتمية الجوانب الأدائية لمهارات إنتاج الإنفوجرافيك الثابت لدي طلاب قسم علم المعلومات، تم تطبيق معادلة حجم التأثير الموجه المكمل للالالة الإحصائية، في ضوء قيمة (ت) ودرجة الحرية، والتي تتضح نتائجها بالجدول التالي. جدول (^) مربع إيتا (2) لقياس حجم التأثير لاستخدام نمطي لقطات الفيديو الرقمي (المستمرة / المجزأة) في تنمية الجوانب الأدائية لمهارات إنتاج الإنفوجرافيك

الثابت لاى عينة الدراسة

\begin{tabular}{|c|c|c|c|}
\hline مستوى & مريع إيتا ( $\left.{ }^{2}\right)$ & قيمة " ت " & ב.د \\
\hline كبير & $\cdot . \leqslant V \leqslant$ & $9 . r$ & $9 \leq$ \\
\hline
\end{tabular}

يتضح من الجدول السابق أن قيمة حجم التأثير المرتبطة بقيمة مربع إيتا ذات تأثثير كبير، مما يؤكد لاستخدام نمطي لقطات الفيديو الرقمي (المستمرة / المجزأة) في تتمية الجوانب الأدائية لمهارات إنتاج الإنفوجرافيك الثابت لدي طلاب قسم علم المعلومات. 
ثالثا: عرض النتائج المرتبطة بالسؤال البحثي الرابع" ما أثر استخدام أسلوب التعلم (الكلي / التتابعي) على الجوانب المعرفية المرتبط بمهارات إنتاج الإنفوجرافيك الثابت لاي طلاب قسم علم المعلومات؟". ولإجابة عنه تم التحقق من صحة الفرض التالي: وينص على أن " لا توجد فروق ذات دلالة إحصائية (عند مستوى> ه ...) بين متوسطات درجات الطلاب في النطبيق البعدي لاختبار التحصبل المعرفي المرتبط بمهارات إنتاج الإنفوجرافيك الثنابت يرجع للتأثير الأساس لاختلاف أسلوب التعلم (الكلي / التتابعي)". ولاختبار صحة هذا الفرض تم استخدام اختبار t-test للمجموعات المرتبطة لمقارنة متوسطات درجات الطلاب في التطبيقين القبلي والبعدي للاختبار التحصيلي المعرفي لمهارات إنتاج الإنفوجرافيك الثابت، كما في جدول (9) (9) جدول (9) نتائج اختبار t-test للفروق بين أسلوب التعلم (الكلي - التتابعي) في

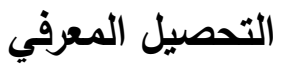

\begin{tabular}{|c|c|c|c|c|c|c|}
\hline مستوى الدلالة & قيمةت ت & |لدرجات & |الانحراف & |الحستوسط & |لعدد & أسلوب التعلم \\
\hline \multirow[t]{2}{*}{$\ldots 1$} & \multirow[t]{2}{*}{$r . \wedge r-$} & \multirow[t]{2}{*}{$9 \leq$} & 7.7 & $\varepsilon \wedge . \wedge 0$ & $\Delta Y$ & الكلي \\
\hline & & & $0 . V \varepsilon$ & Or.\&1 & $\leqslant \varepsilon$ & التتابعي \\
\hline
\end{tabular}

يتضح من الجدول السابق وجود فروق في التحصيل الدراسي بين أسلوب التعلم الكلي والتتابعي لدى طلاب كلية الحاسب الآلي في التحصيل المعرفي لمهارات إنتاج

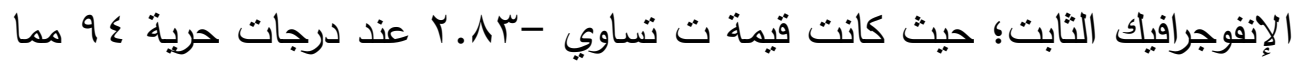

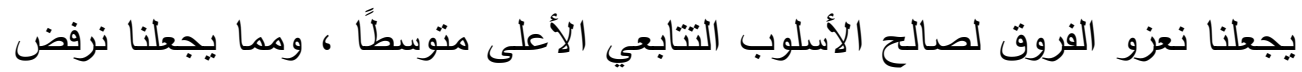

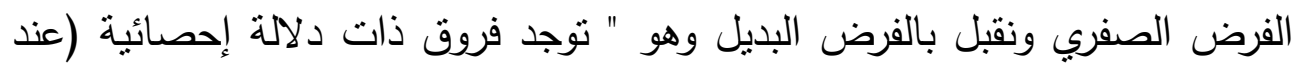
مستوى> 0...) بين متوسطات درجات الطلاب في التطبيق البعدي لاختبار

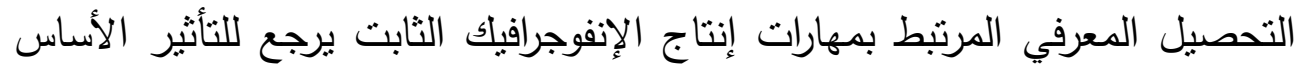
لاستخدام أسلوب التعلم التتابعي". 
رابعا: عرض النتائج المرتبطة بالسؤال البحثي الخامس: ما أثر استخدام أسلوب التعلم (الكلي / التتابعي) على الأداء العملي لمهارات إنتاج الإنفوجرافيك الثابت لائ لإي طلاب قسم علم المعلومات؟ ولإجابة عنه تم التحقق من صحة الفرض التالي: وينص على أن " لا يوجد فرق ذو دلالة إحصائية عند مستوى (0...) بين متوسطي درجات المجموعتين التجريبيتين على بطاقة ملاحظة الأداء العملي لمهارات إنتاج الإنفوجرافيك الثابت يرجع للتأثير الأساسي لاختلاف أسلوب التعلم (الكلي / التتابعي). جدول ( • 1) نتائج اختبار t-test للفروق بين أسلوب التعلم (الكلي- التتابعي) في

الأداء العملي (بطاقة الملاحظة)

\begin{tabular}{|c|c|c|c|c|c|c|}
\hline مستوى الدلالة & قيمة ت & الرجرية & الانعياري & |الحسابي & |العدد & أسلوب التعلم \\
\hline \multirow[t]{2}{*}{$\ldots 1$} & \multirow[t]{2}{*}{$r . .0-$} & \multirow[t]{2}{*}{$9 \leqslant$} & 7.74 & 9 Y.VO & $\Delta Y$ & الكلي \\
\hline & & & 7.74 & $97 . \wedge 9$ & $\varepsilon \varepsilon$ & التتابعي \\
\hline
\end{tabular}

يتضح من الجدول السابق وجود فروق في التحصيل الدراسي بين أسلوب التعلم الكلي والتتابعي لدى طلاب كلية الحاسب الآلي في الأداء العملي لمهارات إنتاج

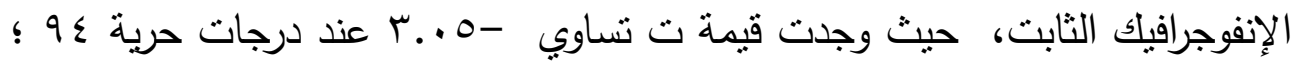
مما يجعلنا نعزو الفروق لصالح الأسلوب التتابعي الأعلى متوسطًا ، ومما يجعلنا نرفض الفرض الصفري ونقبل بالفرض البديل ، وهو " يوجد فرق ذو دلالة إحصائية عند مستوى (0.. (·) بين متوسطي درجات المجموعتين التجريبيتين على بطاقة ملاحظة الأداء العملي لمهارات إنتاج الإنفوجرافيك الثابت برجع للتأثير الأساسي دئي لاستخدام أسلوب التعلم التتابعي". خامساً: عرض النتائج المرتبطة بالسؤال البحثي السادس وينص على أنه ما أثر التفاعل بين بين أسلوب التعلم ( الكلي - التتابعي) ونمطي تقديم المهارات بلقطات الفيديو الرقمي (المستمرة / المجزأة) على الجوانب المعرفية المرتبط بمهارات إنتاج الإنفوجرافيك الثابت لدي طلاب قسم علم المعلومات؟ 
ولإجابة عنه تم التحقق من صحة الفرض التالي: وبنص على "لا يوجد تفاعل

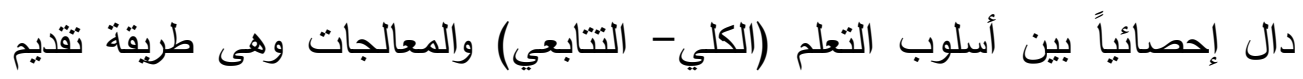
المهارات ( المستمرة- المجزأة) في تأثيرهما على التحصيل المعرفي لدى طلاب قمم علم المعلومات ". ولاختبار صحة هذا الفرض تم استخدام تحليل التباين لمجموعات الدراسة في القياس البعدي للتحصيل المعرفي المرتبط بمهارات إنتاج الإنفوجرافيك الثابت، كما في جدول (1) جدول (11) يوضح نتائج تحليل التباين لمجموعات الاراسة في القياس البعدي

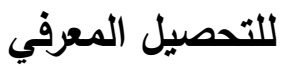

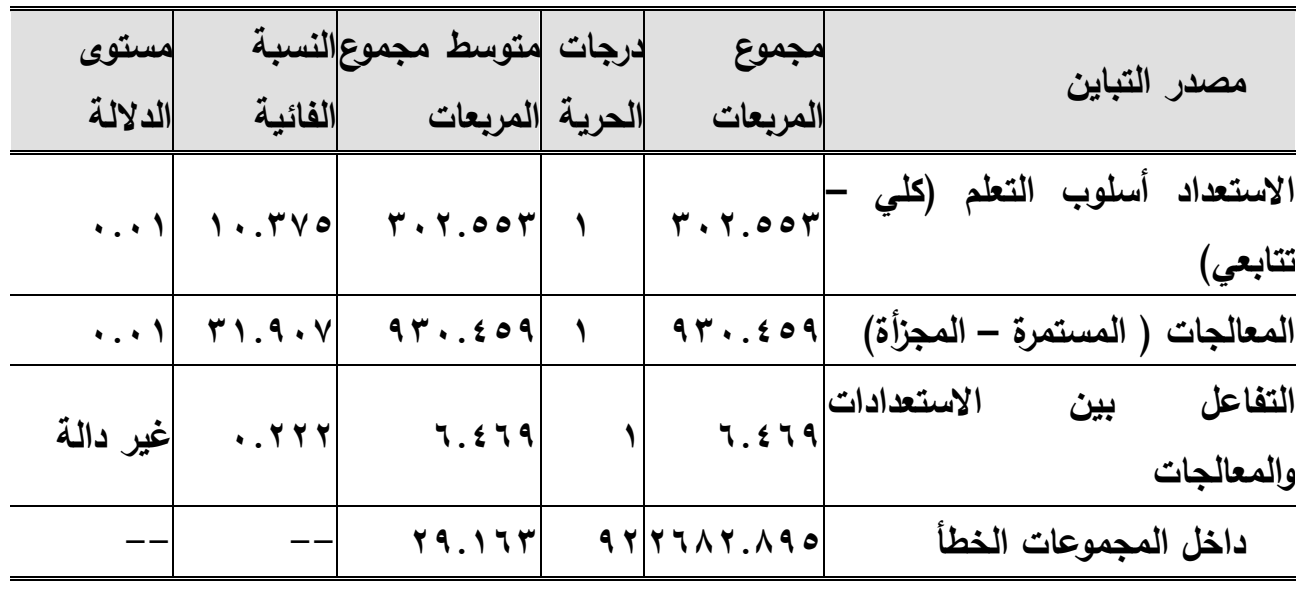

ويتضح من الجدول السابق أن قيمة "ف"(مV0. • (1) دالة بين المعالجات (نمط لقطات الفيديو (المستمرة - المجزأة) ؛ حيث كانت قيمة مجموع المربعات

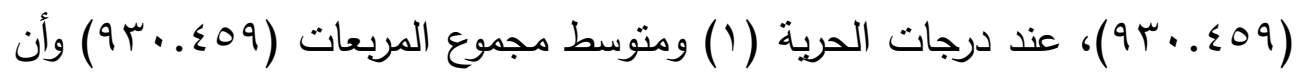
هناك فروقاً دالة إحصائياً بين مجموعتي الدراسة فى التحصيل المعرفي عند مستوى دلالة (1 +. • ) ؛ وذللك في القياس البعدي. كما يتضح من الجدول أن قيمة "ف" التي ترجع للتباين في الاستعداد أسلوب

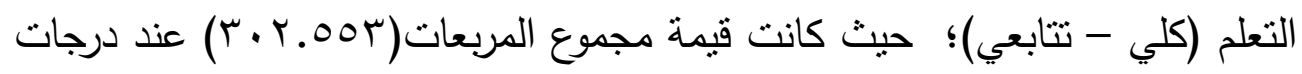

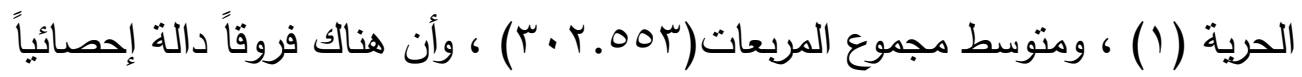
بين مجموعتي الدراسة فى التحصيل المعرفي عند مستوى دلالة (1 ...) ؛ وذلك في 
القياس البعدي دالة عند مستوى (1 ...) أي أن هناك فروقاً ذات دلالة إحصائية بين الطلاب ذوي أسلوب التعلم (كلي - تتابعي) في التحصيل المعرفي.

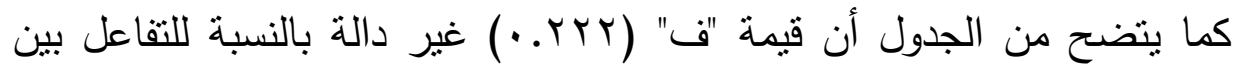

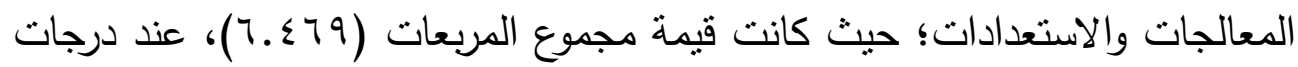
الحرية (1) ، ومنتوسط مجموع المربعات (9 79 ـ 7) أي أنه ليس هناك تفاعل دال بين الاستعدادات وهو أسلوب التعلم (كلي - تتابعي) ، والمعالجات التجربيية (نمط لقطات الفيديو (المستمرة - المجزأة) في تأثيرهما على التحصيل المعرفي في مهارات إنتاج الإنفوجرافيك الثابت مما يجعلنا نقبل الفرض الصفري. والثكل التالي يوضح ذلك:

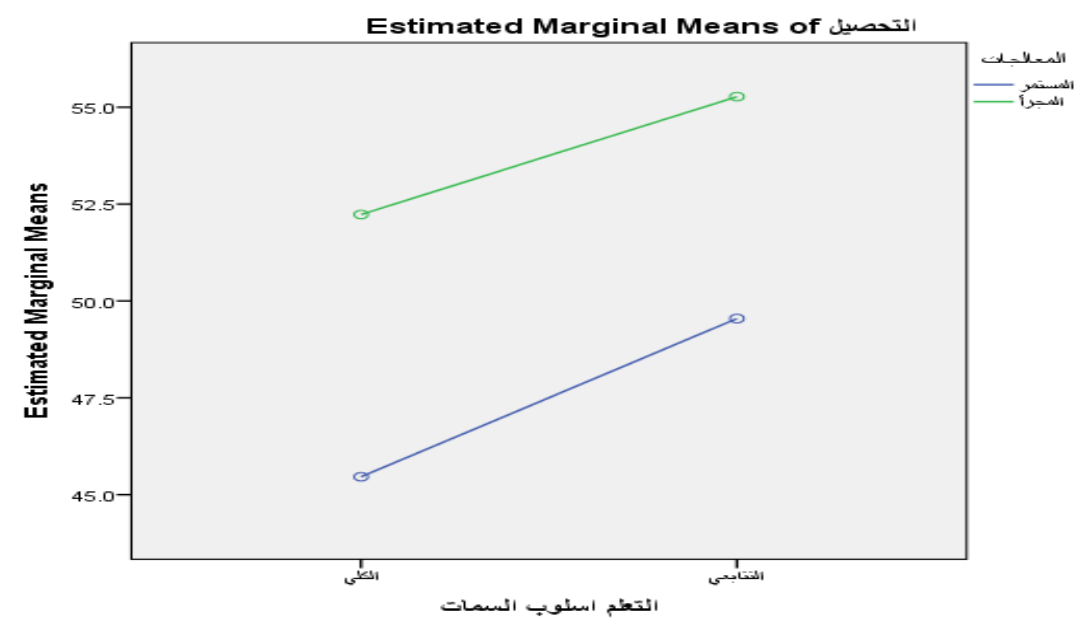

شكل (0) التفاعل بين أسلوب التعلم ولقطات الفيديو (المستمرة والمجزأة) على الجوانب المعرفية المرتبطة بمهارات إنتاج الإنفوجرافيك الثابت سادساً: عرض النتائج المرتبطة بالسؤال البحثي السابع وينص على الإنى أنه ما أثر التفاعل بين بين أسلوب التعلم (الكلي- التتابعي) ونمطي تقديم المهارات بلقطات الفيديو الرقمي (المستمرة / المجزأة) على الجانب الأدائي المرتبط بمهارات إنتاج الإنفوجرافيك الثابت لاي طلاب قسم علم المعلومات؟ ولإجابة عنه تم التحقق من صحة الفرض التالي: وينص على "لا يوجد تفاعل دال إحصائياً بين أسلوب التعلم (الكلي- التتابعي) ، والمعالجات وهي طريقة تقديم 
المهارات (المستمرة- المجزأة)، في تأثثرهما على الجانب الأدائي لمهارات إنتاج الإنفوجرافيك الثابت لدى طلاب قسم علم المعلومات ". ولاختبار صحة هذا الفرض تم استخدام تحليل التباين لمجموعات الدراسة في

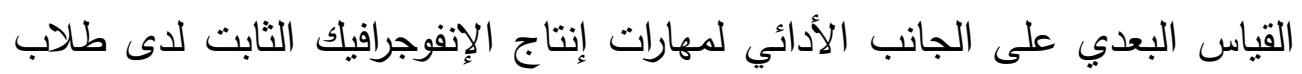

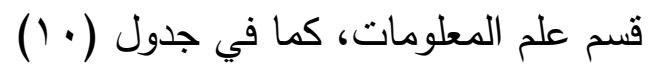
جدول (Y I) يوضح نتائج تحليل التباين لمجموعات الاراسة في القياس البعدي لمهارات إنتاج الإنفوجرافيك الثابت

\begin{tabular}{|c|c|c|c|c|c|}
\hline | مستوى & |الفائية & |لمترسط & | & مجموع المربعات & مصدر التباين \\
\hline$\cdots 1$ & 11.99 & $\varepsilon \cdot V \cdot V \vee V$ & 1 & $\varepsilon \cdot v \cdot v \vee v$ & (كلي - تلابعيداد أسلوب التعلم \\
\hline$\cdot . \cdot 1$ & $19.0 \leqslant$ & rIM૬.VTr & 1 & rIrq.Vrr & المجزأة) \\
\hline غير دالة & $\ldots+\mathrm{V}$ &.$r \circ v$ & 1 &.$r \circ v$ & والتفاعل بين الاستعدادات \\
\hline-- & -- & rI. $\leqslant V$ & $9 r$ & $19 \vee \leq . \vee \wedge r$ & داخل المجموعات الخطأ \\
\hline
\end{tabular}

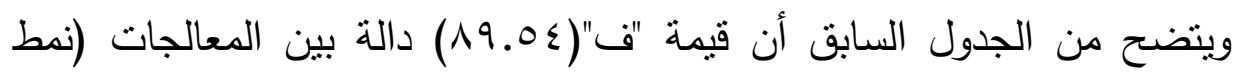
لقطات الفيديو (المستمرة - المجزأة) ؛ حيث كانت قيمة مجموع المربعات

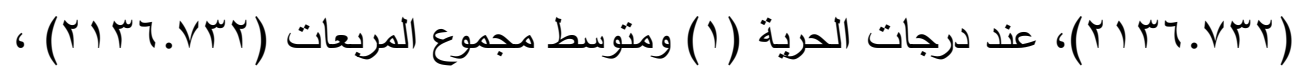
وأن هناك فروقاً دالة إحصائياً بين مجموعتي الدراسة فى فى الأداء المهاري الملاحظة) عند مستوى دلالة ( ( ...) وذللك في القياس البعدي. كما يتضح من الجدول أن قيمة "ف"(1.99 () التي نرجع للتباين في الاستعداد

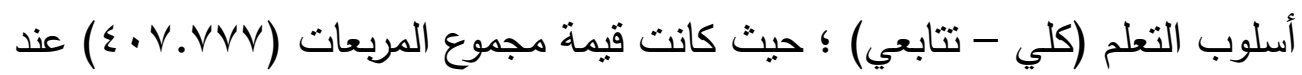

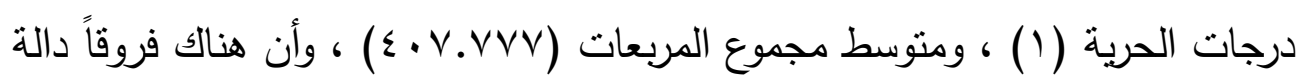
إحصائياً بين مجموعني الدراسة فى فى الأداء المهاري (الملاحظة) عند مستوى دلالة ( ( . .) ؛ وذلك في القياس البعدي دالة عند مستوى (1 ...)، أي أن هنالك فروقاً 
ذات دلالة إحصائية بين الطلاب ذوي أسلوب التعلم (كلي - تتابعي) في الأداء

$$
\text { المهاري (الملاحظة). }
$$

كما يتضح من الجدول أن قيمة "ف" (V) (V) ...) غيردالة بالنسبة للتقاعل بين

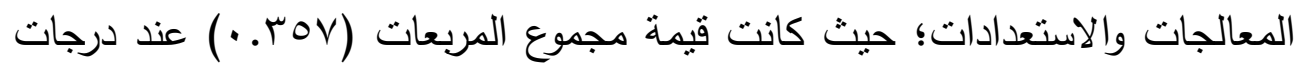

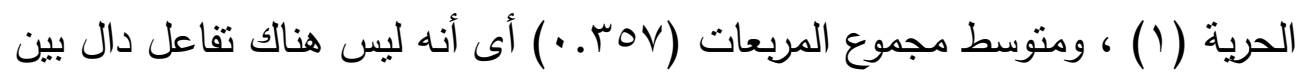
الاستعدادات ، وهو أسلوب التعلم (كلي - تتابعي) والمعالجات التجربيية (نمط لقطات الفيديو (المستمرة - المجزأة) في نأثيرهما على الأداء المهاري (الملاحظة) لمهارات إنتاج الإنفوجرافيك الثابت مما يجعلنا نقبل الفرض الصفري.

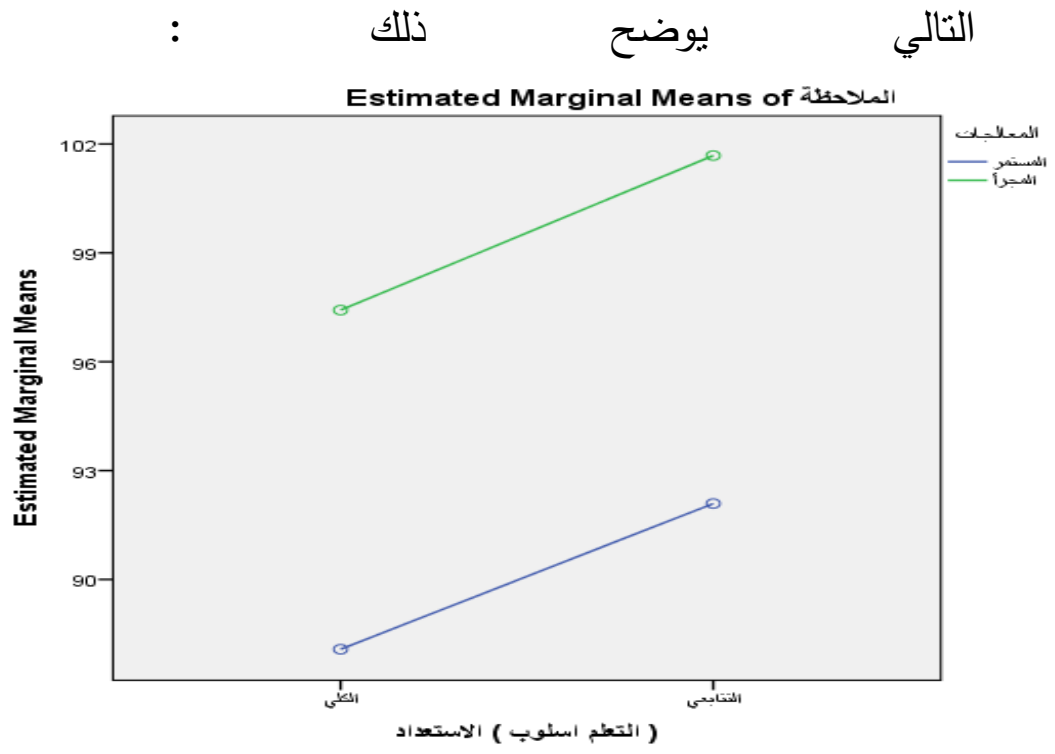

شكل (T) التفاعل بين أسلوب التعلم ولقطات الفيديو (المستمرة والمجزأة) على الجانب الأدائي المرتبط بمهارات إنتاج الإنفوجرافيك الثابت لئ ثانيا: مناقثة وتفسير النتائج: 1-مناقشة وتفسير التتائج المتعلقة بالتأثير الأساس لاستخدام نمطي لقطات الفيديو الرقمي (المستمرة - المجزأة) في تنمية مهارات إنتاج الإنفوجرافيك 
(1/1) فيما يتعلق بأثز استخدام نمطي لقطات الفيديو الرقمي (المستمرة المجزأة) في تنمية مهارات إنتاج الإنفوجرافيك الثابت: لنائ

أثنارت نتائج البحث إلى وجود فرق دال إحصائياً عند مستوى (0...) بين متوسطي درجات المجموعتين في التحصيل المعرفي المرتبط بمهارات إنتاج الإنفوجرافيك الثابت يرجع للتأثير الأساسي لاختلاف لقطات الفيديو الرقمي (المستمرة - المجزأة) لصالح المجموعة التي تستخدم لقطات الفيديو الرقمي المجزأة. ويمكن إرجاع هذه النتيجة إلى عدة عوامل أهمها: - اتفقت نتائج هذا الفرض مع دراسة (Spanjers, et al., 2011) بينت أن الذاكرة العاملة تحتاج إلى تتشيط لمعالجة المعلومات المتذفقة، وأن الحمل المعرفي الزائد يحدث حينما تتجاوز معالجة تلك المعلومات قدرة الذاكرة العاملة، وأن سرعة وتيرة تدفق الصور والرسوم المتحركة يشكل عبئا زائدا على الذاكرة العاملة للمتعلم مدا يجعله عاجزا عن معالجتها. - - الوقفات المجزئة للقطات الفيديو سمحت للمتعلمين باستيعاب الجزء السابق لتلك الوقفات، وساهمت بشكل كبير فى عدم تشتيت انتباه الطالب، وركزت انتباهه على المثيرات الهامة فى لقطات الفيديو، وساعدت الطالب فى التغلب على الحمل المعرفي الزائد الناتج عن سرعة وتيرة لقطات الفيديو، وساعدت الطالب على القيام بالمعالجة المعرفية اللازمة للمعلومات الجديدة وتتظيمها وتكاملها وتماسكها دون زيادة فى الحمل المعرفي، ومنحت الطالب وقتا إضافيا لنقل المعلومات من الجزء السابق فى اللقطة إلى الذاكرة.( طارق عبدالودود

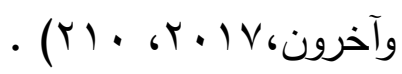

- طريقة تقديم لقطات الفيديو الرقمي المجزأة في شكل متتابع لوحدات التعلم ساهم في تتمية التحصيل المعرفي المرتبط بمهارات إنتاج الإنفوجرافيك الثابت. أنتاء تلك الوقفات فى تركيز انتباه الطالب على الأجزاء الهامة فى لقطات الفيديو قبل زوالها بالحركة؛ وبذلك فقد مكنت الطالب من معالجة المعلومات دون فقد أجزاء منها نتيجة سرعة العرض المرئي وكثرة المثيرات، وساعدته على بناء 
تمثيل عقلي منماسك نم دمجه فى نموذج عقلى منكامل لتصور المفاهيم

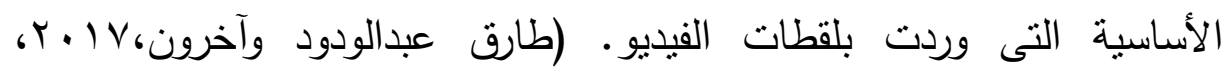
.$(r)$. وتتفق هذه النتيجة مع أثنارت اليه نتائج البحوث والدراسات على فاعلية استخدام لقطات الفيديو الرقمي المجزأة في تتمية التحصيل المعرفي لدى المتعلمين ومنها دراسة (Hassanabadi,et al., 2011) ( (Spanjers, et al., 2011) كما تتفق مع دراسة عبداله محمد عبداله (19) ؛ (19) ؛ حيث توصلت النتائج لصالح المجموعة التي تستخدم (مقاطع الفيديو الرقمية المجزاة). ( ) فيما يتعلق بأثر استخدام نمط لقطات الفيديو الرقمي (المستمرة - المجزأة) في تنمية الأداء العملي لمهارات إنتاج الإنفوجرافيك الثابت: أثنارت نتائج البحث إلى وجود فرق دال إحصائياً عند مستوى (0.. •) بين الإسين متوسطي درجات المجموعتين في الأداء العملي لـهارات إنتاج الإنفوجرافيك الثنابت يرجع للتأثير الأساسي لاختلاف استخدام نمطي لقطات الفيديو الرقمي (المستمرة المجزأة) لصالح المجموعة التي تستخدم لقطات الفيديو الرقمي المجزأة. ويمكن إرجاع هذه النتيجة إلى عدة عوامل أهمها: - ارتباط هذه النتيجة بالنتيجة السابقة ، وهي فاعلية لقطات الفيديو الرقمي المجزأة في تتمية التحصيل المعرفي المرتبط بمهارات إنتاج الإنفوجرافيك الثابت عند طلاب هذه المجموعة. - للقطات الفيديو قواعد تحكمها كما هو الحال في قواعد اللغة الواجب مراعاتها لإنتاج جمل مفهومة، ومن ثم فإن القواعد البنائية للقطات المرئية المتمثلة في مفردات هذه اللغة يجب مراعاتها لإنتاج تسلسل مرئي مفهوم، فاللقطة تعد بمثابة فكرة، والتتابع المرئي للقطات بمثابة تتابع أفكار يتم تركيبها لإعطاء تدفق هردي وتجانس منطقي يعبر عن الأفكار ، والحقائق ، والمفاهيم ، والمهارات المختلفة

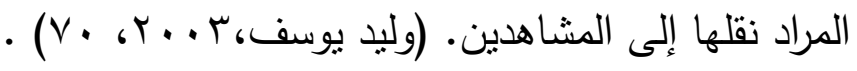


- - تجزئة اللقطات إلى أجزاء قصيرة يساهم بشكل كبير في إكساب المتعلمين المهارات في إطار يسمح لهم بالتركيز على جوانب الأداء ضمن المهارة ؛ حيث إن المتغيرات المرتبطة بملقطات الفيديو الرقمي لها دور كبير في إكساب المتعلمين المهارات المتتوعة ، وبخاصة المهارات المعقدة التي يتت تقديمها • للمتعلمين • (D'Alene, P., \& Taylor, B. ,2003,7) - تحقق لقطات الفيديو المجزأة "مبدأ التطابق" من خلال توفير تمثيل خارجي لإجراءات أقرب إلى التمثيل العقلي الداخلي المتوقع من المتعلمين، والذي يصور

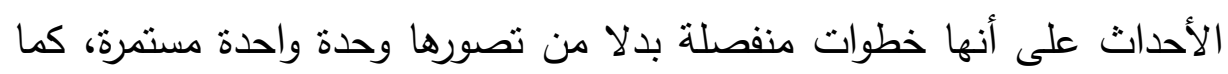
تحقق لقطات الفيديو المجزأة "مبدأ القبض" وهو إدراك الصورة وإجراء المعالجة

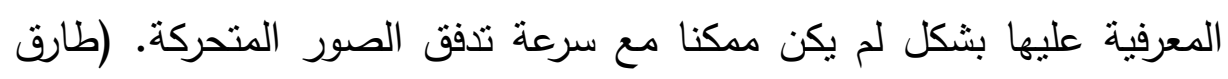

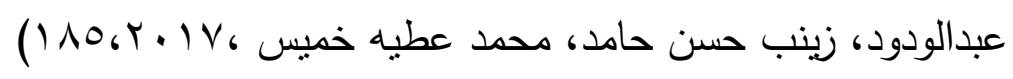
وتتفق هذه النتيجة مع ما أثنارت إليه نتائج البحوث والدراسات على فاعلية لقطات الفيديو الرقمي المجزأة في تتمية المهارات المنتوعة لدى المتعلمين ، ومنها :دراسة في Spanjers, et al., 2011) (تمية التحصيل المعرفي لدى المتعلمين ،ومنها: دراسة • (Hassanabadi,et al., 2011

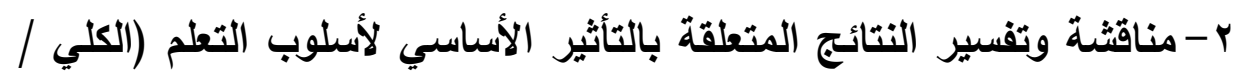
التتابعي) في تنمية مهارات إنتاج الإنفوجرافيك الثابت: ( ) فيما يتعلق بأثر استخدام أسلوب التعلم (الكلي / التتابعي) في تنمية التحصيل المعرفي المرتبط بمهارات إنتاج الإنفوجرافيك الثابت:

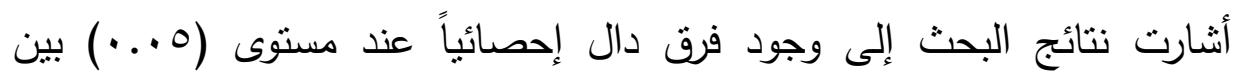
متوسطي درجات المجموعتين التجريبيتين في التحصيل المعرفي المرتبط بمهارات

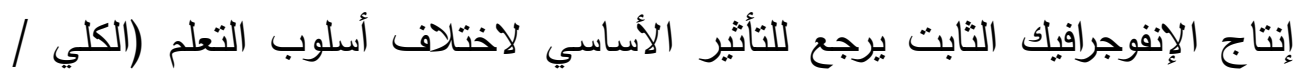
التتابعي) لصالح المجموعة التي تدرس بأسلوب التعلم التتابعي. ويمكن إرجاع هذه النتيجة إلى عدة عوامل أهمها: ويعزى ذلك إلى العوامل التالية: 
- ترتبط هذه النتيجة بنظرية فرض التشفير الثنائى المتكامل لبافيو ؛ حيث افترض أن ذاكرة الفرد نتألف من نظامين لترميز المعلومات أحداها خاصة بتمنيل ومعالجة اللغة غبر اللفظية ، والآخر لمعالجة اللغة اللفظية ؛ حيث بمكن تتشيط كلا النظامين

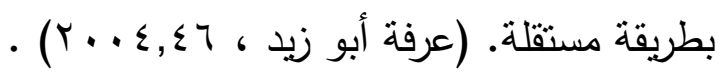

- ترتبط هذه النتيجة بنظرية انتقاء المعلومات لبرودينت عام 901 ام فالمثنيرات

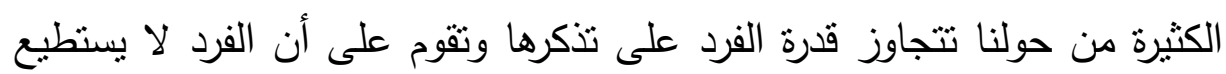
أن يقوم بمعالجة المعلومات التى بتلقاها من خلال حواسه دفعة واحدة فى ذات

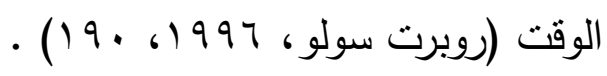

- تدعم هذه النتيجة نظرية فرض الترميز الثنائى المنفصل ، والذي يفترض أنه

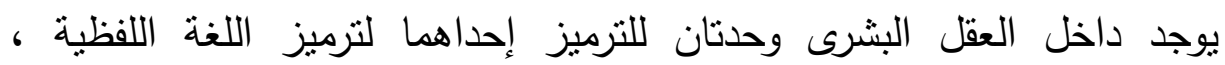
والأخرى لترميز اللغة غير اللفظية كالصور والرسومات، وطبقا لذلك فإن عرض وهن المواد المرئية والمسموعة معا فى آن واحد فإنه يحدث تشويش للمتعلم. (دنيا

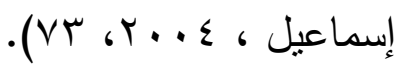
- وتثير نظرية انتقاء المعلومات الى أنه أثناء نقل المعلومات من خلال اللغة غير اللفظية (المصورات) ، واللغة اللفظية فى آن واحد فإنه يحدث تشوش لهاء إذ إذهاء

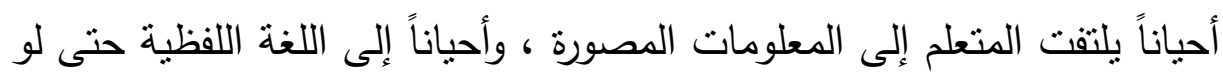
كان المحتوى العلمى لكليهما واحد ، وهى بذلك تستتدإلى فرض الترميز الثنائى

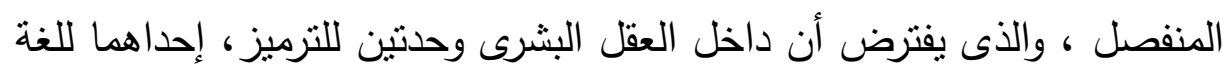

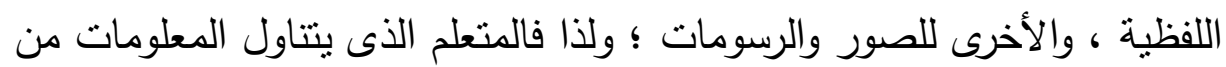
خلال قناتين منفصلتين أفضل من المتعلم الذى يتتاولها من خلال قناة واحدة

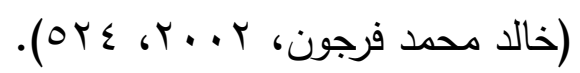

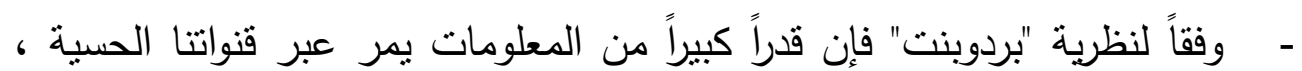

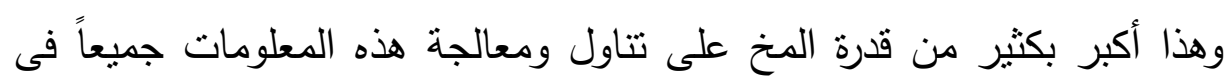
لحظة واحدة ؛ وبالتالي فهذه النظرية تؤيد التتابع فى عرض اللغة اللفظية وغير 
اللفظية عند التعلم، وعللت ذلك بأن العرض المتزامن يؤدى إلى تشتيت انتباه

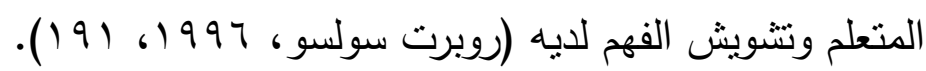

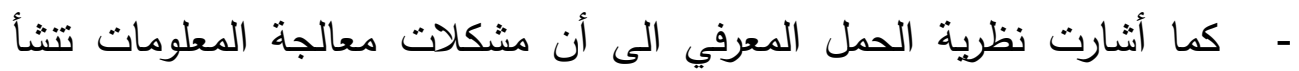
عندما يتعلم الفرد من عناصر عديدة مختلفة فى آن واحد حيث يكون الانتباه لمصادر معلومات متعددة ومختلفة بصورة لفظية وغير لفظية يتطلب مصادر ذهنية أكثر من الانتباه لمصدر واحد فقط ، ويعتبر تزامن عرض النص مع ومع الصورة مثنا تجزئ لانتباه المتعلم؛ ومن هنا تؤيد هذه النظرية استخدام التمثيلات المترابطة المتتابعة لإتاحة فرصة للمتعلم ليركز انتباهه فى مصدر ومثير واحد

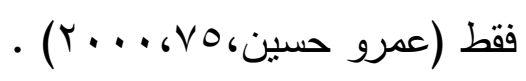

(Y/Y) فيما يتعلق بأثر استخدام أسلوب التعلم (الكلب / التتابعي) في تنمية الأداء

\section{العملي لمهارات إنتاج الإنفوجرافيك الثابت:}

أثنارت نتائج البحث إلى عدم وجود فرق دال إحصائياً عند مسنوى (0 . •) بين متوسطي درجات المجموعنين التجريبيتين على بطاقة ملاحظة الأداء العملي لمهارات

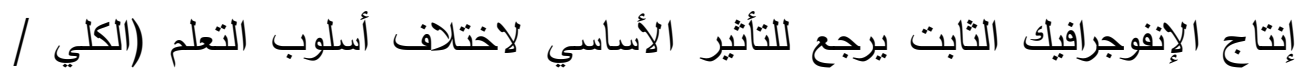
التتابعي) ؛ لصالح المجموعة التي تدرس بأسلوب التعلم التتابعي. ويمكن إرجاع هذه النتيجة إلى عدة عوامل أهمها:

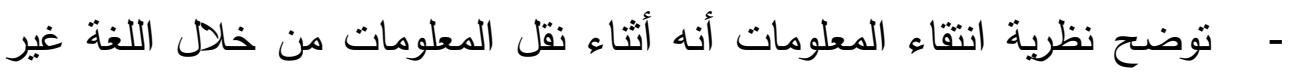
اللفظية واللغة اللفظية في آن واحد فإنه يحدث نتويش لها إذ أحيانا يلتقت المتعلم إلى المعلومات المصورة ، وأحيانا إلى اللغة اللفظية حتى لو كان المحتوى العلمي لكليهما واحد. (Porter, 2013, p.209) - El-Bishouty, 2019) عندما قام بيناء نموذج نمط التعلم Silverman Felder التعليم" في كلية التربية عبر الإنترنت، وقد أظهرت النتائج أن الدورة بأقسامها لناهي

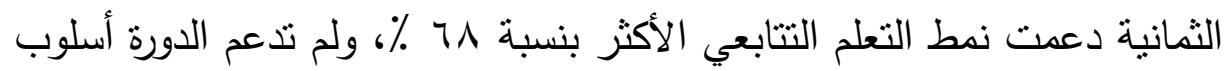

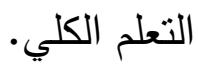


- مط لقطات الفيديو الرقمي (المستمرة - المجزأة)، كان كافيا للطلاب من أجل

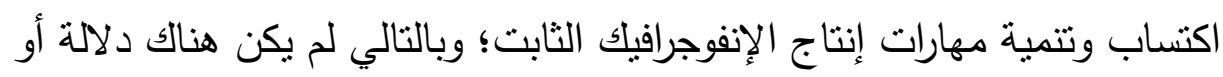
تأثثر لنمطي تقديم لقطات الفيديو الرقمي (المستمرة - المجزأة) على تتمية تلكابك

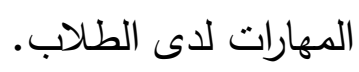
- أسلوب تقديم المهارات بأسلوب التعلم التتابعي أدى إلى زيادة قدرة المتعلم على إنقان مهارات إنتاج الإنفوجرافيك الثابت. - العرض التتابعي للمهارات وما نتتمل عليه البيئة من مثيرات متعددة أدى إلى الى إحداث تأثنير إيجابي على تتمية مهارات إنتاج الإنفوجرافيك الثابت.

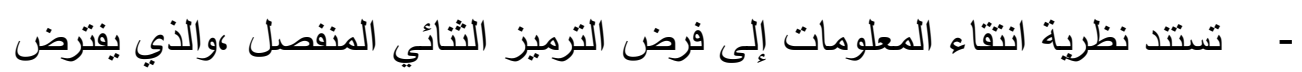

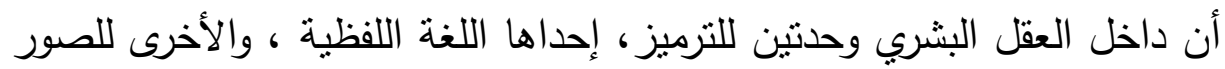
والرسومات ؛ ولذا فالمتعلم الذي يتتاول المعلومات من خلال قناتين منفصلتين أفضل من المتعلم الذي يتتاولها من خلال قناة واحدة. (Ho, S., ) ( Hou, H. T. 2015) وتتفق هذه النتائج مع دراسة كل من من من (Chen, C., Jones, K. T., \& Xu, S. 2018) (Tian, H., 2018) 2017 في أن أسلوب التعلم التتابعي يمكن أن يقود الطلاب لارتفاع التحصيل مع أساليب التعلم المتتابعة.

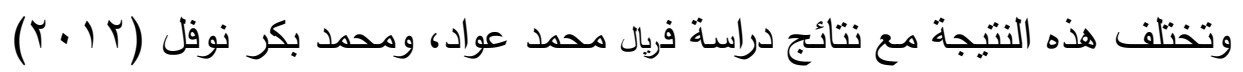
، ودراسة (ربيع رمود، سيد شعبان، 1. (Kuo, Y. C., Chu,2017) (Heidrich, L,2018)، والتي أكدت على فاعلية أسلوب التعلم الكلي في نتمية الجوانب المعرفية والأدائية. r-مناقشة وتفسير النتائج المتعلقة بأثر التقاعل بين نمطي لقطات القيديو الرقمي (المستمرة - المجزأة) أسلوب التعلم (الكلي / التتابعي) في تنمية مهارات إنتاج 


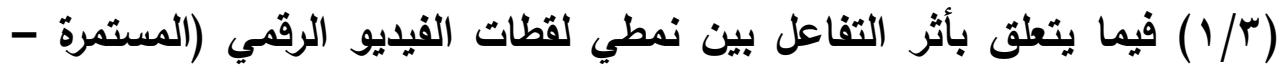
المجزأة) أسلوب التعلم (الكلي / التتابعي) في تنمية التحصيل المعرفي المرتبط بمهارات إنتاج الإنفوجرافيك الثابت:

أثنارت نتائج البحث إلى عدم وجود فرق دال إحصائياً عند مستوى (0. . •) بين متوسطي درجات المجموعات التجريبية في التحصيل المعرفي المرتبط بمهارات إنتاج الإنفوجرافيك الثابت يرجع للتأثنر الأساسي للتفاعل بين نمطي لقطات الفيديو الرقمي

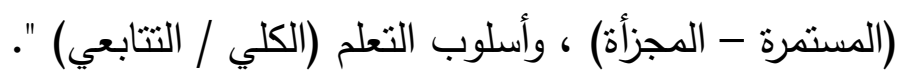
ويمكن إرجاع هذه النتيجة إلى عدة عوامل أهمها:

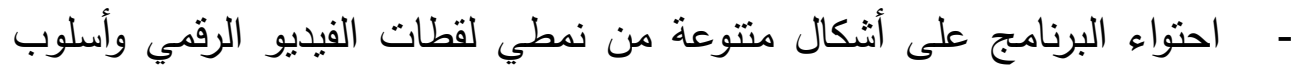
التعلم أدى إلى تغيير مفهومها فلم تعد تقوم على التقاعل المباشر بين المتعلم

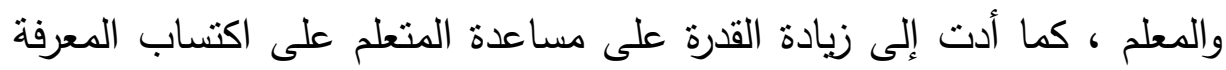
والمفاهيم المرتبطة بمهارات إنتاج الإنفوجرافيك الثابت. - - التحصيل المعرفي المرتبط بمهارات إنتاج الإنفوجرافيك الثابت لا يتأثر بالتفاعل

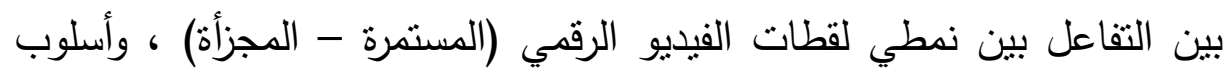
التعلم (الكلي / التتابعي)؛ وإن كانت هناك فروق في منوسطي المجموعتين، ولكنها غير دالة إحصائيا. - إن البرنامج القائم على نمطي لقطات الفيديو الرقمي وأسلوب التعلم ساهم في تتمية المعارف والمفاهيم المرتبطة بالتحصيل المعرفي؛ حيث قدمت المستويات المختلفة بطرق تتاسب خصائص المتعلمين؛ بحيث يتم تتظيم المهمة التعليمية بطرق تجعل المتعلم قادرا على القيام بها بطريقة سهلة ومتاحة. - اشتمل البرنامج على أنواع وأنماط مختلفة من نمط لقطات الفيديو الرقمي (المستمرة - المجزأة) أدى إلى زيادة دور المتعلم ، وقلل من التتخل المباشر للمعلم، وساهم في تتمية التحصيل المعرفي المرتبط بمهارات إنتاج الإنفوجرافيك ملك 
- أنواع وأنماط لقطات الفيديو الرقمي ساعدت المتعلم في تتظيم مهمة للموضوعات المعقدة في بيئات التعلم الإكترونية ، والتي لم يكن بسنطيع المتعلم اكتسابها إذا ما قام بتعلمها معتمدا على نفسه فقط.

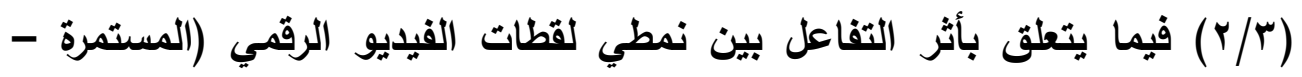
المجزأة) أسلوب التعلم (الكلي / التتابعي) في تنمية الأداء العملي لمهارات

\section{إنتاج الإنفوجرافيك الثابت:}

أثنارت نتائج البحث إلى عدم وجود فرق دال إحصائياً عند مستوى (0. . .) بين متوسطي درجات المجموعات التجريبية على بطاقة ملاحظة الأداء العملي لمهارات إنتاج الإنفوجرافيك الثابت يرجع للتأثثر الأساسي للتفاعل بين نمطي لقطات الفيديو

$$
\begin{aligned}
& \text { الرقمي (المستمرة - المجزأة) أسلوب التعلم (الكلي / التتابعي). } \\
& \text { ويمكن إرجاع هذه النتيجة إلى عدة عوامل أهمها : }
\end{aligned}
$$

- يقوم الأسلوب التتابعي على المدخل الأفقي لعرض المحتوي التعليمي؛ بحيث

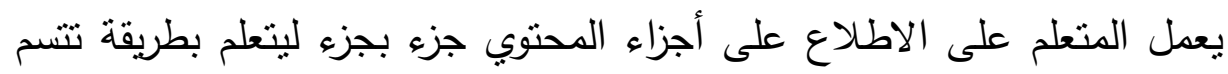

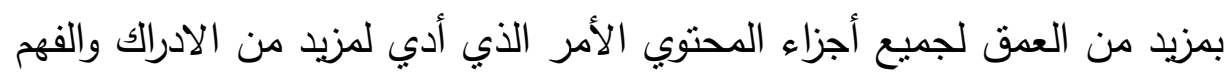
الصحيح له بما انعكس على نتائجهم في اختبار الجوانب المعرفية لمهارات إنتاج الإنفوجرافيك.

- يقوم الأسلوب النتابعي على التبسيط مما يعطي مزيد من الوضوح والسهولة ؛

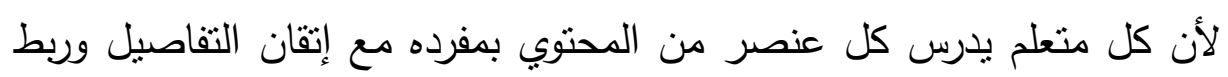
الأجزاء.

- الأسلوب الكلي يعتمد على المدخل الرأسي في عرض المحتوي التعليمي؛ بحيث يجد المتعلم على الاطلاع على أجزاء المحتوي معروضة أمامه ،وعليه أن يقرر

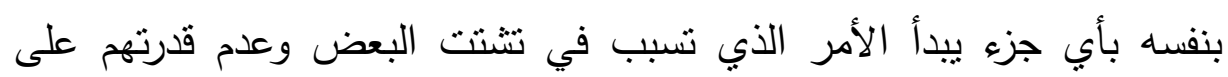
إدراك العلاقات بين أجزاء العنصر الواحد ؛ وذللك لكثرتها وعدم تجزئة عرضها لابها

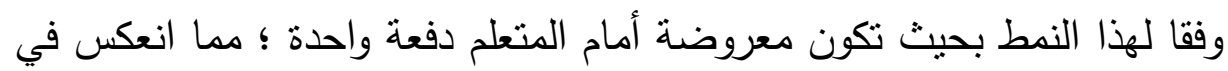
النهاية على نتائجهم في اختبار الجوانب المعرفية لمهارات إنتاج الإنفوجرافيك. 
- ربما يكون هناك قوة وتأثير لكل من نمطي للقطات الفيديو الرقمي على حدة ؛

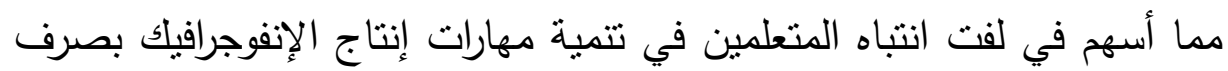
النظر عن التفاعل بين نمطي للقطات الفيديو الرقمي وأسلوب التعلم. توصيات البحث:

في ضوء النتائج التي أسفر عنها البحث يمكن صياغة التوصيات التالية : - ـ الاستفادة من بيئة التعلم الإلكتروني القائم على الويب التي احتوت على برنامج

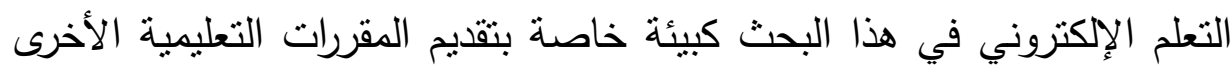
المقررة على تلاميذ المراحل المختلفة. - البحث في كيفية تدعيم وتتشيط وابتكار منغيرات جديدة لبحوث تصميم وإنتاج مهارات الإنفوجرافيك الثابت ، وعلاقتها بالتفضيلات الشخصية للمتعلمين. - ت توجيه أنظار القائمين على تطوير برامج التعلم الإلكتروني القائم على الويب إلى وعلى الاهتمام بنتائج هذا البحث في تصميم وتطبيق إستراتيجيات نتتاسب وأسلوب الهب التعلم (الكلي / التتابعي). - توظيف النتائج التي توصل إليها البحث الحالي بضرورة البحث والاستكثاف للمزيد من المتغيرات المرتبطة بتصميم لقطات الفيديو الرقمي عبر بيئات التعلم الإلكترونية. - الاهتمام بالجانب الوجدانى للمتعلمين مثل : الميول والاتجاهات والإنطباعات ، الإنهات وخصوصاً فى ضوء الاعتماد المتزايد على البيئات الإفتراضية أو الإلكترونية. - ضرورة مراعاة والاهنمام بتصميم وإنتاج لقطات الفيديو الرقمي باعتبارها مصادر للمعلومات للاستفادة منها في مجال تخصص علم المعلومات.

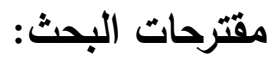
في ضوء النتائج التي توصل إليها البحث الحالي، يقترح البحث إجراء عدد من البحوث ذات الصلة بموضوع البحث، وتتمنل في : 
- إجراء دراسة تكثف أثز تفاعل أنماط لقطات الفيديو الرقمي ؛ لتصميم واجهة التفاعل مع أسلوب تعلم آخر ، منل :أسلوب (المندفع -المنروى) على تتمية التفكير الابتكاري ، أو مهارات التعلم المنظم ذاتيا ،أو وحل المشكلات.

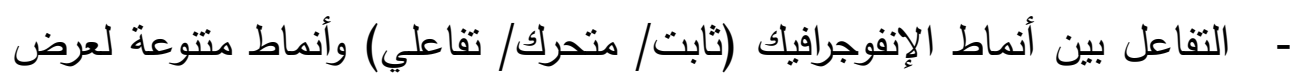

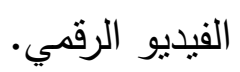
- إجراء دراسة تتتاول العلاقة بين أنماط تقديم لقطات الفيديو الرقمي ، وطريقة تصميم المحتوى الإلكتروني - العلاقة بين تنوع أنماط تقديم لقطات الفيديو الرقمي في بيئة التعلم الإكتروني

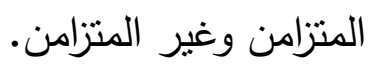
- - أنماط تقديم نصوص داخل لقطات الفيديو الرقمي وعلاقتها بنظرية الحمل المعرفي والتعلم المنظم ذاتيا. 
المراجع

أولا: المراجع العربية

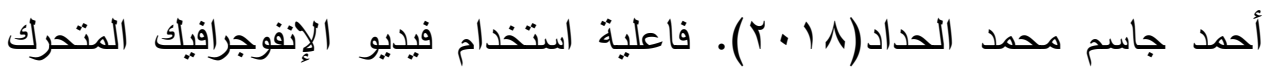
Motion infographic video الاجتماعيات ومدى تقبله لاى متعلمي الصف السادس بدولة الكويت. رسالة ماجستير ، كلية التربية، جامعة الكويت. أحمد عاطف عبدالرحمن (1) (1). واقع استخدام الطلاب معلمي اللغة الإنجليزية

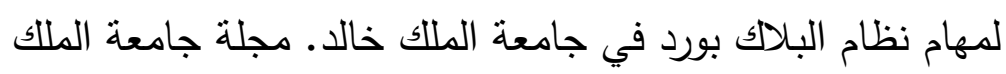
خالد للعلوم التربوية: جامعة الملك خالد - كلية التربية - مركز

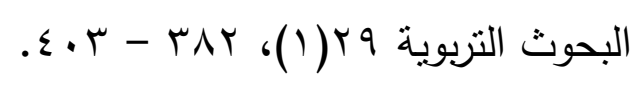

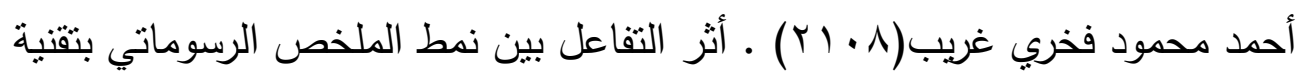

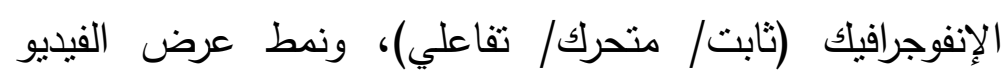
(أرني/ جرب ذلك/ اختبرني) بالمقررات الإلكترونية ؛ لتتمية الحس ونس العددي وخفض التنمر لتلاميذ الصف الثالث الابتدائي. مجلة

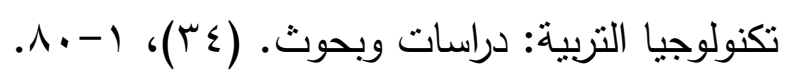

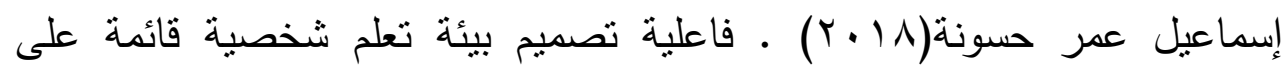
الإنفوجرافيك في التحصيل المعرفي والاتجاه نحوها لاى طلبة كلية التربية في جامعة الأقصى. مجلة العلوم التربوية والنفسية.

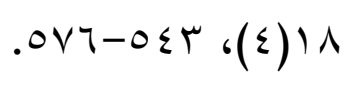

أنشرف أحمد عبدالعزيز ، وليد سالم الحلفاوي (1) ـ (1). أثز التفاعل بين نمط الوصول ونمط التتابع المرئي لمقاطع الفيديو عبر الويب في تتمية المهارات العملية لدى الطلاب الصم. مجلة الجمعية المصرية لتكنولوجيا

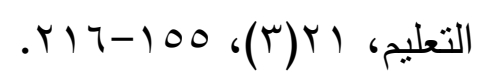


إلهام بنت إبراهيم محمد وقاد(9 \& ())أساليب التفكير وعلاقتها بأساليب التعلم

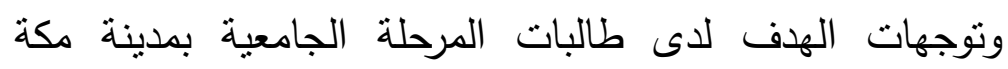
المكرمة، رسالة دكتوراه، كلية التربية، جامعة أم القري. إيمان محمد مكرم مهني (ع ( ا Y). أثر برنامج تدريبي مقترح لإكساب أعضاء هيئة

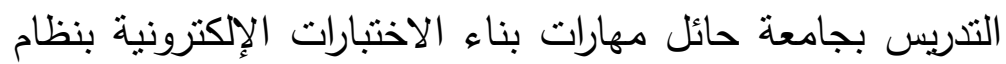
إدارة التعلم بلاك بورد Blackboard. دراسات عربية في التربية

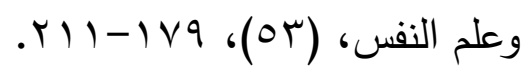

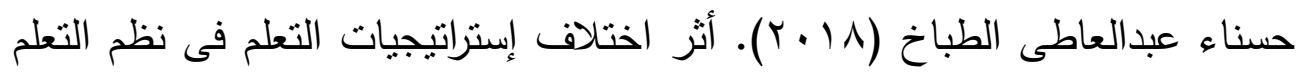
الذكية على تتمية مهارات إنتاج الإنفوجرافيك لدى طلاب تكنولوجيا التعليم المستقلين والمعتمدين إدراكيا. مجلة كلية التربية، جامعة الإسكا

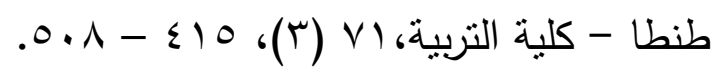

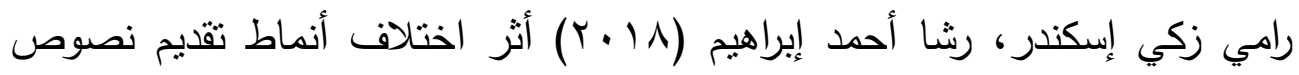
الفيديو الرقمي بنظرية الحمل المعرفي على اكتساب الطلاب مقرر حقوق الإنسان تكنولوجيا والاتجاه نحوها. مجلة تكنولوجيا التربية - دراسات وبحوث، الجمعية العربية لتكنولوجيا التربية، (مب)،

$$
\text { .9人-or }
$$

ربيع عبدالعظيم رمود (9 ( ب). اختلاف نمط الدعم الإكتروني (شخصي، اجتماعي) بييئة الحياة الثانية ثلاثية الأبعاد ومستوى دافعية التعلم (مرتفعة، منخفضة) لتتمية مهارات إنتاج الإنفوجرافيك التعليمي لدى طلاب تقنيات التعليم. المجلة التربوية: كلية التربية، جامعة سوهاج،

$$
\text { .r } 19-\text { ror ، (T) }
$$

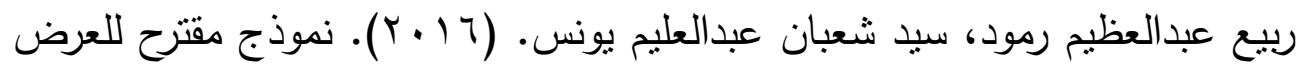
التكيفي لمحتوى الوسائط الفائقة وأثزه في تتمية مهارات التصوير الفوتوغرافي الرقمي لدى طلاب تكنولوجيا التعليم وفقاً لأسلوب 
تعلمهم .تكنولوجيا التعليم: الجمعية المصرية لتكنولوجيا

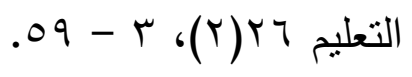

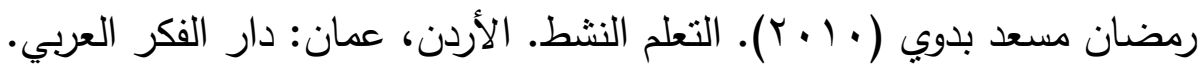

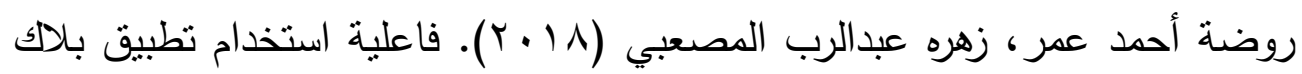
بورد للتعلم النقال (Black Board Mobile Learn) في تتمية الاتجاهات نحو التعلم الإكتروني النقال لاى طالبات جامعة نجران. المجلة الدولية التربوية المتخصصة: دار سمات للدراسات

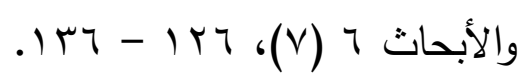

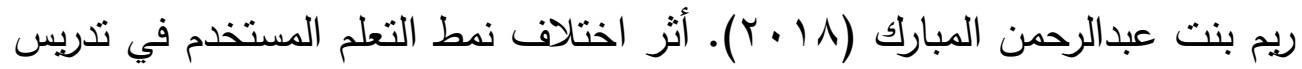
المقررات بنظام إدارة التعلم (البلالك بورد) على التحصيل المعرفي لطالبات جامعة الأميرة نورة بنت عبد الرحمن واتجاهاتهن نحوه. مجلة الجامعة الإسلامية للدراسات التربوية والنفسية: الجامعة

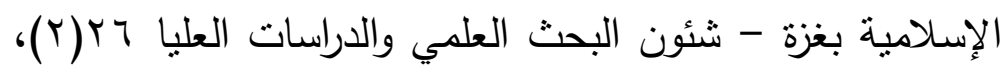

$$
\text { . Ar - or }
$$

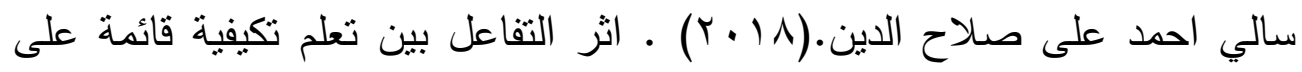
الويب وأسلوب التعلم في تتمية نواتج تعلم مقرر تصميم المواقف التعليمية لطلاب تكنولوجيا التعليم، رسالة (دكتوراه) ، كلية التربية

$$
\text { النوعية، جامعة عين شمس. }
$$

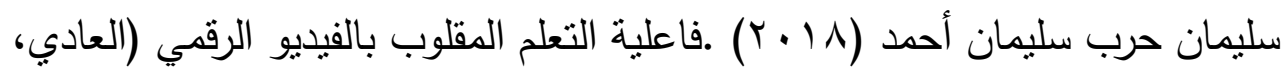

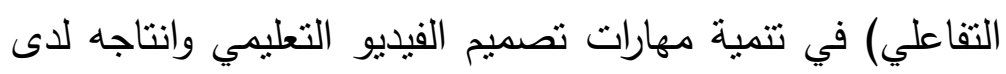
طالبات جامعة الأقصى بغزة، المجلة الفلسطينية للتعليم المفتوح

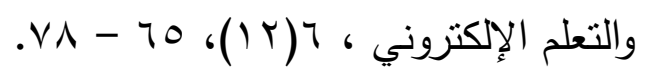

السيد محمد أبو هاشم (Y ( ب). الصدق البنائي لنموذج فلدر وسيلفرمان لأساليب التعلم لدى طالب الجامعة. مجلة جامعة الملك سعود للعلوم 
التربوية والدراسات الإسلامية: جامعة الملك سعود، ع ب (ع)،

$$
1 \% 17-1 \text { - Y } 99
$$

شيماء سمير محمد خليل (1/ • ( ). العلاقة بين نمط العرض التكيفي المقاطع الصفحات المتتوعة وأسلوب التعلم تسلسلي شمولي في بيئة تعلم افتراضية وأثرها على تتمية مهارات إنتاج العناصر الثناثية الأبعاد والانخراط في التعلم لطلاب تكنولوجيا التعليم. تكنولوجيا التربية

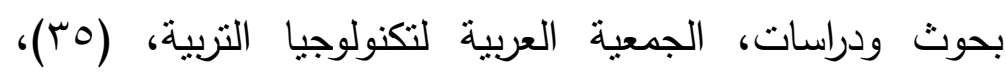
$. r q r-r v q$

طارق عبدالودود، زينب حسن حامد، محمد عطيه خميس (Y IV). نمطان للقطات الفيديو بنموذج الفصل المقلوب وأثرهما على تتمية الانتباه لدى طلاب التعليم الثانوي الصناعي. مجلة البحث العلمي في

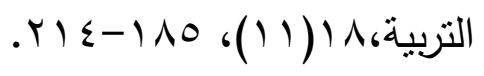

عاصم عمر (T ( ا Y). فاعلية إستراتيجية مقترحة قائمة على الإنفوجرافيك في اكتساب المفاهيم العلمية وتتمية مهارات التفكير البصري والاستمتاع بتعلم العلوم لدي تلاميذ الصف الخامس الابتدائي. مجلة التربية

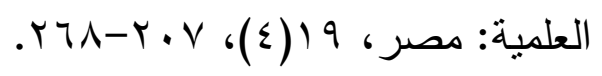

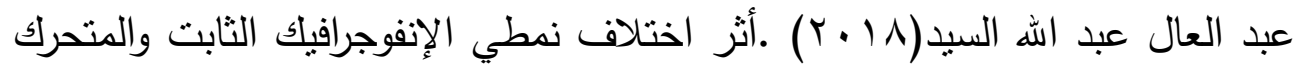
في تتمية مهارات المواطنة الرقمية لدى طلبة المعاهد العليا

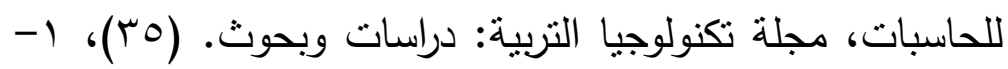
.or

عبدالعزيز بن شريتح حسين الرويلي (1) • ب). معوقات استخدام التعلم الإلكتروني (Blackboard) سعود .مجلة كلية التربية : جامعة أسيوط - كلية التربية، ؟ب( (1)، 
عبدالعزيز طلبة (• ( • ). الرحلات المعرفية عبر الويب إحدى إستراتيجيات التعلم عبر الويب، جامعة المنصورة ، مجلة التعليم الإلكتروني، (0)،

$$
.1 r-1 r
$$

عبدالله محمد عبداله (9 ( • ( ). أثر استخدام نمطي الفيديو الرقمي "مجزأ- متصل" في تتمية مهارات البرمجة لدى طلاب الصف الثالث المتوسط في مدينة الطائف، المجلة الدولية للعلوم التربوية والنفسية، المؤسسة

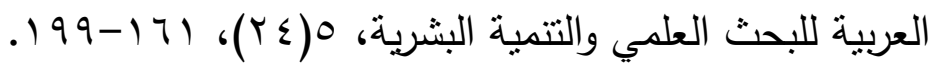
علي حسين، أسامة جواد، عبير حسين (1/ • (Y). تأثير منهج تعليمي بالأسلوب (التتابعي - الكلي) في تعلم بعض المهارات الاساسية بالجمناستاك

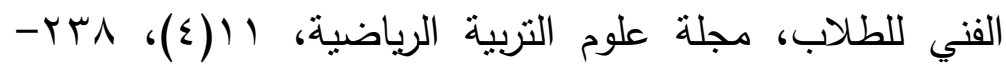
roN

فادي فريد، محمد أبو شقير، أحمد حمدان (Y V • V). فاعلية الفيديو التفاعلي في تتمية الأداءات المهارية المركبة في كرة القدم لطلاب المرحلة الأساسية العليا، مجلة الجامعة الإسلامية للدراسات التربوية والنفسية،

$$
.11 V-170 \text { (0) Y Y } 7
$$

فيصل فهد محمد الثمري، فرحان محمد حمدان الثمري (19 (ب). برنامج مفترح قائم على الفيديو الرقمي في تدريس مقرر الحاسب وأثزه على تتمية مهارات الجداول الحسابية لدى طلاب الصف الثاني المتوسط ، مجلة كلية التربية الأساسية للعلوم التربوية والإنسانية / جامعة لهابية

$$
\text { بابل، (م) ( }
$$

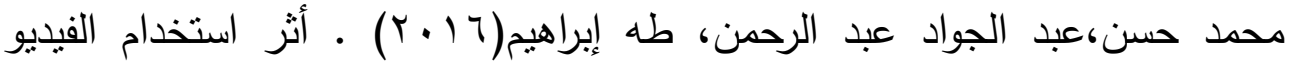
الرقمي على تتمية مهارات الطلاب المعلمين في استخدام المواد اليدوية الملموسة عند تدريس الرياضيات، مجلة تربويات

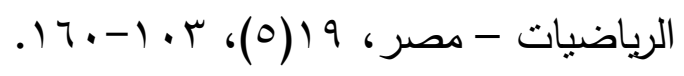


محمد شلتوت (T ( ب ). الإنفوجرافيك من التخطيط إلى الإنتاج، الرياض -المملكة العربية السعودية، وكالة أساس للاعاية والإعلان.

محمد عطيه خميس (11) (1). الأصول النظرية والتاريخية لتكنولوجيا التعلم الإلكتروني . القاهرة: دار السحاب.

محمد عطيه خميس (10 ( 1). مصادر التعلم الإلكتروني : (1) الأفراد والوسائط. القاهرة: دار السحاب للطباعة والنشر والتوزيع.

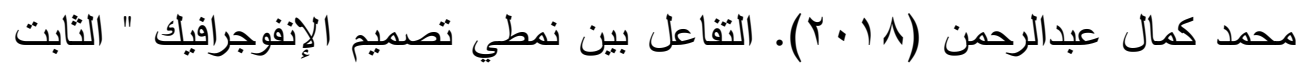
والمتحرك " ومنصنى التعلم الإلكتروني " البلاد بورد، الواتس آب " التهي" وأثثر في تتمية مهارات تصميم التعلم البصري وإدراك عناصره."

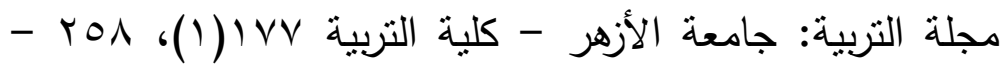
q محمد مختار المرادنى (r ( r). تكنولوجيا التعليم. كلية التربية بالعريش: جامعة قناة السويس.

مروة عبدالمقصود المحمدي (T (Y). تصميم بيئة تعلم إلكترونية تكيفية وفقا لأساليب التعلم في مقرر الحاسب الآلي وأثرها على تتمية مهارات تصميم مواقع الويب والقابلية للاستخدام لدى نلاميذ المرحلة الإعدادية، رسالة دكتوراه، معهد الدراسات التربوية، جامعة القاهرة. منى سعد الغامدي (1 ( • ب). أثز المتغيرات الديموغرافية على مستوى وعي معلمات الرياضيات في مدينة الرياض بتقنية الإنفوجرافيك ودرجة امتلاكهن

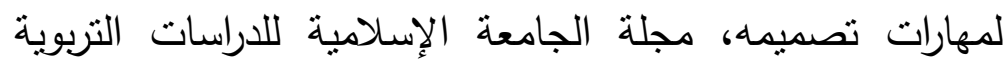

$$
\text { والنفسية. }
$$

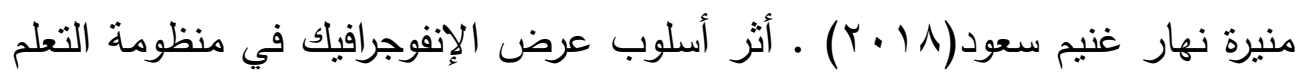
الإكتروني على دافعية طلاب الصف الثاني عثر واتجاههم نحو الإندر بيئة التعلم في مادة اللغة العربية ، مجلة العلوم التربوية ، جامعة

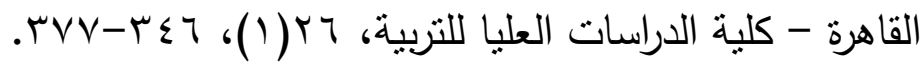




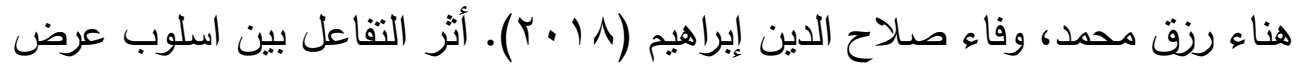

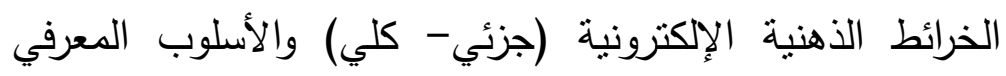

(تركيز - سطحية) في تتمية التحصيل الفوري والمرجأ لدى طلاب الاب

الدراسات العليا بكلية التربية، تكنولوجيا التربية: دراسات وبحوث.

$$
\text { EYA.-rqr ، (ro) }
$$

وداد عسير عائد العتيبي(1) • r) أثر استخدام الإنفوجرافيك التعليمي على تحصيل قواعد اللغة الإنجليزية لاى طالبات الصف الأول المتوسط بمدينة

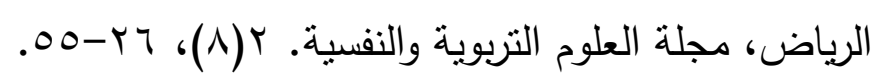

وليد سالم الحلفاوي (7 ( ا ب). الفصول المقلوبة: العلاقة بين معدل تجزئة الفيديو

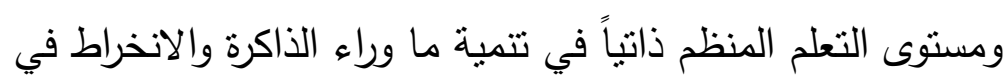
التعلم لدى طلاب الدراسات العليا التربوية، دراسات في المناهج وطرق التريس، الجمعية المصرية للمناهج وطرق التدريس،

$$
\text { . } 1 \leqslant r-97 ،(r r \varepsilon)
$$

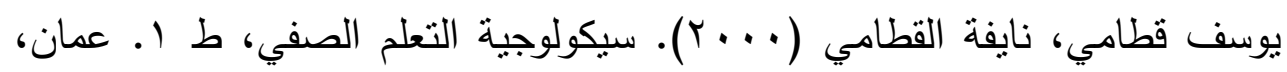
دار الثروق للنشر والتوزيع.

$$
\text { - }
$$

Afify, M. K. (2018). The Effect of the Difference between Infographic Designing Types (Static vs Animated) on Developing Visual Learning Designing Skills and Recognition of its Elements and Principles. International Journal of Emerging Technologies in Learning, 13(9), 204223. https://doiorg.sdl.idm.oclc.org/10.3991/ijet.v13i09.8541

Ahmed, M. U., Hussain, S., \& Bagram, M. M. M. (2017). EContent Presentation based on Learning Styles. University 
of Engineering and Technology Taxila. Technical Journal, $22(1), 128$.

Al-Mohammadi, N. (2017). Effectiveness of using infographics as an approach for teaching programming fundamentals on developing analytical thinking skills for high school students in the city of Makkah in Saudi Arabia. Global Journal of Educational Studies, 3(1), 22-42.

Alrwele, N. S. (2017). Effects of Infographics on Student Achievement and Students' Perceptions of the Impacts of Infographics. Journal of Education and Human Development, 6(3), 104-117.

Alshehri, M. A., \& Ebaid, M. (2016). The effectiveness of using interactive infographic at teaching mathematics in elementary school. British Journal of Education, 4(3), 1-8. Alyahya, D. M., \& Nasser, R. (2019). Message Design: Color Impact and its Effectiveness on Designing Instructional Infographic. International Journal of Learning, Teaching and Educational Research, 18(2.(

Aslaksen, K., \& Lorås, H. (2018). The modality-specific learning style hypothesis: A mini-review. Frontiers in psychology, 9, 1538.

Balakrishnan, V., \& Gan, C. L. (2016). Students' learning styles and their effects on the use of social media technology for learning. Telematics and Informatics, 33(3), 808-821. 
Cavus, N., \& Kanbul, S. (2010). Designation of Web 2.0 tools expected by the students on technology-based learning environment. Procedia-Social and Behavioral Sciences, 2(2), 5824-5829.

Chtouki, Y., Harroud, H., Khalidi, M., \& Bennani, S. (2012). The impact of YouTube videos on the student's learning. In 2012 International Conference on Information Technology Based Higher Education and Training (ITHET) (pp. 1-4). IEEE.

Dahmash, A. B., Al-Hamid, A., \& Alrajhi, M. (2017). Using Infographics in the Teaching of Linguistics. Arab World English Journal (AWEJ) Volume, 8.

Damyanov, I., \& Tsankov, N. (2018). The role of infographics for the development of skills for cognitive modeling in education. International Journal of Emerging Technologies in Learning (iJET), 13(1), 82-92 .

De Boer, J., Kommers, P. A., De Brock, B., \& Tolboom, J. (2016). The influence of prior knowledge and viewing repertoire on learning from video. Education and information technologies, 21(5), 1135-1151.

Demirkan, H. (2016). An inquiry into the learning-style and knowledge-building preferences of interior architecture students. Design Studies, 44, 28-51.

DeWitt, D., \& Alias, N. (2017). Infographic posters for enhancing 21 st century communication skills. 
El-Bishouty, M. M., Aldraiweesh, A., Alturki, U., Tortorella, R., Yang, J., Chang, T. W., \& Graf, S. (2019). Use of Felder and Silverman learning style model for online course design. Educational Technology Research and Development, 67(1), 161-177.

eM Elsawy, A., \& Ahmed, O. S. (2019). E-Learning using the Blackboard system in Light of the Quality of Education and Cyber security, International Journal of Current Engineering and Technology Vol.9, No.1,pp.49-54 (Jan/Feb 2019), Available at http://inpressco.com/category/ijcet

Fadzil, H. M. (2018). Designing infographics for the educational technology course: perspectives of pre-service science teachers. Journal of Baltic Science Education, 17(1), 8-18. Fleming, N. D., \& Bonwell, C. C. (2002). VARK (Version. 1) [Questionnaire]. Available from www. Vark-learn. com.

Ghode, R. (2012): Infographics in news presentation: A study of its effective uses in Times of India and Indian Express the two leading newspapers in India. Journal of Business Management \& Social Sciences Research, 1 (1), 35-34.

Hassan, H. G. (2016). Designing Infographics to support teaching complex science subject: A comparison between static and animated Infographics, Doctoral dissertation, lowa State University.

Hassounah, E. O. (2017). Effectiveness of Personal Learning Environment Design Based on Infographics in Developing 
Cognitive Achievement and Attitudes towards its Use among Students of the College of Education at Al Aqsa University. Journal of Educational \& Psychological Sciences, 18(04), 543-576.

Hatsidimitris, G., \& Allen, B. (2010). An Online Resource for the Design of Instructional Videos and Animations. In E-Learn: World Conference on E-Learning in Corporate, Government, Healthcare, and Higher Education (pp. 10241028). Association for the Advancement of Computing in Education (AACE).

Heidrich, L., Barbosa, J. L. V., Cambruzzi, W., Rigo, S. J., Martins, M. G., \& dos Santos, R. B. S. (2018). Diagnosis of learner dropout based on learning styles for online distance learning. Telematics and Informatics, 35(6), 1593-1606.

Ho, S. B., Teh, S. K., Chan, G. Y., Chai, I., \& Tan, C. H. (2017). Sequential and Global Learning Styles as Pathways to Improve Learning in Programming. In International Conference on Computational Science and Technology (pp. 1-10).

Hou, H. T. (2015). Integrating cluster and sequential analysis to explore learners' flow and behavioral patterns in a simulation game with situated-learning context for science courses: A video-based process exploration. Computers in human behavior, 48, 424-435. 
Kavas, G, Ozdener, N. (2012): Effects of Video-Supported Web-Based peer Assessment on Microteaching Application: Computer Teacher Candidates Sample, Scientific Research (Creative Education Journal), And Vol.3 (7), PP.1220-1230.

Kazu, I. Y. (2009). The effect of learning styles on education and the teaching process. Journal of Social Sciences, 5(2), 85-94.

Kibar, P. N., \& Akkoyunlu, B. (2014). A new approach to equip students with visual literacy skills: Use of infographics in education. In European Conference on Information Literacy (pp. 456-465). Springer, Cham.

Kuo, Y. C., Chu, H. C., \& Tsai, M. C. (2017). Effects of an integrated physiological signal-based attention-promoting and English listening system on students' learning performance and behavioral patterns. Computers in Human Behavior, 75, 218-227.

Manochehri, N. \& Sharif, K. (2010) 'A model-based investigation of learner attitudes towards recently introduced classroom technology', Journal of Information Technology Education: Research, vol. 9, pp. 31-52.

Manochehri, N. N., \& Young, J. I. (2006). The impact of student learning styles with web-based learning or instructor-based learning on student knowledge and 
satisfaction. Quarterly Review of Distance Education, 7(3), 313.

Martin, L. J., Turnquist, A., Groot, B., Huang, S. Y., Kok, E., Thoma, B., \& van Merriënboer, J. J. (2019). Exploring the Role of Infographics for Summarizing Medical Literature. Health Professions Education, 5(1), 48-57.

Niebaum, K.; Cunningham-Sabo, L.; Carroll, J. \& Bellows, L. (2015). Infographics: An Innovative Tool to Capture Consumers" Attention. Journal of extension, 53(6), 1-6.

Polman, J. L., \& Gebre, E. H. (2015). Towards critical appraisal of infographics as scientific inscriptions. Journal of Research in Science Teaching, 52 (6), 868-893.

Quinn, M. M., Smith, T., Kalmar, E. L., \& Burgoon, J. M. (2018). What type of learner are your students? Preferred learning styles of undergraduate gross anatomy students according to the index of learning styles questionnaire. Anatomical sciences education, 11(4), 358365.

Sherer, P., \& Shea, T. (2011). Using online video to support student learning and engagement. College Teaching, 59, 56-59.

Spanjers, I. A., Van Gog, T., \& Van Merrienboer, J. J. (2012). Segmentation of worked examples: Effects on cognitive load and learning. Applied Cognitive Psychology, 26(3), $352-358$. 
SUPAT, P., Bangthamai, E. (2018). The Development of Infographic Design e Training with Massive Open Online Course (Doctoral dissertation, Silpakorn University.(

Tian, H., Zheng, H. C., \& Chen, S. C. (2018). Sequential deep learning for disaster-related video classification. In 2018 IEEE Conference on Multimedia Information Processing and Retrieval (MIPR) (pp. 106-111). IEEE.

Vizeshfar, F., \& Torabizadeh, C. (2018). The effect of teaching based on dominant learning style on nursing students' academic achievement. Nurse education in practice, 28, 103-108.

Weeks, B. K., \& Horan, S. A. (2013). A video-based learning activity is effective for preparing physiotherapy students for practical examinations. Physiotherapy, 99(4), 292-297.

Wright, A. (2016). Tools for the creation and sharing of infographics. Journal of Electronic Resources in Medical Libraries, 13(2), 73-76.

Yuruk, S. E., Yilmaz, R. M., \& Bilici, S. (2018). An examination of postgraduate students' use of infographic design, metacognitive strategies and academic achievement. Journal of Computing in Higher Education, 1-19 . 